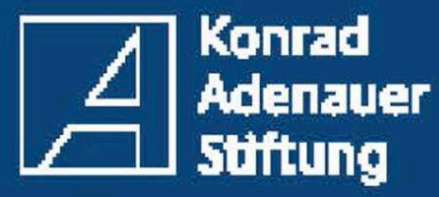

\title{
MIGRANTS AU MAROC
}

\section{COSMOPOLITISME, PRÉSENCE D'ÉTRANGERS}

ET TRANSFORMATIONS SOCIALES

\section{SOUS LA DIRECTION DE}

NADIA KHROUZ ET NAZARENA LANZA

AVEC LA PARTICIPATION DE LEPOSHS (UIR)

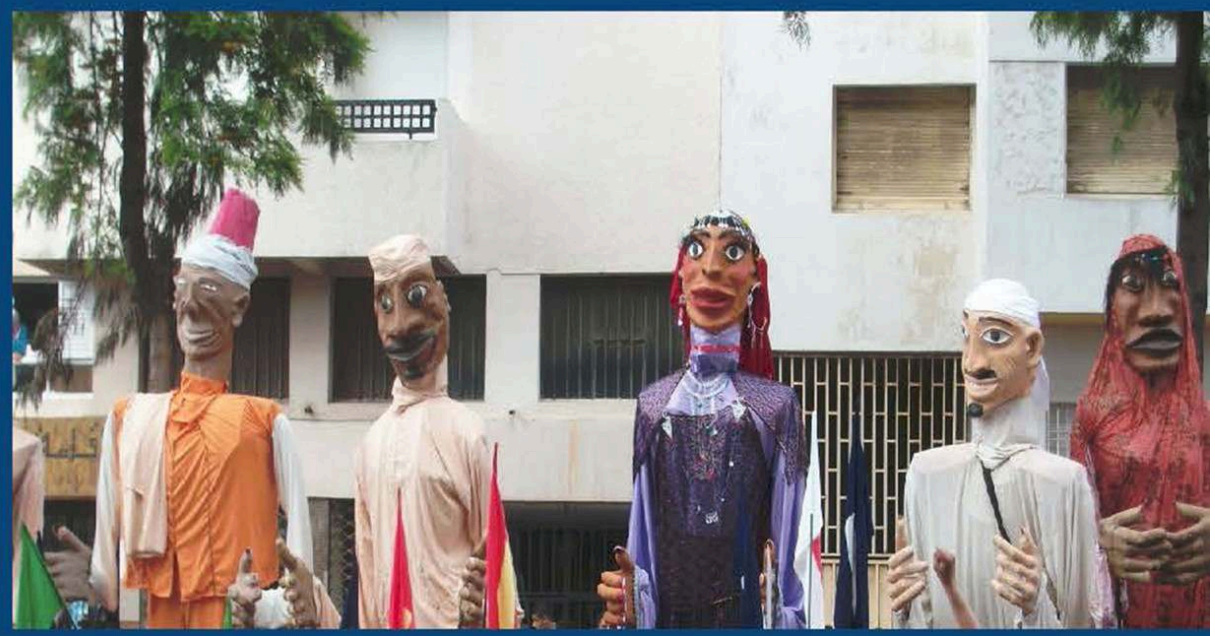




\section{Migrants au Maroc}

Cosmopolitisme, présence d'étrangers et transformations sociales

\section{Nadia Khrouz et Nazarena Lanza (dir.)}

DOI : 10.4000/books.cjb.865

Éditeur : Centre Jacques-Berque, Fondation Konrad Adenauer Stiftung

Lieu d'édition : Rabat

Année d'édition : 2015

Date de mise en ligne : 5 septembre 2016

Collection : Description du Maghreb

EAN électronique : 9791092046298

\section{Qboooks}

http://books.openedition.org

\section{Édition imprimée}

EAN (Édition imprimée) : 9789954367964

Nombre de pages : 184

\section{Référence électronique}

KHROUZ, Nadia (dir.) ; LANZA, Nazarena (dir.). Migrants au Maroc : Cosmopolitisme, présence d'étrangers et transformations sociales. Nouvelle édition [en ligne]. Rabat : Centre Jacques-Berque, 2015 (généré le 21 septembre 2021). Disponible sur Internet : <http://books.openedition.org/cjb/865>. ISBN

9791092046298. DOI : https://doi.org/10.4000/books.cjb.865.

Ce document a été généré automatiquement le 21 septembre 2021.

(C) Centre Jacques-Berque, 2015

Conditions d'utilisation:

http://www.openedition.org/6540 
Par cet ouvrage collectif, nous espérons apporter une plus-value à la recherche sur les migrations, tout en interrogeant différentes réalités et concepts régulièrement diffusés, en particulier dans le contexte du Maroc contemporain.

Nous espérons que ces réflexions pourront se poursuivre dans différents cadres, s'élargir, être interpellées, confortées ou réinterrogées, actualisées pour soutenir les analyses futures sur ces questions fondamentales et une meilleure connaissance des migrations et du cosmopolitisme au Maroc.

\section{NADIA KHROUZ}

Politologue, chercheure associée au CJB.

\section{NAZARENA LANZA}

Doctorante IDEMEC/AMU (Aix-en-Provence), chercheure associée au CJB. 
SOMMAIRE

\author{
Avant-propos \\ Nadia Khrouz et Nazarena Lanza \\ Introduction \\ Nadia Khrouz et Nazarena Lanza
}

\title{
Circulations et modalités d'installation : le Maroc à l'épreuve des migrations internationales
}

Un monde en mouvement, du transit à la transmigration

Mehdi Alioua

De l'errance organisée à la transmigration

Un monde en mouvement : du cosmopolitisme aux droits cosmopolitiques?

Les nouveaux migrants français à Essaouira et Marrakech Liza Terrazzoni

Saisonniers du temps libre : modalités socio-spatiales de la présence des " hivernants » européens au Maroc

Brenda Le Bigot

Une présence européenne sous diverses formes

Les hivernants : un profil intermédiaire entre touriste et résident?

Conflit de légitimité et sociabilité d'entre-soi

Conclusions et perspectives : et les autres étrangers?

Rencontre et mise en scène de soi : de la construction de réseaux chez les migrants guinéens de Rabat

Anna Dessertine

Des aventuriers en quête de « connexions »

Se positionner socialement et temporellement par la mise en scène de soi

Les migrations chinoises au Maroc : les commerçants séjourneurs de Casablanca Jean-Pierre Taing

Derb omar, un quartier de commerçants

Historique et profil de l'immigration chinoise à Casablanca

Des profils de séjourneurs

Le personnel des ONG internationales au Maroc : l'expérience cosmopolite à l'épreuve? Chadia Boudarssa

Le Maroc: une destination pas toujours choisie mais de fortes attentes de rencontres

Le Maroc : entre un mode de vie communautaire et « un autre chez soi »

Le Maroc : des rapports différenciés en fonction du genre, de la nationalité et du lieu de rencontre 
Mobilités religieuses au Maroc : religion en migration et tourisme spirituel

Les églises de maison congolaises de Rabat : la participation du secteur informel à la pluralisation religieuse au Maroc

Bernard Coyault

Genèse des communautés de maisons congolaises de Rabat

Entre carrières individuelles et logiques institutionnelles : dynamiques circulatoires

Adéquation de l'offre religieuse aux besoins des personnes migrantes

Les Congolais, " peuple missionnaire »

Le contexte de l'islam

Quelques enjeux du soufisme au Maroc : le tourisme religieux sénégalais et la construction d'un imaginaire sur l'amitié

Nazarena Lanza

Les enjeux du soufisme au Maroc. Quelle place pour la Tidjaniyya?

Discours pèlerin...

... et contre-discours « migrant »

Ré-enchantement ou désenchantement?

Mobilité des Musulmans ivoiriens au Maroc : entre formation islamique et tourisme religieux

Mamadou Bamba

Quelques facteurs explicatifs de la mobilité des étudiants et religieux ivoiriens au Maroc

Les étudiants et les religieux ivoiriens au Maroc

L'impact des formations islamiques et du tourisme religieux sur le Maroc et sur la Côte-d'Ivoire

\section{De la prise en compte de la présence étrangère au Maroc}

Immigration estudiantine subsaharienne : quel enjeu pour le Maroc?

Lionel Nzamba

La formation en question

Les étudiants en marge de la recherche scientifique

Labour market situation of sub-Saharan migrants in Morocco : the case of call centers Silja Weyel

Call centers as one major employment sector for migrants

Migrants' employment conditions in call centers

Migrants' background and working conditions

Signs of segmentation?

Loi sur l'entrée et le séjour des étrangers au Maroc : les conditions pour résider

régulièrement au Maroc

Nisrine Eba Nguema

Les conditions du séjour régulier au Maroc

L'étranger « dangereux » ou en situation irrégulière

De la respécification de la notion de transit

Nadia Khrouz

Des « migrants en transit » vers l’Europe

Le « transit » dans et par le droit positif

La catégorie de «transit » comme qualification juridique

Une nouvelle politique migratoire marocaine : vers une nouvelle perception de la migration? 
Migration au Maroc et faits du « printemps arabe » : cas des Syriens Bouchra Sidi Hida

Itinéraires et profils migratoires

Politique migratoire : évolution et blocage

Quelle école sur le chemin de la migration? L'exemple de Caritas (Rabat, Casablanca) Dorothée Barrière

\section{Le Maroc : une société plurielle au prisme de l'altérité}

Les étudiants subsahariens, nouveaux portraits de la présence étrangère au Maroc:

l'exemple des Maliens de Fès

Touré Niandou

Cinquante ans de présence étudiante subsaharienne

L'étudiant dans la ville, une figure différente de l'étranger

Atlas et Florence, des quartiers « ouest-africains »

Le microcosme social des étudiants maliens de Fès

Représentations de soi et d'autrui, les rapports ambivalents des étudiants avec les "immigrés »

Conclusion

Quelle intégration pour les étrangers au Maroc? Les écueils d'un terme à éviter Sylvain Beck

Les « affinitaires », une double appartenance contrastée

Les « expérimentateurs ", un séjour temporaire

Les « internationaux », une appartenance délocalisée

L'intégration, les difficultés d'une notion stricte

Nomadic Paths to Modes of Being and Ways of Cosmopolitan Becoming in La littératureMonde :Youssouf Amine Elalamy's Amour Nomade (2013)

Valérie K. Orlando

Introduction : Yae and Moroccan cosmopolitanism

Littérature-monde, afropolitanism and « making the story go » in our era of globalization

Nomadic thought and Becoming in Amour Nomade : Tachfine's Becoming-Nomad and Being-in-theWorld

From Slavery to the Screen : Sub-Saharan Migrants in Moroccan History and Cinema Jamal Bahmad

Routes and roots : the sub-saharan presence in Morocco

Screening the Other Within

Communautarisme, cosmopolitisme, internationalisme. Étude de cas de la région Atlantique Suleiman G. Nasser

Migrants subsahariens à Rabat, une entrée spatiale : l'épreuve des espaces publics Khadija Karibi

La migration subsaharienne au Maroc, une nouvelle réalité urbaine?

Migrants subsahariens et espaces publics, l'élargissement prudent des lieux de "visibilité » Des lieux d'entre-soi... aux lieux de mixité

\section{Conclusion}

Le Maroc comme carrefour migratoire et pays d'accueil : quels défis pour le futur? Ellinor Zeino-Mahmalat 
Liste des auteurs 


\section{NOTE DE L'ÉDITEUR}

La version papier de cet ouvrage a été co éditée par la Fondation Konrad Adenauer Stiftung de Rabat et le Centre Jacques Berque, fin 2015. Cette version électronique a été mise à jour et augmentée de l'article de Chadia Boudarssa. Pour toute question concernant la version papier, prière de contacter catherine.filippone@cjb.ma 


\title{
Avant-propos
}

\author{
Nadia Khrouz et Nazarena Lanza
}

1 Ce recueil de courts articles n'a pas l'ambition d'être exhaustif; s'il permet d'évoquer des sujets peu courants et de s'intéresser à des populations qui font classiquement l'objet d'un moindre intérêt, il vise essentiellement à rassembler des regards de chercheurs travaillant sur les migrations dans leur sens le plus large et sur les changements sociaux qu'elles engendrent et parfois impulsent au Maroc. Cet ouvrage collectif est le fruit d'un travail de réflexion initié dans le cadre de deux journées d'étude, «Présence des étrangers, cosmopolitisme et changements sociaux au Maroc contemporain ", qui se sont tenues à Rabat les 3 et 4 novembre 2014.

2 Le choix éditorial, contraignant les contributeurs à des articles courts et à des bibliographies limitées, visait à opérer des zooms sur leurs terrains spécifiques et à apporter des éclairages susceptibles d'alimenter des réflexions et d'évoluer vers des travaux et publications ultérieurs.

3 Nous tenons à les remercier vivement pour leur patience dans les allers-retours inhérents à un tel projet et pour la richesse des échanges.

4 Nous espérons que ce travail apportera des éclairages nouveaux ainsi qu'une meilleure connaissance des présences d'étrangers au Maroc, dans leur diversité et leur complexité.

Deux institutions ont épaulé et aidé à la réalisation de ce projet depuis le début: le Centre Jacques Berque et la Fondation Konrad Adenauer. Nous remercions vivement les directeurs respectifs, Baudouin Dupret et Helmut Reifeld, pour leur engagement et leur confiance, ainsi que les membres des équipes administratives et logistiques.

6 Nous tenons à remercier également les chercheurs, spécialisés dans les différents axes de recherche de ce travail, qui se sont impliqués dans l'organisation et le déroulement des journées d'étude ainsi que dans les relectures successives. Le soutien, la participation et les conseils avisés de Houria Alami Mchichi, Sophie Bava, Mehdi Alioua, Mahamet Timera et Liza Terrazzoni ont été précieux dans l'aboutissement de ce projet.

7 Enfin, l'expression de nos vifs remerciements va à toutes celles et à tous ceux qui, d'une manière ou d'une autre, nous ont apporté un soutien dans les différentes étapes de ce 
travail parfois semé de doutes et d'embûches mais qui a abouti à cet ouvrage qu'on ne pourrait plus collectif et participatif. 


\title{
Introduction
}

\author{
Nadia Khrouz et Nazarena Lanza
}

1 Le Maroc s'est constitué d'un brassage inextricable de populations de différentes origines, alimenté par des migrations successives, provenant en particulier de pays avec lesquels le Royaume entretient des relations particulières et anciennes (France, Espagne, Algérie ou Sénégal). Depuis les années 1990, le pays fait face à des réalités migratoires - émigration comme immigration - qui se modifient et se complexifient. À sa dimension traditionnelle d'espace d'émigration internationale et d'immigration discrète, s'ajoutent désormais non seulement celle d'étape vers l'Europe mais aussi d'espace d'immigration plus visible et diversifié.

2 En octobre 2005, les événements de Ceuta et Melilla ${ }^{1}$ ont contribué à focaliser l'attention sur la migration d'Africains subsahariens vers l'Europe, transitant par le Maroc, qui occupe depuis une place centrale dans les discours publics, médiatiques et politiques dans le Royaume.

3 Pourtant, d'autres formes de migrations émergent, temporaires ou d'installation à plus long terme, issues de populations d'origines nationales et de profils divers comme il en est de travailleurs, réfugiés, retraités, saisonniers, conjoint(e)s de marocain(e)s, chefs d'entreprises ou d'étudiants. Depuis 2005, les conditions de vie des «migrants subsahariens » et le traitement accordé à la migration subsaharienne au Maroc ont été mis en lumière et dénoncés. Cette catégorie de migrants, rendue plus visible, est devenue une préoccupation affichée tant par des organisations de la société civile que par des institutions nationales et supranationales.

4 Les réalités de la migration au Maroc restent, pourtant, opaques. Malgré la diversité des expériences migratoires au Maroc, on ne considère encore souvent que la migration d'Africains subsahariens, considérés comme étant en transit ou installés par défaut dans le Royaume et perçus comme une population homogène, au mépris des diversités de situations et d'origines nationales.

5 L'intérêt à appréhender ces réalités migratoires complexes constitue l'une des motivations de ce projet de publication, qui se situe dans un contexte particulier de remise en question des modalités de perception et de gestion des étrangers au Maroc, accompagné par l'annonce en septembre 2013 d'une nouvelle politique migratoire. 
6 Les contributions intégrées dans ce recueil sont le fruit, pour l'essentiel, des travaux des participants aux journées d'études «Présence des étrangers, cosmopolitisme et changements sociaux au Maroc contemporain » qui se sont tenues les 3 et 4 novembre 2014 à Rabat. Cette rencontre internationale a eu lieu grâce à la collaboration du Centres Jacques Berque pour les études en sciences humaines et sociales (CJB), au soutien de la Fondation Konrad Adenauer (KAS) et à la participation du Laboratoire d'études politiques et de sciences humaines et sociales (LEPOSHS) de l'Université Internationale de Rabat (UIR) ${ }^{2}$.

7 L'idée de cette publication vient cependant de plus loin. Elle fait suite à l'organisation en juin 2013 de journées d'étude ayant abouti à la création d'un réseau international de chercheurs travaillant sur les migrations, prises de différents points de vue et perspectives de départ, mais ayant le Maroc comme " carrefour " ${ }^{3}$. Notre projet veut se centrer sur le Maroc comme terre d'immigration, tout en sortant du paradigme dominant faisant des Africains subsahariens les seuls «migrants» au Maroc. Nous avons ainsi, d'un côté, restreint le champ d'analyse au Maroc et, de l'autre, nous l'avons élargi en l'ouvrant aux changements sociaux, politiques et religieux apportés par une multiplicité d'étrangers, traités sur un même pied d'égalité épistémologique. Si nous nous intéressons à la figure du migrant, nous mettons de côté les dimensions liées aux parcours migratoires, en amont et en aval de sa présence au Maroc. Nous ignorons volontairement les enjeux supranationaux et ne traitons pas, en tous cas directement et pleinement, certains éléments de compréhension qui dépassent le contexte marocain. Notre volonté s'ancre davantage dans le souci d'apporter des éclairages alimentant - tout en restant incomplets, partiels ou originaux - la compréhension de certains enjeux et perceptions des migrations au Maroc. Parler de présence d'étrangers et de transformations sociales au Maroc nous a semblé une bonne manière d'approcher de formidables transformations agissant sur le Maroc contemporain.

Nous avons également voulu mobiliser une diversité de chercheur- e-s travaillant sur les étrangers au Maroc qui, à divers moments, ont fréquentés le $\mathrm{CJB}$, alimentant ainsi les échanges entre chercheurs de différentes institutions et orientations disciplinaires. Ces chercheur-e-s (doctorant-e-s ou seniors) en sociologie, en anthropologie, en littérature ou en science politique, ayant participé aux journées d'étude Présence des étrangers, cosmopolitisme et changements sociaux au Maroc contemporain, ont pu présenter leurs analyses, échanger, confronter leurs points de vue et approches.

9 À la base de notre engagement, il y a le souhait de contribuer à alimenter la littérature scientifique sur les migrations au Maroc au travers de perspectives variées. D'une part, une grande partie des recherches et études réalisées ces dernières années se concentre sur les mobilités en provenance du sud du Sahara. Malgré la richesse de ces études ayant abordé les migrations subsahariennes sous différents angles (économique, anthropologique, juridique, etc.), celles-ci ont toutefois contribué à former une vision biaisée de l'immigration. Différentes dimensions des mobilités et présences étrangères du et vers le Maroc n'ont fait l'objet que de peu d'intérêt scientifique et médiatique.

D'autre part, certaines notions surexploitées, telles que "migration de transit", " expat », « migrant illégal » ou « subsahariens » ont saturé le débat public et méritent d'être analysées et respécifiées empiriquement et épistémologiquement.

11 Il s'agit alors de réfléchir aux interprétations variées que recouvrent les termes d'« étranger », de "migrant » et d' " intégration » notamment, dans le contexte marocain. Lors des échanges et dans les contributions intégrées dans cette publication, certaines 
notions n'ont pas fait nécessairement consensus. Mobilisées par certains, elles sont réinterrogées ou bannies par d'autres. Elles sont aussi révélatrices de perceptions hétérogènes des réalités migratoires marocaines qui se retrouvent chez les chercheurs.

Ces divergences expriment les regards divers des chercheurs, des citoyens, des États et des étrangers eux-mêmes sur la migration ou les migrations. Elles questionnent des enjeux politiques, juridiques, économiques ou sociaux, ainsi que des dispositions à prendre en compte et à prendre en charge les différentes dimensions de cette immigration. Ce sont également ces désaccords et perceptions divergentes, visibles au travers de certaines contributions de ce recueil, que nous souhaiterions saisir et interpeller pour des recherches et analyses susceptibles d'alimenter le débat et une meilleure connaissance de ces réalités complexes.

Certaines des contributions intégrées dans cette publication vont au-delà de leur propre champ d'analyse et mettent en discussion des notions ou lectures qui touchent à des réalités plus marocaines que rattachées exclusivement aux populations d'étrangers au Maroc, comme il en est du cosmopolitisme, des influences culturelles et religieuses, de l'appréhension du droit ou de la mise en œuvre des politiques publiques. Cela a conduit chacun à entamer une démarche d'ouverture sur les préoccupations et constats des autres, à creuser, à mettre en commun pour élargir les regards et mieux appréhender ces présences étrangères dans leur diversité, spécificités et complexités.

Dans ces analyses qui se répondent, se confortent ou s'ignorent, les figures de l'étranger se brouillent régulièrement pour se réinterroger mutuellement. Un intérêt particulier a été accordé à la manière dont les populations étrangères agissent sur le Maroc contemporain et sur son "cosmopolitisme», considérant en effet que la migration n'est pas un champ à part et que les étrangers impactent, de par leur présence, les sociétés à tous les niveaux. Comment la présence d'étrangers, temporaire ou de plus longue durée, interagit-elle avec le politique, le religieux, ainsi qu'avec les différentes dimensions qui constituent la société marocaine? Comment la société marocaine intègre-t-elle les diversités qui constituent sa population, au travers notamment de la mixité, des appartenances nationales multiples ou de certaines mobilités circulaires?

Ce recueil n'a pas l'ambition d'être exhaustif; s'il permet d'évoquer des sujets peu courants et de s'intéresser à des populations qui font classiquement l'objet d'un intérêt moindre, il vise essentiellement à rassembler des regards de chercheurs travaillant sur les migrations dans leur sens le plus large et sur les changements sociaux qu'elles engendrent et parfois impulsent au Maroc.

Les articles de cet ouvrage s'organisent autour de quatre axes.

17 Le premier axe traite des circulations et modalités d'installation des étrangers au Maroc. Quelle est la place du Maroc à l'épreuve des migrations internationales? En observant de plus près certaines des populations migrantes au Maroc, quelles sont leurs spécificités, les réseaux sociaux sur lesquels elles s'appuient, leur mode migratoire ? Les chercheurs de cet axe interrogent la manière dont les migrations au Maroc se remodèlent et s'adaptent aux environnements. Du transit à la transmigration, les populations migrantes reconfigurent les formes, les temps et les territoires de la migration en cherchant de nouvelles destinations mais aussi de nouvelles manières de contourner les contraintes territoriales, les frontières et les injonctions qui leurs sont liées (Mehdi Alioua). Ces questionnements sont aussi appréhendés au travers des itinéraires des migrants guinéens et de leur attente au quotidien (Anna Dessertine), des 
migrations chinoises au Maroc (Jean- Pierre Taing), ainsi que des travailleurs des ONG internationales au Maroc (Chadia Boudarssa). Dans le même axe, Liza Terrazzoni réinterroge la notion de "migration » en analysant les pratiques mobiles des français au Maroc, alors que Brenda Le Bigot se penche sur les modalités socio- spatiales de la présence des «hivernants" européens, notamment à Agadir. Enfin, l'immigration récente de populations syriennes fait l'objet d'une analyse du lien entre la migration au Maroc et les faits du « printemps arabe » (Bouchra Sidi Hiba).

18 Le deuxième axe envisage spécifiquement les mobilités religieuses: la religion en migration et le tourisme spirituel. Ces deux catégories de mobilité fondamentalement différentes mais liées par le fil rouge de la présence du religieux permettent d'appréhender, d'un côté, l'importance des réseaux religieux dans les projets migratoires ou en lien avec les séjours plus ou moins prolongés des étrangers au Maroc et, d'un autre côté, la place du Maroc en termes de destination et de référence spirituelle - largement valorisée par les autorités marocaines. Quelques enjeux du soufisme au Maroc sont ainsi abordés au travers du tourisme religieux sénégalais et des discours qu'il contribue à produire, en décalage avec ceux des "migrants » installés dans le pays (Nazarena Lanza), ainsi que par les mobilités des musulmans ivoiriens animés par l'attrait du tourisme et des formations religieuses au Maroc (Mamadou Bamba). Bernard Coyault interroge quant à lui la place accordée et prise par les religions des Autres, au travers de son travail sur les églises de maison congolaises de Rabat.

19 Un troisième axe traite des modalités de prise(s) en compte de diverses présences d'étrangers au Maroc. Cette question est tout d'abord appréhendée au travers des enjeux de l'immigration estudiantine subsaharienne (Lionel Nzamba) et de l'intégration des migrants subsahariens sur le marché du travail, en particulier dans le secteur des calls centers (Silja Weyel). Elle est également envisagée au travers des conditions légales pour résider régulièrement au Maroc (Eba Nguema Nisrine), ainsi que par une respecification de la notion de transit qui s'intéresse aux pratiques administratives et judiciaires (Nadia Khrouz). Dorothée Barrière traite, quant à elle, des parcours et conditions d'accès à la scolarité de mineurs étrangers, à partir de l'exemple de Caritas à Rabat et Casablanca.

Enfin, le quatrième axe envisage la pluralité de la société marocaine au travers des modalités par lesquelles elle intègre l'altérité ou les altérités. Comment cette " mixité » ou ce «cosmopolitisme» interviennent-ils dans la recomposition de la société marocaine et de ses perceptions? En se centrant sur différentes dimensions du « vivre ensemble » induites par la présence d'étrangers au Maroc, quels éléments apparaissent de l'évolution globale de la société en matière de " mixité »? Ces questions sont traitées par Niandou Touré qui l'appréhende via la présence estudiantine subsaharienne et l'exemple des étudiants maliens de Fès, alors que Sylvain Beck interroge la notion d'intégration au travers de l'expérience d'enseignants français au Maroc. Des approches originales se penchent sur les figures de l'altérité et leur appréhension par les marocains, comme il en est de l'analyse de Valérie Orlando sur la littérature d'un auteur cosmopolite marocain d'expression française, ou de celle élaborée par Bahmad Jamal au travers de supports cinématographiques et de l'image des migrants subsahariens dans l'histoire du Maroc. Cet axe intègre également une lecture novatrice de la figure de l'altérité et du communautarisme à Azemmour, dans la région Atlantique (Nasser Suleiman Gabryel). Enfin, Karibi Khadija envisage la présence des 
immigrés subsahariens d'un point de vue spatial et du «cosmopolitisme» dans les espaces publics de Rabat.

21 Par cet ouvrage collectif, nous espérons apporter une plus-value à la recherche sur les migrations, tout en interrogeant différentes réalités et concepts régulièrement diffusés, en particulier dans le contexte du Maroc contemporain. Nous espérons que ces réflexions pourront se poursuivre dans différents cadres, s'élargir, être interpellées, confortées ou réinterrogées, actualisées pour soutenir les analyses futures sur ces questions fondamentales et une meilleure connaissance des migrations et du cosmopolitisme au Maroc.

\section{NOTES}

1. En 2005, suite à plusieurs tentatives de franchissement des frontières qui séparent le Maroc des enclaves espagnoles de Ceuta et Melilla, 11 ressortissants subsahariens sont tués à coups de balles par la police aux frontières. Ces évènements provoquent une attention médiatique importante - de la presse marocaine et internationale - sur la question des « migrants aux portes de l'Europe ", bloqués au Maroc.

2. Dans ce recueil ont également été intégrés certains articles de contributeurs, ayant répondu à l'appel à contribution lancé, sélectionnés sur la base de la pertinence et/ou de l'originalité de leurs sujets d'étude et/ou de leur démarche de recherche.

3. Ces journées ont été organisées avec la collaboration d'Abdourahmane Seck (CER, Université Gaston Berger, Saint-Louis) et Mehdi Alioua (UIR, Rabat), avec le soutien du CJB et de la KAS. 
Circulations et modalités d'installation : le Maroc à l'épreuve des migrations internationales 


\title{
Un monde en mouvement, $\mathrm{du}$ transit à la transmigration
}

\author{
Mehdi Alioua
}

1 L'instauration du système Schengen a eu un impact considérable sur les routes et les formes migratoires en Afrique méditerranéenne. Depuis la généralisation du régime des visas et les restrictions auxquelles sont confrontés la plupart des Africains qui désirent migrer dans l'Union Européenne (UE), les migrants ont dû s'adapter en prospectant de nouvelles destinations, renforçant ainsi les migrations Sud-Sud, autant qu'en cherchant de nouvelles portes d'entrée et en produisant de nouvelles stratégies de contournement. Ainsi, des pays d'émigration, comme ceux du Maghreb, deviennent aussi des pays d'installations, longues ou temporaires. Les catégories de migrants ellesmêmes se brouillent, complexifiant le phénomène. Par exemple, le regroupement familial est devenu le principal critère d'entrée régulière en Europe. Ou encore, depuis Schengen, les migrants économiques, réfugiés, commerçants, étudiants venues d'Afrique subsaharienne sont systématiquement renvoyés à un même système de tri et beaucoup passent par les mêmes routes sahélo-sahariennes (Bredeloup et Pliez, 2005) pour tenter leur chance dans un pays méditerranéen en attendant de rejoindre les rives européennes.

2 Pour ces migrants subsahariens vivant en Afrique méditerranéenne, passer sans visa la frontière européenne prend des années, ce qui vide de son sens la notion de transit. Mais celle d'immigration reste insatisfaisante pour rendre compte de ce qui se passe dans cette région. Pour ces populations, la migration se déroule durant plusieurs années et dans plusieurs pays qui n'avaient pas prévu leur venue ni leur installation. La dimension spatio-temporelle (Tarrius, 2015) doit donc être impérativement replacée dans ce contexte où les trajectoires migratoires sont rythmées par des étapes au cours desquelles les migrants se réorganisent, le temps de passer la frontière qui s'érige devant eux. Ils doivent à chaque étape de leur parcours se loger, travailler, commercer, se soigner, parfois même défendre leurs droits, avant d'essayer de passer à une nouvelle étape.

3 Vue de l'intérieur, l'UE semble travaillée par deux logiques apparemment contraires: une force d'intégration posant la question des limites de l'UE, de la gestion de ses 
frontières extérieures et de ses politiques de voisinage, pendant que des forces nationales se réveillent pour résister à cette intégration. Mais vues de l'extérieur, notamment d'Afrique méditerranéenne, ces deux logiques n'apparaissent pas en contradiction radicale: peu à peu une seule frontière a été imposée aux pays limitrophes, là où il y en avait auparavant autant que des nations. On peut alors interpréter les politiques migratoires restrictives mises en œuvre dans l'Union, au niveau national comme communautaire, et celles qu'elle tente d'imposer aux pays voisins, comme un moyen de se définir sur les plans politique, identitaire et territorial, notamment par une délimitation stricte du « dedans » et du « dehors ». Non seulement la migration joue-t-elle un rôle dans la construction d'un "nous » collectif européen, mais avec la coopération imposée en matière de contrôle et de répression des flux migratoires aux pays limitrophes, participant à externaliser la frontière européenne, elle recompose à la fois le cosmopolitisme au sein de toutes ces sociétés et leurs liens avec la migration en général.

C'est dans ce contexte ambivalent où s'articulent circulations migratoires, mobilités transnationales, crispations territoriales et durcissement des contrôles aux frontières, que le Maghreb est traversé par différentes dynamiques migratoires dont les points communs, malgré qu'elles soient produites par des populations aux origines différentes ou avec des projets migratoires différents, sont la mise en place de réseaux migratoires transnationaux qui s'étalent dans le temps et l'espace, leur permettant, tant bien que mal, de contourner les frontières de l'Europe ou alors de trouver un projet alternatif. Ces populations espèrent subvenir à leurs besoins en utilisant la circulation et la dispersion dans l'espace, et tentent leur chance dans les pays d'Afrique méditerranéenne qui offrent parfois quelques opportunité économiques ou, comme le Maroc, permet aux réfugiés d'avoir un statut. Mais la majorité de ces migrants espèrent pourvoir passer et circuler en Europe à partir de l'Afrique.

5 Ainsi, aux portes de l'Europe, les formes, les temps et les territoires de la migration se reconfigurent sous l'action de populations mobiles cherchant de nouvelles destinations mais aussi de nouvelles manières de contourner les contraintes territoriales, les frontières et les injonctions des États-nations.

\section{De l'errance organisée à la transmigration}

6 C'est dans ce contexte que des dizaines de milliers d'Africains subsahariens tentent de réaliser leur projet migratoire: ils utilisent la dispersion dans l'espace comme une ressource, ou, pour le dire avec leurs mots, « ils vont chercher leur vie ». Des dizaines de milliers de migrants parcourent l'Afrique par étapes, se dirigeant ainsi vers l'Europe, traversant le Sahara et passant par les pays du Maghreb où ils s'installent, généralement pour un temps plus long que lors de leurs précédentes étapes. Fuyant la misère, la guerre et le chômage, ou se sentant tout simplement à l'étroit dans une société où ils ne trouvent pas leur place, ils effectuent des parcours de milliers de kilomètres et cherchent des solutions pour leur projet personnel en contournant les législations des pays traversés et en ré-agençant leur itinéraire migratoire, devenant ainsi en cours des routes, au moins le temps de leur périple, transmigrants. Les transmigrants réalisent la figure de l'étranger dont parlait Simmel au XIXe siècle finissant: celui dont les populations sédentaires ne savent pas s'ils prendront place parmi elles ou s'ils poursuivront plus avant leurs déplacements. Au départ, ils font 
groupe avec des parents et des voisins, ce qui justifie pour certains la désignation de " migration ethnique ", voire de diaspora, puis durant le temps long de la transmigration, des étapes urbaines, des recrutements, ils partagent leur destinée, affective, sociale, politique ou commerciale, avec toutes sortes «d'étrangers» qui deviennent leurs nouveaux compagnons: l'altérité se substitue progressivement à l'identité pour qualifier le lien dans leur nouveau monde social et la désignation initiale d'ethnique ne se justifie plus.

7 En effet, le phénomène migratoire dont nous parlons ici ressemble à la transmigration (Tarrius, Missaoui, Qacha, 2013) car une de ses formes essentielles réside dans l'enchaînement des nombreuses étapes nationales et urbaines où ils se rencontrent. Pourtant, ce n'était pas la volonté première de ces migrants, même si certains, très minoritaires, avaient déjà ce projet en tête. En voulant "aller chercher leur vie" ailleurs malgré les politiques migratoires restrictives édictées par les pays de l'UE, puis par certains pays Africains, ils ont dû s'adapter à un mode de vie quasi semi-nomade pour échapper aux contrôles, voire aux répressions d'État. C'est par imitation et nécessité qu'ils se sont mués peu à peu, dans la mobilité et dans l'urgence, en transmigrants: ils ont suivi des routes migratoires déjà "dessinées " et balisées d'étapes déjà établies par des migrants antérieurs, puis ils ont imité leur savoircirculer, voire leur mode de vie. Cependant, à l'image de cette migration dite "clandestine » et "de transit", il ne s'agit pas là d'une catégorie stable, mais bien " fragile » et transitoire. Cette " aventure », telle qu'il la nomme eux-mêmes, est une étape dans la vie de ces migrants subsahariens qui, à l'origine, se destinaient aux marchés du travail des pays d'Europe et pour certains des pays du Maghreb, principalement la Libye. Mais elle est suffisamment longue pour avoir des effets sur eux et sur certaines populations qui les voient passer et s'installer. C'est bien plus qu'un « entre-deux » : la dimension spatio-temporelle est primordiale pour appréhender cette " aventure ", plus ou moins transitoire pour les personnes qui la produisent et la vivent (la subissent aussi), mais bien plus longue en tant que forme sociale (Simmel, 1999).

8 En effet, la majorité de ces migrants subsahariens finissent par passer en Europe, ils s'y installent ou poursuivent leur périple ; d'autres s'établissent dans les étapes africaines où ils sont (notamment au Maghreb) et abandonnent leur « aventure » (du moins, pour un temps); d'autres encore rentrent chez eux, ou bien, plus dramatiquement, sont expulsés ou meurent. Mais, tous les jours, de nouvelles personnes les remplacent, avec les mêmes stratégies, prolongeant le phénomène de transmigration. Ces migrants construisent ainsi une sorte de continuité territoriale grâce aux réseaux qu'ils élaborent. Ils partagent leurs expériences et leur carnet d'adresses («les connexions » comme ils le disent). Mais cela suppose que les signes balisant ces routes soient reconnaissables par tous, c'est-à-dire qu'une conscience collective rapproche socialement tous ces individus et leur permettent d'interpréter les codes qu'ils élaborent. Tous ces signes sont en effet le résultat d'une multitude de relations sociales qui, liées les unes aux autres, forment des réseaux sociaux transversalement aux nations, mais se solidifiant lors des étapes, et leur confèrent une conscience collective : ces migrants deviennent en cours de route, dans la mobilité choisie ou contrainte, des transmigrants. Ainsi distribuées, de telles informations sur la route à suivre et la manière de vivre en mobilité migratoire contribuent à l'acquisition d'une des dimensions du savoir- faire nomade des transmigrants : instituer des circulations en 
repérant des routes déjà existantes ou en en dessinant de nouvelles pour pouvoir y circuler, y repasser ou faire passer ceux qui suivent.

\section{Un monde en mouvement : du cosmopolitisme aux droits cosmopolitiques?}

Cette transmigration, nous renseigne sur les désirs d'émancipation individuelle de ces transmigrants subsahariens dont nous essaierons ici de dévoiler certaines logiques qui les sous-tendent ainsi que les stratégies mises en œuvre pour y parvenir. Elles soulignent également combien ces dynamiques migratoires définies par de nouveaux seuils d'individualisation de la vie sociale et par la construction de nouvelles formes d'agrégation de la vie collective, dans lesquels les logiques collectives et individuelles se croisent en des lieux toujours plus complexes, bousculent les ordres sociaux et politiques institués par le système démocratique dont l'État-nation est l'agencement historique. Ce n'est effectivement plus simplement la localité, le territoire ou la nation, ni seulement les cadres légaux et les institutions des États qui délimitent les prérogatives de l'intégration sociale et politique, que le sociologue doit prendre en compte pour comprendre comment les individus construisent collectivement des actions sociales qui les lient les uns aux autres dans des formes particulières d'interdépendances, parfois à cheval sur plusieurs territoires, sur plusieurs pays. Car, avec la globalisation et la contraction du monde, de nouveaux espaces de circulations et de confrontations, qui sont connectés par un ensemble de liens sociaux denses et complexes, émergent et débordent quasi- systématiquement les cadres locaux et nationaux institutionnalisés de socialisation et de production identitaire.

Dans un monde où la contrainte territoriale n'est alors plus aussi prégnante qu'avant et où les initiatives individuelles et collectives sont importantes, même chez des populations a priori pauvres ou marginales, l'action sociale devient possible partout sur la terre, directement ou à distance, matériellement ou virtuellement. Cela a un effet extrêmement important sur le plan politique puisque la distance a cessé d'être cette ressource d'État qu'elle a été pendant des siècles : l'autorité de l'État- nation reposait en partie sur la distance, car elle donnait un sens au territoire national et une fonction médiatrice à l'État, dès que les individus cherchaient à communiquer entre eux (Badie, 1999). Même si l'État-nation reste l'institution principale de mise en œuvre de politique de gestion des populations, des territoires et des richesses, ses frontières sont de plus en plus poreuses. Non pas que celles instituées historiquement ne soient plus effectives, mais elles n'ont plus le même monopole sociologique dans la réalité que nous observons, et peut-être, demain n'auront-elles plus le même monopole politique.

11 Il faut alors un effort de "déterritorialisation» de la pensée et surtout de «dénationalisation» des cadres d'analyse pour comprendre les nouvelles formes de socialisation et d'action collective à l'œuvre dans les phénomènes de mobilité transnationale. Surtout que les États nationaux, face à cette prolifération d'acteurs transnationaux et à la porosité de leurs frontières, tentent de se réorganiser transnationalement. La reconfiguration territoriale et la réorganisation transnationale de la gouvernance (pour l'instant plus bureaucratique que politique) à l'œuvre avec la construction européenne est un bon exemple de la volonté des États de continuer à être les acteurs principaux sur la scène locale comme sur la scène globale; et cela est très parlant en ce qui concerne la gestion des frontières extérieures de l'UE. Mais si on 
assiste à une accélération sans précédent de la transnationalisation de la gouvernance à l'échelle mondiale, est-ce que pour autant il peut émerger une transnationalisation de la contestation et de la lutte politique, sans lesquelles il n'y a pas de démocratie, s'émancipant du cadre politique national et étatique, et créant un espace public de même dimension que celui de cette nouvelle forme de gouvernance? Nous n'avons pas la prétention de répondre, surtout ici, de manière définitive à cette question, mais, les résistances transnationales face à la politique européenne d'externalisation des contrôles des flux migratoires aux pays limitrophes, dans lesquels les transmigrants subsahariens jouent un rôle important, nous semble être un terrain d'investigation prometteur.

En effet, la vie en transmigration est souvent très dure, dénuée de protection, vie instable où règne l'exclusion, voire la répression étatique. Mais elle est aussi, et parfois en même temps, mutation permanente, innovation, coopération, voire solidarité : elle est une transformation sociale. Car les transmigrants s'approprient leurs espaces migratoires qu'ils balisent d'étapes en créant du lien: la marge devient refuge, «l'errance organisée » devient vivable, l'étape aménagée devient "habitable ». Dès lors, les articulations entre ces étapes engendrent une économie de la circulation, voire, créent une forme de consistance cosmopolitique (Beck, 2006) reliant l'Afrique subsaharienne, le Maghreb et l'Europe, et ceci, depuis les mobilisations politiques et depuis que les transmigrants entretiennent des liens avec des organisations militantes nationales et internationales les soutenant et leur servant de relais.

\section{BIBLIOGRAPHIE}

B. Badie, Un monde sans souveraineté, Paris, Fayard, 1999.

U. Beck, Qu'est-ce que le cosmopolitisme?, Paris, Aubier, 2006.

S. Bredeloup et O. Pliez (éd.), « Migrations entre les deux rives du Sahara », Autrepart, vol. 4, $\mathrm{n}^{\circ} 36$, Paris, Armand Colin et IRD-éditions, 2005.

G. Simmel, Sociologie. Études sur les formes de la socialisation, coll. « Sociologies », Paris, PUF, 1999.

A. Tarrius, Étrangers de passage : la mondialisation entre pauvres, la Tour d'Aigues, L'Aube, 2015.

A. Tarrius, L. Missaoui et F. Qacha, Transmigrants et nouveaux étrangers : hospitalités croisées entre jeunes des quartiers enclavés et nouveaux migrants internationaux, Toulouse, Presses Universitaires du Mirail, 2013. 


\title{
Les nouveaux migrants français à Essaouira et Marrakech
}

\author{
Liza Terrazzoni
}

1 L'installation des Européens au Maroc apparait significative des bouleversements qui traversent l'espace euro-maghrébin, comme des transitions qui travaillent le Maroc, notamment celle du passage entre pays d'émigration et d'immigration. Si les Africains subsahariens étaient jusqu'à récemment la figure récurrente de cette transition, les Européens, et surtout les Français, sont aujourd'hui une figure de plus en plus représentée. Depuis ces dix dernières années, selon la Direction des Français à l'étranger et l'administration consulaire (ministère des Affaires étrangères, France), le nombre des Français installés au Maroc augmente : 34097 s'étaient enregistrés sur les registres consulaires à la fin de l'année 2007, ils étaient 46995 fin 2013, parmi lesquels une moitié de bi-nationaux. Ces Français incarnent en effet le phénomène des migrations en provenance d'Europe vers le Maroc. Celui-ci mérite d'être décrit à la fois du point de vue des expériences et des itinéraires mais également en étant réinscrit dans une réflexion théorique qui viserait à renverser la perspective binaire entre pays d'émigration et pays d'immigration à partir de laquelle ont été pensées les circulations entre Europe et Maghreb, d'une part; à réfléchir aux concepts de migration et de cosmopolitisme, de l'autre.

2 Les enquêtes menées sur le terrain marocain depuis 2012, et en particulier à Essaouira et Marrakech, font apparaître un «nouveau » régime de migrations. Ainsi, on voit des Français s'installer, parmi lesquels des jeunes actifs venus ouvrir un restaurant, d'autres partis rejoindre un (e) amoureux (se) rencontré au détour d'un voyage, des couples se lancer dans l'ouverture d'une maison d'hôtes, des retraités s'établir pour leur retraite, etc. L'obtention de conditions privilégiées d'installation par leur État d'origine, d'un détachement ou d'un contrat pour une institution publique ou une entreprise, comme l'acquisition d'un statut dont les privilèges socio-économiques sont institutionnellement garantis (couverture sociale, prime d'expatriation par exemple), ne forment plus ni les cadres principaux de ces mobilités ni les raisons majeures qui les provoquent. C'est précisément l'un des aspects qui caractérise la nouveauté de ce phénomène : ces Français ont en commun d'avoir négocié eux-mêmes les conditions de 
leur déplacement et de leur avenir migratoire. En ce sens, leurs expériences se distinguent à la fois de celles des colons, des expatriés ou des détachés, qui caractérisaient jusqu'à récemment la plupart des mouvements de population de la France vers le Maghreb (Terrazzoni, 2015). La nouveauté du phénomène tient également au fait que les expériences de ces Français viennent bousculer les catégories d'expatriés, d'immigrés et de migrants au prisme desquelles les déplacements de populations sont généralement décrits, y compris dans les sciences humaines. Enfin, cette nouveauté est aussi liée à l'invisibilité de ces Français dans les chiffres. Ceux que nous avons cités ci-dessus ne représentent en effet que la face visible du phénomène, puisque les enquêtes de terrain montrent que le nombre de ces Français est bien plus important. Ils sont en effet nombreux à négliger de se déclarer au consulat, la démarche étant facultative, et à vivre sous le statut de touriste. Qui sont ces Français, que font-ils au Maroc et comment y vivent-ils?

Les villes de Marrakech et d'Essaouira ont connu, au cours des quinze dernières années, un développement touristique et urbain exceptionnel. Entre 2001 et 2009, à Essaouira par exemple, la capacité d'hébergements classés a été multipliée par 2,5 (plus forte augmentation des villes du Maroc). En 2002, on comptait une vingtaine de maisons d'hôtes dans la ville. En 2012, il y en avait plus de 100. Selon les estimations de la Direction des études et des prévisions financières, la région de Marrakech se positionne en première place pour les nuitées enregistrées au Maroc, avec 6,3 millions de nuitées enregistrées en 2010 (soit $35 \%$ du total). La région de Souss- Massa-Drâa (Agadir) arrive en deuxième position avec 5,8 millions de nuitées (33\%). Si la province de MarrakechTensift-Al Haouz, à laquelle appartient Essaouira, a connu une hausse de $71 \%$ des effectifs étrangers entre 1994 et 2004, Escher et Petermann (2013) ont comptabilisé une croissance des investissements européens et notamment français dans la médina souiri et recensé 298 propriétaires étrangers en 2003, 382 en 2008, Français en tête. Cette population tient donc un rôle stratégique puisqu'elle est au cœur du déploiement de l'offre touristique qui caractérise la région: le "riad» et le "beldi chic», respectivement maison ancienne du vieux centre urbain - la médina - restaurée et transformée en maison d'hôtes et maison d'hôte à la campagne. Elle est également au cœur d'un certain nombre d'activités, liées aux économies de la mobilité, qui offrent des services aux touristes (hébergement, restauration) mais également aux nouveaux installés européens (services immobilier, secondarisation résidentielle, architecture d'intérieure, etc.).

4 Aux alentours d'Essaouira, sur la route qui mène à Ghazoua, l'extension nouvelle de la ville, ont été construits, ces cinq dernières années, un Sofitel, un golf et trente-sept villas qui ont fini d'être vendues en 2013, principalement à des Français, des Belges et des Marocains, à des prix variant de 600000 à 2 millions d'euros. Les pistes se détachant des routes goudronnées au départ d'Essaouira en direction d'Agadir, de Marrakech ou de Safi, traversent des forêts d'arganiers et mènent à des douars dont les habitants comptent, parmi leurs voisins, de plus en plus d'Européens. Une partie d'entre eux louent de petites maisons beldi (traditionnelles), une autre vit dans de gigantesques maisons, résidences secondaires ou principales, construites par et pour des Européens. Oscillant entre $300 \mathrm{~m}^{2}$ pour les plus petites et $1000 \mathrm{~m}^{2}$ pour les plus vastes, leur architecture extérieure et intérieure s'inspire à la fois des maisons traditionnelles européennes (italiennes et françaises surtout) et marocaines. 
5 Çà et là, toujours sur les pistes, il y a de nombreuses maisons d'hôtes tenues par des Européens qui ont développé le concept d'hébergement à la campagne dans la région. Dans la médina, les deux rues principales affichent une succession de riads ou de dars, maisons traditionnelles urbaines, transformées en maison d'hôtes et tenues aussi, pour la plupart, par des Européens ; les Français étant toujours en première ligne.

On peut regrouper ces Français sous trois statuts professionnels principaux: des retraités, des entrepreneurs (agent immobilier, architecte, hôtelier, restaurateur, commerçant, etc.), des salariés déclarés ou non déclarés (cuisiniers, personnel hôtelier, agents immobiliers, etc.) qui constituent souvent le personnel des précédents. Parce qu'ils ne sont ni venus dans le cadre d'un contrat ni dans celui d'un détachement ou d'une coopération, leurs expériences se différencient de celle des expatriés dont les conditions de mobilité étaient encadrées par une entreprise ou une institution. Ils vivent au Maroc, sous deux types de statuts administratifs. Soit ils sont résidents et bénéficient d'un permis de séjour, ce qui leur permet d'ouvrir un compte bancaire qui sera alimenté en monnaie locale, le dirham; soit ils sont pendulaires, autrement dit vivent au Maroc avec un visa tourisme, qui leur donne le droit de séjourner 3 mois dans le pays, prorogeable, en théorie une fois, en pratique beaucoup plus, et qui doivent sortir du territoire pour le renouveler.

7 Ces derniers n'ont pas le droit de travailler et ne peuvent pas ouvrir un compte alimenté en dirham. Ils sont pourtant nombreux à vivre et travailler au Maroc sous ce régime, ou pour le dire autrement, à travailler au noir. Cette situation pose une première question : celle de la mesurabilité et permet de constater que nous sommes dans l'incapacité de mesurer ces flux. On est donc face à une population qui échappe à certaines catégorisations administratives et institutionnelles. Si 46995 Français étaient inscrits sur les registres consulaires en 2013, les représentants officiels français comme marocains invitent en effet à revoir les données à la hausse en y rajoutant 25000 à 30000 personnes supplémentaires: s'ils recensent en effet obligatoirement les titulaires d'un permis de séjour, ces chiffres n'incluent pas systématiquement les pendulaires, ceux qui vivent et travaillent au Maroc avec un visa touristique et pour qui la démarche est facultative. Ainsi fin 2007, par exemple, on recensait 21914 permis de séjour français pour 34097 inscrits sur les registres consulaires, selon les chiffres de la Direction de la Sûreté nationale du Royaume du Maroc et du ministère des Affaires étrangères français. Parmi ces 12181 individus, certains sont binationaux (porteurs de la nationalité française et marocaine), d'autres vivent sous le régime de la pendularité. Ce dernier groupe qui s'impose au chercheur sur le terrain, est composée d'individus qui font des allers-retours tous les trois mois pour renouveler leur visa et dont un certain nombre travaille sans autorisation. Une enquête du ministère de l'Emploi réalisée en 2007 et relayée par plusieurs médias mettait en évidence que les Français, étaient, avec les Chinois et les Turcs, la première nationalité à contourner les formalités de séjour et de travail. En 2010, M. Kachani (2010) évoquait, lui, 3000 travailleurs au noir, Chinois et Français en tête. L'enquête du ministère date mais rien ne montre, ni les transformations institutionnelles locales, ni les enquêtes de terrain, que le phénomène régresse et ce groupe s'impose bien au chercheur sur le terrain. Une partie des Français, est donc, comme le titrait Le Courrier de l'Atlas en juillet 2008, "sanspapiers ». Un terme utilisé d'ordinaire, en Europe, pour qualifier la situation d'individus en provenance du Maghreb et d'Afrique subsaharienne en situation irrégulière. Ce vocable, employé à l'adresse des Français installés au Maroc, est bien le 
signe des mutations qui traversent leur statut. À Essaouira, ou Marrakech, ces Françaislà forment souvent le personnel de leurs compatriotes et travaillent, le plus souvent, dans des secteurs dont les activités sont rattachées à l'économie des flux touristiques. Ils sont, par exemple, directeurs de maisons d'hôtes, chefs cuisiniers ou serveurs de restaurants, vendeurs dans les boutiques, agents immobiliers.

Qu'ils soient installés depuis de nombreuses années ou récemment, ces Français ont, pour la plupart, développé des activités visibles dans les centres urbains, au moins parce qu'elles sont liées à la rénovation des vieux bâtis. Ils ont en effet été nombreux à rénover des maisons traditionnelles pour les transformer en maisons d'hôtes. Certaines rues des médinas de Marrakech et d'Essaouira ont par ailleurs vu se multiplier les restaurants et boutiques tenues par des Européens. L'installation de cette population a en effet conduit au développement de commerces leur étant destinés. Mais paradoxalement, ils restent, par certains aspects, invisibles. Ils se confondent souvent avec les touristes dans l'espace urbain, notamment dans les lieux qu'ils fréquentent, mais également, il faut le rappeler, dans les chiffres, comme nous l'avons exposé plus haut. Les contacts avec la population locale se limitent, la plupart du temps, aux relations de travail - que celles-ci relèvent de l'association ou du salariat - et, au quotidien, aux relations liées à l'espace privé, puisque les Marocains forment généralement leur personnel de maison. Ces Français ne forment pourtant pas un groupe ou une communauté et se diluent dans la société marocaine, aussi bien du point de vue de leurs activités économiques que de leurs pratiques. Une part d'entre eux est souvent insaisissable car en mobilité régulière, entre la France et le Maroc, autant que le statut de touristes, avec lequel elle joue, le lui impose et le permet. Ils intègrent à la fois les ressources et les contraintes du Maroc, tout en maintenant des liens forts, économiques et familiaux, mais surtout symboliques, avec la France.

9 L'une des questions qui revient dans l'observation de ce nouveau régime de migration est la suivante : comment nommer ces Français et le phénomène dont ils sont les acteurs? L'idée est de regarder ces circulations, interprétées jusqu'alors en termes d'expatriation et de tourisme, avec une "optique cosmopolitique », selon les termes d'Ulrich Beck (2006) et au prisme du concept de migration. Il s'agit donc d'adopter un point de vue détaché du nationalisme méthodologique, au sein duquel la sociologie des migrations (comme la sociologie en général) et les catégories qu'elle a construite pour appréhender les déplacements humains se sont formées. Adopter cette optique, comme le montre Ulrich Beck, est l'une des conditions nécessaires pour comprendre et analyser les réalités sociales d'un monde en mouvement, dans lequel les frontières et les distinctions propres aux États sont renégociées, et dont ces Français au Maroc sont l'une des manifestations.

10 Même si leur installation, qu'elle prenne la forme de la résidence ou de la penduralité, semble bien s'apparenter à un phénomène migratoire, il reste difficile de les qualifier de «migrants", ce que pourtant nous pensons qu'ils sont. Les expériences de ces Français semblent très éloignées de celles des individus en provenance de pays dits du «Sud» (à faible revenu selon la définition adoptée par l'office internationale pour les migrations) essayant de gagner les pays du « Nord». Ces derniers sont souvent bloqués aux frontières, vivent dans un espace- temps contraint par les États, qui les maintiennent dans une certaine immobilité via les visas. Ces migrants sont devenus des archétypes des migrations contemporaines et convoquent une vision misérabiliste de la migration qui reste un cadre d'interprétation dominant des phénomènes migratoires 
(Peraldi, Rahmi, 2007). Les expériences dont nous parlons ici, celles des Français au Maroc, sont au contraire valorisées et tendent à s'émanciper des États. En développant des pratiques transnationales d'organisation, notamment économiques, et en tirant partie et profit de leur droit à la mobilité, ils tendent à s'affranchir, en partie, de leurs États d'appartenance.

11 Peut-on parler de migration pour décrire ces expériences ou doit-on parler de mobilité ? Il nous semble qu'il y a ici un enjeu théorique important à utiliser migration, à condition de sortir ce dernier terme des connotations qui lui sont attachées ainsi que des visions duale et nationale (pays émetteur et pays récepteur) ou des enjeux politiques (intégration) auxquels il renvoie. Ce n'est qu'à la condition de reproblématiser la question migratoire, en déconstruisant notamment les catégories utilisées, et en les mettant à l'épreuve de certains phénomènes contemporains, que l'on pourra dessiner les contours des dynamiques migratoires contemporaines. Des dynamiques au sein desquelles la mobilité semble s'imposer comme cadre de vie et d'expérience, en imprégnant à la fois les activités économiques et les pratiques des individus concernés. Il s'agit de replacer le terme migration dans une vision cosmopolitique (Beck, 2010) plutôt que nationale.

Cette optique cosmopolitique nous semble cependant pertinente d'un point de vue théorique seulement. Au niveau empirique, les enquêtes de terrain montrent en effet que, bien que dilués dans la société marocaine, ces Français portent les signes d'une (auto)distinction historique. S'il existe bien des endroits mixtes, c'est parce qu'ils sont fréquentés à la fois par les touristes, les résidents au long court et la classe aisée marocaine. Les groupes d'amis mixtes sont, cependant, bien rares. Les appartenances identitaires des uns et des autres semblent, malgré des discours qui revendiquent une condition cosmopolite, autrement dit placée sous le signe du mélange et d'appartenances éclatées qui transcenderaient les frontières, bien ancrées. Aussi, la condition cosmopolite reste-t-elle, autant qu'il nous a été donné de l'observer, une chimère entretenue dans un rêve d'Orient.

\section{BIBLIOGRAPHIE}

U. Beck, Qu'est-ce que le cosmopolitisme ?, Paris, Aubier, 2006.

A. Escher et S. Petermann, « Du jet-setter au retraité : parcours et profils des habitants étrangers des médinas de Marrakech et d'Essaouira », dans E. Coslado, J. McGuinness et C. Miller (dir.), Médinas Immuables? Gentrification et changement dans les villes historiques marocaines (1996-2010), Rabat, Centre Jacques Berque, 2013, p. 189-214.

M. Khachani, Maroc, migration, marché du travail et développement. Document de travail, Organisation internationale du travail (Institut international d'études sociales), 2010.

M. Peraldi, A. Rahmi, « Des 'pateras' au transnationalisme. Formes sociales et image politique des mouvements migratoires au Maroc », Hommes et migrations, $n^{\circ}$ 1266, 2007, p. 67-80. 
L. Terrazzoni, «Les Français au Maroc : profils et temporalités d'un nouveau régime de migration », dans Migrations et temporalités. Les migrations à l'épreuve du temps XIX ${ }^{e}-X X I^{e}$ siècle, Karthala, à paraître en 2015. 


\title{
Saisonniers du temps libre : modalités socio-spatiales de la présence des « hivernants » européens au Maroc
}

\author{
Brenda Le Bigot
}

1 Les «retraités au soleil» sont devenus au cours des dernières années un objet médiatique récurrent de la presse ou de l'audio-visuel français. Climat, crise économique, quête de bien-être et avantages fiscaux sont souvent présentés comme des éléments attractifs pour ces occidentaux seniors. Le phénomène commence à être abordé par les sciences sociales (Benson and O'Reilly, 2009). Il est néanmoins relativement peu envisagé du point de vue de la société de destination, en l'occurrence la société Marocaine, et peu connu dans la diversité des profils qu'il concerne. La présence d'Européens au Maroc, et plus spécifiquement d'Européens seniors, au Maroc, se décline en effet sous différentes formes. L'une d'elle se manifeste de façon durable, mais intermittente, il s'agit des " hivernants ». Présents chaque hiver sur le territoire marocain, ces étrangers occupent une place spécifique par rapport à la société marocaine, qu'il s'agit ici de commencer à préciser.

L'article repose sur une enquête menée dans la région d'Agadir en mars 2014. Elle mobilise une observation ethnographique ainsi que des entretiens conduits avec des «hivernants ", mais également avec des Européens présents au Maroc de façon plus brève pour certains (touristes), et plus durable pour d'autres (résidents), ainsi qu'avec des responsables de structures (campings, résidences, institutions culturelles) en contact fréquent avec les « hivernants ». Cet éclairage sur la présence d'Européens au Maroc a pour objectif de s'inscrire dans une démarche de mise en regard de ce travail en cours sur les «hivernants ", groupe bénéficiant d'une accessibilité privilégiée à la mobilité vers le Maroc, avec des travaux menés par d'autres chercheurs sur d'autres catégories d'étrangers au sein de la société marocaine, afin de faire émerger des différences de traitement et de perception. 


\section{Une présence européenne sous diverses formes}

3 Selon le Recensement Général de la Population et de l'Habitat de 2004, les Européens constituent le groupe majoritaire de résidents étrangers, représentant $45,9 \%$ de cette population. Suivent les groupes de résidents étrangers issus du Maghreb (23,9\%), du Moyen Orient (11,5\%), puis des autres pays d'Afrique $(10,4 \%)$. Ces chiffres sont à relativiser sur divers plans (Haut-commissariat au Plan, Direction de la statistique, 2009). Ils reposent tout d'abord sur la déclaration des enquêtés, et non sur le statut administratif. Aussi, ils ne tiennent pas compte du statut régulier ou irrégulier de l'étranger présent sur le territoire. Enfin, ces chiffres ne considèrent pas la présence d'Européens qui restent au Maroc grâce à leur autorisation d'entrée sur le territoire pour motif touristique. Cette autorisation, liée aux accords bilatéraux entre le Maroc et certains pays européens, est valable 3 mois, avec possibilité de prolongation pour 3 mois supplémentaires. Elle est également utilisée par certains pour rester de façon plus durable au Maroc, grâce à des sorties régulières du territoire suivies d'entrées immédiates.

4 Si les Européens présents plus de 6 mois par an au Maroc sont difficilement identifiables quantitativement, une partie est quasiment noyée dans d'autres catégories. Ainsi, la catégorie que nous nommons « hivernants", séjournant 3 à 6 mois au Maroc se trouve confondus avec la catégorie "touriste». Bénéficiant de l'autorisation d'entrée de 3 mois, ils peuvent obtenir facilement une prolongation de 3 mois supplémentaires. Les résidences ou campings dans lesquels ils sont accueillis proposent généralement de prendre en charge les démarches. Si celles-ci peuvent être ressenties comme des contraintes administratives, elles sont généralement très bien intégrées par les hivernants. L'enquête a permis de constater que ces retraités développent rapidement un "savoir-faire » lié à la mobilité et qu'ils font face à assez peu d'entraves pour séjourner au Maroc durant près de la moitié de l'année.

S'il n'est pas possible de dresser un profil type d'hivernants sur une base statistique, l'enquête conduite à Agadir auprès de 49 répondants (représentant 88 personnes dont 39 couples) permet de repérer des traits communs, ainsi que des éléments introduisant une forte diversité au sein du groupe. En termes de situations de mobilité, le profil " couple " est très majoritaire avec 39 couples. Les individus voyageant seuls sont, parmi les personnes rencontrées, autant d'hommes (5) que de femmes (5). La moyenne d'âge est de 69 ans, et la nationalité française prédomine, avec 38 répondants (les autres nationalités représentées étant la belge, la britannique, la suédoise, l'allemande et l'italienne). Contrairement aux nationalités identifiées par le Recensement Général de la Population et de l'Habitat (RGPH), les hivernants comptent, selon l'enquête, peu d'Espagnols. Ceux-ci sont inscrits dans une mobilité longue vers le Maroc plutôt dans le cadre d'un projet professionnel que lors de la retraite, qui s'oriente dans les provinces du Nord, notamment Tanger-Assilah et Tétouan (Haut-commissariat au Plan, Direction de la Statistique 2009).

6 Un élément introduit néanmoins une grande diversité parmi les hivernants rencontrés dans la région d'Agadir, il s'agit du mode d'hébergement. Deux sous-groupes peuvent être identifiés, les camping-caristes et ceux choisissant un logement en dur. Parmi les camping-caristes, se différencient les itinérants, partageant leur 3 à 6 mois de séjour marocain entre plusieurs lieux, et les sédentaires, s'installant dans un seul camping pour toute la durée du séjour. Parmi les résidents en dur, on peut également distinguer 
des itinérants et des sédentaires, même si la majorité séjourne dans un seul lieu ; mais surtout, se différencient les personnes qui résident en hôtel, en studio résidence, qui louent une maison ou un appartement, et celles qui sont propriétaires d'une maison, d'un appartement ou d'un mobile-home. Ces modes d'hébergement, et notamment la distinction camping-car et logement en dur, participent d'une segmentation sociospatiale forte de la présence des hivernants européens au Maroc. Avant de détailler ces enjeux, il est possible de détailler le processus par lequel un Européen devient un hivernant au Maroc.

\section{Les hivernants : un profil intermédiaire entre touriste et résident?}

7 Dans la pratique même de l'enquête, les contours de la catégorie « hivernant » ont été compliqués à tracer. Les divers profils d'Européens présents, par exemple les touristes, ou encore les résidents, ont nourri largement la compréhension de ce que l'on pourrait saisir comme un profil intermédiaire, celui des hivernants.

Ces expériences diverses du territoire marocain ne peuvent être séparées de la compréhension des « hivernants » car elles se situent généralement dans un continuum biographique.

9 Ainsi, le parcours identifié de façon très courante chez les hivernants, consiste en un ou plusieurs séjours touristiques courts avant ou au tout début de la retraite, suivis de la décision de rester plusieurs mois, 3 mois pour les premières années, comme le permet l'autorisation pour motif touristique, puis 5 à 6 mois grâce à la prolongation. À ce stade, plusieurs voies sont possibles, celles de s'installer définitivement, en formulant la demande d'une carte de résidence, et parfois en achetant un bien immobilier, ou s'installer dans un mode de vie alternant entre deux lieux, le pays d'origine et le Maroc. Ainsi, le profil d'hivernant prolonge celui du touriste, et peut être une étape vers l'émigration, mais peut aussi s'avérer une situation durable.

10 Le mode de vie dans lequel s'installent les hivernants, alternant entre l'Europe et le Maroc, s'inscrit dans le cadre d'une rupture biographique forte, la sortie de la vie active (Thomsin, 2001). Après ce moment charnière, les hivernants peuvent s'installer dans un cycle saisonnier d'aller-retour très durable, jusqu'à la dégradation de leur état de santé. Ainsi, sur 48 répondants, couples ou personnes seules, 16 profils d'hivernants étaient venus entre 4 et 9 fois au Maroc, 15 étaient venus entre 10 et 14 fois, 9 plus de 15 fois. On peut mettre en regard ce nombre assez impressionnant d'aller-retour avec l'espérance de durée de vie à la retraite en France qui s'est largement accru ces dernières décennies, selon la Direction de la recherche, des études, de l'évaluation et des statistiques (DREES) de 23,8 ans passés à la retraite (21,2 ans pour les hommes, 26,5 ans pour les femmes).

11 Ce mode de vie conduit à des formes de sociabilité spécifiques. Les observations identifient des espaces de vie différenciés à l'intérieur même du groupe d'hivernants et caractérisés par un relatif entre-soi. 


\section{Conflit de légitimité et sociabilité d'entre-soi}

12 Dans la région d'Agadir, la présence de ces hivernants est bien visible (Desse, 2010). Elle se confond avec celle des retraités présents à l'année, par exemple sur la promenade du bord de mer, ainsi que dans certains restaurants comme ceux de la place du marché du Talborj. Elle se repère spécifiquement par la présence de camping-cars, dans les campings majoritairement, mais également installés de façon informelle et tolérée dans certains centres villes ainsi que sur des terrains en friche ou en travaux sur le littoral.

13 La perception de cette présence européenne éphémère mais répétée se formule chez les professionnels marocains, régulièrement en contact avec eux, de façon ambiguë. L'arrivée des hivernants est d'une part indissociable de l'apport économique qu'elle permet.

14 Certains campings et résidences fonctionnent ainsi presque exclusivement avec cette clientèle durant les mois d'hiver. Parallèlement, le passé colonial, le différentiel économique et les rapports de domination qui en découlent peuvent entraîner des crispations chez certains habitants marocains.

15 Cette perception antagoniste se retrouve fortement dans les discours des hivernants eux-mêmes. Ainsi, les entretiens ont permis d'identifier la mobilisation récurrente d'un argumentaire de justification de la présence sur le territoire marocain. Cet argumentaire se construit généralement dans l'opposition : il s'agit pour l'hivernant de disqualifier les mauvaises pratiques d'autres hivernants afin de mettre en valeur ses bonnes pratiques et ainsi de légitimer sa présence. Ces discours structurent fortement les relations socio-spatiales entre Européens sur le territoire marocain, et met notamment en évidence la fracture entre le groupe des hivernants camping-caristes et celui des hivernants résidant en dur. Les arguments de dynamisation économique et de comportements dominants sont utilisés largement dans cette opposition. Le groupe des camping-caristes est par exemple accusé par les autres groupes de ne rien apporter à l'économie locale et de rester entre eux. À l'inverse, les camping-caristes ont intégré ces accusations et les vivent comme des critiques de la part d'un groupe économiquement dominant, envers leur groupe, caractérisé par une pratique identifiée comme populaire, celle du camping-carisme. Perçus par les camping-caristes comme plus riches qu'eux, les hivernants logeant en dur sont critiqués pour leurs comportements dominant avec les Marocains. Comme dans l'étude proposée par N. Élias et J.-L. Scotson (1965) (Logique de l'exclusion), le rejet de l'autre ne repose pas ici sur un racisme de race, mais sur une intégration par chaque groupe de sa propre situation de dominée et de dominant parmi les Européens au Maroc. La position de légitimité ou l'illégitimité de l'hivernant vis-à-vis de la société marocaine est utilisée comme argument pour justifier sa propre présence d'une part, et pour entériner son appartenance à un groupe qui se place au sein de la hiérarchie sociale.

16 Ces divisions à l'intérieur même du groupe des hivernants impliquent dans le cas d'Agadir des formes spatiales de sociabilité différentes et donc un rapport différencié à la société marocaine. Du fait de leur mode d'hébergement, les hivernants logeant en dur sont davantage présents dans l'espace urbain. Cela peut s'exprimer par l'achat d'une maison dans le quartier de Charaf, prisé par les Européens et les classes moyennes d'Agadir, ou encore par la location d'un studio dans l'une des nombreuses résidences du centre-ville. Les Européens logeant en dur sont ainsi dispersés dans différents pôles de l'espace urbain, en coprésence - mais pas nécessairement en 
interaction - avec certains groupes de Marocains, ainsi qu'avec des Européens résidents à l'année. Du fait de leur véhicule utilisé comme un logement, les camping-caristes se trouvent davantage regroupés dans les lieux spécifiquement produits pour eux comme les campings, ou des lieux qu'ils s'approprient pour un usage spécifique, comme les parkings de centre-ville ou les terrains en friche. La coprésence avec les Marocains est ainsi moins importante et concerne quotidiennement surtout des relations de service marchand.

\section{Conclusions et perspectives : et les autres étrangers ?}

Les hivernants européens constituent une catégorie d'étrangers au Maroc assez mal identifiée quantitativement mais bien visible. L'enquête menée à Agadir a permis de replacer ce groupe dans la continuité des différents statuts d'Européens présents. Plus vraiment un touriste, mais pas encore un résident, les hivernants s'installent dans une dynamique d'aller-retour, entre le Maroc et le pays d'origine, répétée généralement durant plusieurs années.

Marqués par la perception ambiguë de leur présence, entre l'apport économique et les rapports de domination, ce groupe développe un fort besoin de justification de sa présence au Maroc. Celle-ci passe notamment par la délégitimation des sous-groupes d'hivernants européens perçus comme différents par leurs pratiques. Dans cet argumentaire de la justification, les bons rapports avec les Marocains sont utilisés comme des arguments importants de quête de légitimité.

L'identification de ces sous-groupes met en outre en lumière des modes d'appropriation de l'espace différenciés, en co-présence plus ou moins forte avec les Marocains.

L'enquête permet par ailleurs de remarquer l'absence quasi-totale de référence aux étrangers non-européens, notamment aux Africains subsahariens, dans les discours des hivernants européens au Maroc. Ces migrants subsahariens peuvent pourtant être concernés par l'emploi dans le secteur touristique, et donc être en contact avec les hivernants européens. Ainsi, on peut postuler que l'absence dans le discours ne soit pas nécessairement le reflet d'une absence d'interaction pratique entre ces différents groupes d'étrangers présents au Maroc.

\section{BIBLIOGRAPHIE}

M. Benson et K. O'Reilly, Lifestyle Migration: Expectations, Aspirations and Experiences, Ashgate Publishing, 2009.

M. Desse, « Mobilités touristiques et recompositions socio spatiales dans la région d'Agadir », Norois, vol. 214, $\mathrm{n}^{\circ} 1,2010$, p. 55-65.

N. Elias et J.-L. Scotson, Logiques de l'exclusion. Enquête sociologique au cour des problèmes d'une communauté, Paris, Fayard, 1997 (première édition en anglais en 1965). 
Haut-commissariat au Plan, Direction de la statistique, Les résidents étrangers au Maroc : profil démographique et socio-économique, Enquête, Maroc, 2009.

L. Thomsin, « Les mobilités de la retraite », Pratiques du champ social, 2001, p. 223-42. 


\title{
Rencontre et mise en scène de soi : de la construction de réseaux chez les migrants guinéens de Rabat
}

\author{
Anna Dessertine
}

Le temps n'est réel que dans la mesure où il a un
contenu, c'est-à-dire où il offre une matière
d'événements à la pensée. (Maurice Halbwachs)

Le 15 mars 2014 à Rabat, dans le quartier de Takadoum. Trois migrants guinéens sont assis en silence. Ils attendent la sollicitation d'un "patron », qui leur permettrait de travailler en tant que manœuvre pour quelques heures, voire quelques jours. La matinée passe, l'un d'entre eux fait maintenant les cent pas et tourne lentement autour de la grande dalle qui leur sert de siège. Un homme passe et attire l'attention d'un des trois migrants. Il dit le connaître et l'interpelle. Après avoir échangé quelques phrases, ils se souviennent s'être rencontrés chez une connaissance commune, près de Hay Nada, un autre quartier de Rabat. Le jeune homme se joint à eux et commence à raconter son histoire : lui aussi est guinéen et est en " aventure » depuis presque deux ans. Il a d'abord passé quelque mois en Mauritanie où il a appris le métier de boulanger. Il cherche désormais un contrat, mais il a "trop souffert ", dit-il. Les dangers de la route, l'argent perdu ou volé, les problèmes de logement et les accros avec la police, structurent son discours. Cependant, son ton est loin d'être plaintif. Il se raconte au contraire sur un mode épique où il apparaît comme le héros de sa propre histoire : «J'ai beaucoup connu et la souffrance maintenant, je l'ai domptée » conclut-il. Les trois autres le regardent, et l'un d'entre eux déclare alors : « Non vraiment, toi tu es notre grand!».

2 Ces scènes de vie font partie intégrante du quotidien des migrants que j'ai pu rencontrer depuis février 2014. Ces moments de rencontre ponctuent les heures creuses et les journées vides, au cours desquelles les migrants se sentent parfois piégés. Pourtant, il ne faut pas s'y tromper : ces périodes d'attente et d'inactivité sont en fait créatrices de sens, de relations sociales dont les mécanismes doivent être mis au jour. Trop souvent en effet, la description anthropologique s'attache à dépeindre des 
individus dans l'action, préférant l'extraordinaire de l'événement à la banalité du quotidien. Les migrants se qualifient certes $d$ '«aventuriers", mais cette notion regroupe des expériences vécues fort diverses, où la perception du temps prend une place primordiale. Par ailleurs, les études qui se sont concentrées sur les conditions de vie des migrants mettent généralement au jour une certaine "misère sociale ", ou à l'inverse, les érigent comme des " héros des temps modernes ", prompts à l'adaptation et à la vie urbaine. Mais ces deux perspectives ont tendance à écarter le quotidien des migrants, le réifiant à une lutte perpétuelle pour la survie. Or, pendant de longs moments, ces migrants « passent le temps » ensemble et/ou attendent un changement : un apport d'argent, une régularisation, le signe d'un passeur ou tout simplement un ami avec qui ils doivent partir, etc. L'objectif est donc ici de s'intéresser à ces périodes de temps long, de "relâchement", pour reprendre les termes d'Albert Piette, en contexte migratoire chez les migrants guinéens à Rabat.

3 «Les temps de l'aventure migratoire - écrit S. Bredeloup - ne se résument pas aux seules périodes d'action ritualisées où les protagonistes peuvent tester leur courage et leur détermination; ils peuvent intégrer également les moments d'attente et de confinement qui sont habituellement occultés dans les récits alors qu'ils peuvent déboucher sur des états d'extrême tension » (2014, p. 73).

$4 \mathrm{Au}$ Maroc, ces temps d'attente prennent d'autant plus d'importance que la situation est vécue comme une situation de "blocage " par les personnes interrogées. Sans rentrer dans les débats sur la notion de «transit» (cf. par exemple Timera, 2009; Bredeloup, 2014), les migrants interrogés font l'expérience d'une temporalité marquée par un présent qui ne dépend pas toujours d'eux, et par un avenir incertain. Pour autant, il ne s'agit pas de considérer les migrants comme pris dans le «flux » de l'aléatoire et du hasard.

5 Leurs mobilités participent en effet à la création de formes sociales particulières, comme l'explique Mehdi Alioua, s'inspirant de G. Simmel : « Une forme sociale est (...) une forme de socialisation ou d'association au sens 'd'entrer en relation sociale' (sociation), c'est un type d'organisation d'échange et d'interdépendance, une structure mobile conservant une certaine autonomie par rapport au contenu» (2011, p. 30). Les rencontres et les interactions (au sens Goffmanien) sont donc ici essentielles. Or, il semblerait que les moments d'attente, grâce aux rencontres qu'ils permettent, soient des moments d'interaction privilégiés, donnant l'occasion aux aventuriers de mettre en avant leurs compétences et de (re)conquérir la maîtrise de leur temps.

6 Comment se manifestent ces interactions et que se joue-t-il véritablement dans une rencontre? Les moments d'attente ne participeraient-ils pas à un processus plus large de construction de réseaux ? Pour répondre à ces questions, je m'intéresserai d'abord brièvement à la notion d'" aventure ", puis je montrerai que les moments d'attente privilégient un mode d'interaction fondé sur la mise en scène de soi, permettant aux migrants de donner une temporalité à leur aventure et de se situer dans des réseaux collectifs.

\section{Des aventuriers en quête de « connexions »}

7 La notion d' " aventure » porte en elle une diversité de destins, du chevalier errant au héros antique, du simple explorateur au migrant actuel. Comme le souligne justement Mehdi Alioua, l'aventure de ces migrants débute très souvent de manière 
« hétéroclite», mais ensuite, «ils utilisent collectivement, en cours de migration, lors de leurs rencontres et de leurs traversées, la circulation comme une ressource, en parcourant l'Afrique, du sud au nord, en se réorganisant et en s'installant durant un certain temps dans des étapes » (2011, p. 163). L'aventure des uns est ainsi balisée par le passage des autres, créant un véritable "territoire circulatoire " pour reprendre les termes d'Alain Tarrius (2010), dans lequel il s'agit avant tout, selon les propos des interrogés, de se "débrouiller», de "créer un réseau» et des "connexions" indispensables à leur parcours. Mais au départ, les aventuriers n'avaient pas forcément envisagé leur mobilité de cette façon. Pour beaucoup, l'aventure était pensée comme une entreprise de "distinction ", où il s'agissait de témoigner du refus "de rester à la place que leurs parents leur avaient assignée» (Bredeloup, 2014, p. 17). Certains y voyaient la possibilité de "devenir quelqu'un» grâce à des opportunités qu'ils n'auraient pas pu avoir dans leur pays d'origine (études, rencontres, création de réseaux relationnels, professionnels, etc.).

Seulement, la "souffrance» (toroya en malinké) de l'attente semble souvent sousestimée par les migrants, qui perçoivent parfois leur quotidien comme monotone et répétitif : "C'est toujours la même chose. Tu peux faire plus d'un mois sans même que quelqu'un vienne te chercher. Alors tu attends et tu bouffes l'argent. On reste avec les potes jusqu'au soir, on blague...on a rien à faire! Le soir, on va faire parfois le bordel en ville, s'ambiancer quoi. Mais c'est tout » (Malick). Ils doivent alors le conjuguer avec un imaginaire de l'aventure, rythmée par des épreuves successives, soumise au hasard des rencontres parfois les plus improbables et où la réussite résonne comme une promesse. V. Jankélevitch avait déjà mentionné cet aspect: "Si l'aventure se place surtout du point de vue de l'instant, l'ennui et le sérieux considèrent le devenir surtout comme intervalle : c'est le commencement qui est aventureux, mais c'est la continuation qui est, selon les cas, sérieuse ou ennuyeuse.» (1963, p. 7). L'aventure est pensée dans l'effervescence quand le quotidien se vit dans l'attente permanente. Mais ne serait-ce pas justement ces moments d'attente qui permettraient l'orchestration de ces deux rythmes opposés? N'est-ce pas dans ces moments particuliers que le migrant écrit la partition de son aventure? Il me semble en effet qu'il existe un mode d'interaction spécifique à ces périodes de "relâchement ", qui permettrait l'établissement de ces « connexions » si chères aux migrants. Comment ce mode d'interaction se manifeste-til ?

\section{Se positionner socialement et temporellement par la mise en scène de soi}

9 Après avoir arpenté pendant une dizaine de minutes les rues de Takadoum, Sory s'arrête devant une petite maison et ouvre péniblement la porte rouillée qui lui sert d'entrée. Le rez-de-chaussé se décompose en plusieurs petites pièces, dans lesquelles logent des migrants, mais aussi quelques Marocains. La décoration de son « appartement» est sommaire: deux matelas posés l'un sur l'autre, des habits, une petite bouteille de gaz, un peu de vaisselle, quelques légumes et du lait en poudre. Il s'étale sur son lit de tout son long, s'assoupissant peu à peu, jusqu'à ce que quelqu'un frappe à la porte. Un très jeune homme rentre et face à l'air interrogateur de Sory, lui explique qu'ils s'étaient rencontrés il y a quelques jours au café et qu'il lui avait dit de passer chez lui s'il avait besoin de travail. Sory possède en effet un petit réseau de 
«patrons » qui embauchent des migrants à la journée pour du travail de manœuvre. Il commence alors à sourire et m'explique avec une pointe de fierté à peine dissimulée :

«Chez moi, tu as vu c'est le défilé. J’ai plein de " petits " comme ça qui viennent me voir. C'est parce que j'ai duré ici, et que moi, je connais. Je sais comment ça marche. D'autres viennent me rendre visite naturellement, d'autres ne viennent jamais les mains vides. Tu connais B. non? Lui ne vient jamais les mains vides. Lui n'a jamais oublié la case de départ. Je n'avais pas où le loger. Mais j'avais des contacts. Il n'a jamais oublié. C'est mon petit. Il viendra même aujourd'hui. Parfois sous la pluie, il vient quand même me saluer. Et je lui dis ah bon? Même avec la fraîcheur, la pluie?».

Son «nouveau petit» hoche ensuite vigoureusement la tête, comme pour asseoir la supériorité du statut de Sory, et après quelques minutes lui raconte son parcours :

«J'ai beaucoup vu, même si je suis encore jeune. Je suis sorti très tôt de la Guinée pour aller chez mon oncle au Mali. Je voulais devenir tailleur mais j'ai trop souffert là-bas. Alors je suis parti en aventure. Moi je veux aller en Europe. C'est là-bas qu'il $\mathrm{y}$ a tout. Et puis je me débrouille bien. Comme je suis bon, les gens m'aident. Après le Mali, j'ai décidé d'aller en Côte d'Ivoire. Et là j'ai gagné de l'argent, beaucoup d'argent même! Je faisais passer des armes et vraiment, j'étais doué ! Jamais les autorités ne m'ont prises. Le monsieur qui était au-dessus, il était tellement content de moi... Mais il y a eu la guerre là, et j'ai pris mon argent, et je suis parti vers le Maroc par la route. Non c'était difficile! Il faut voir! Il y a des femmes toutes seules avec leurs enfants même. Je les ai bien aidées. Il faut être bon, toi même tu sais, tu es déjà un grand au Maroc! [en regardant Sory]. C'est parce que tu es gentil que tu ne souffres pas! Moi aussi je vais devenir grand, ça c'est sûr, parce que je ne connais pas la case " débutant "! »

11 D'emblée, cette interaction, cette rencontre, positionne les deux protagonistes dans un rapport de "petit » à "grand», reprenant les principes hiérarchiques entre aîné et cadet que l'on trouve en Guinée : c'est le plus jeune qui se déplace pour saluer son « grand », il se met «à sa disposition » et se présente comme étant sur ses traces (« Moi aussi je vais devenir grand»). Il le reconnaît d'ailleurs explicitement comme son "grand » dans son discours. De même, Sory l'interpelle directement par «mon petit » et le plaçant dans un ensemble plus vaste d'autres « petits » sur lesquels il a autorité de par dit-il, son expérience ( je connais »). Cette situation est très fréquente, et dès le départ, les interactions situent les uns par rapport aux autres, suivant le principe de l'aînesse. De plus, ce positionnement hiérarchique se manifeste par un mode de la mise en scène de soi, visible d'une part pour Sory, par une démonstration d'autorité fondée sur l'expérience, et d'autre part pour le jeune homme, par la valorisation de ses compétences et de son aptitude à se " débrouiller ", légitimées par son expérience de la " souffrance ». C'est le moment où chacun se raconte, se met en scène par des récits de vie épiques, mais aussi par des postures, des échanges, relevant très souvent des relations à plaisanterie bien connues des travaux portant sur l'Afrique de l'Ouest. Ainsi, on raconte mais on joue également son aventure dans l'attente de la migration.

Cette mise en scène de soi, cette quasi-théâtralité dans la rencontre, n'est donc pas seulement un "passer le temps", mais participerait selon moi à l'élaboration des « connexions » recherchées par les migrants. La véracité des histoires importe peu et il serait réducteur de ne les interpréter qu'en terme de "revalorisation de soi » en situation dite «difficile». Ce type de discours permettrait également de (re) donner une temporalité à l'attente quotidienne que vivent ces migrants, puisque par la mise en scène, ils ordonneraient temporellement leur aventure. Les moments d'attente seraient ceux qui permettraient son déploiement, grâce à ces histoires, répétées à chaque 
nouvelle arrivée d'un individu, et qui, en devenant de plus en plus épiques et précises, donneraient la saveur extraordinaire qui manque à l'ordinaire du quotidien des aventuriers. Le paradoxe entre la banalité du quotidien et l'aventure comme horizon des possibles paraît être alors résolu dans l'instant de la mise en scène de soi.

Les moments de "relâchement " permettent ainsi aux aventuriers de réconcilier, en (se) racontant, deux rythmes a priori inverses : celui de l'aventure fondé sur l'instant et l'occasion, et celui du quotidien, marqué par l'attente et parfois l'ennui. La mise en scène de soi cristalliserait ce moment où ils pourraient composer la partition de leur aventure, en rehaussant d'une temporalité épique la banalité des jours et des heures. Mais plus encore, privilégier l'épique semble aussi être un moyen de mettre en avant un certain apprentissage de la "souffrance » et de légitimer publiquement son statut d'aventurier.

Dans l'attente se construit donc un mode particulier de mise en scène de soi, grâce auquel les migrants se situent dans des réseaux collectifs plus larges, créant les connexions nécessaires à la transmigration.

\section{BIBLIOGRAPHIE}

M. Alioua, L'étape marocaine des transmigrants subsahariens en route pour l'Europe : l'épreuve de la construction des réseaux et de leurs territoires, thèse de doctorat soutenue le 29 juin 2011 à

l'université de Toulouse le Mirail, http://tel.archives-ouvertes.fr/tel-00639285/fr/

Bredeloup, Migrations d'aventures. Terrains africains, Paris, CTHS- Géographie, 2014.

V. Jankélévitch, L'aventure, l'ennui et le sérieux, Paris, Aubier-Editions Montaigne, 1963.

A. Piette, L'acte d'exister : une phénoménographie de la présence, Marchienne-au-Pont, Socrate éditions Promarex, 2009.

A. Tarrius, « Territoires circulatoires et étapes urbaines des transmigrant(e)s », Regards croisés sur l'économie, $\mathrm{n}^{\circ} 8,2010 / 2$.

M. Timera, « Aventuriers ou orphelins de la migration internationale », Politique africaine, $\mathrm{n}^{\circ} 115$, $2009 / 3$. 


\title{
Les migrations chinoises au Maroc: les commerçants séjourneurs de Casablanca
}

\author{
Jean-Pierre Taing
}

1 L'apparition de la figure chinoise dans la société marocaine au cours des années 2000 est évocatrice des transformations qui s'opèrent au Maroc. D'après les autorités chinoises, il y aurait quelques 3000 ressortissants chinois dans le pays. Leur présence résulte de deux courants migratoires bien distincts qui entretiennent peu de relations entre eux. Il y a d'un côté des migrations encadrées, principalement composées d'expatriés qui officient dans le cadre diplomatique, dans les projets de coopérations bilatérales et plus majoritairement au sein des grandes sociétés chinoises qui œuvrent au Maroc et dont le développement est intimement corrélé à celui des relations bilatérales sino-marocaines. De l'autre côté, on observe des migrations volontaires qui impliquent de petits entrepreneurs commerçants.

2 S'ils sont minoritaires parmi le contingent chinois, leur visibilité est renforcée par l'apparition d'un «quartier chinois » à Derb Omar, dans le centre-ville de Casablanca, né de la concentration de petits commerces chinois positionnés dans la vente en gros et en semi-gros de marchandises directement importées de Chine. Les médias se sont penchés sur ce phénomène, avec des articles colportant parfois des préjugés et certaines légendes à leur égard qui reflètent un manque de connaissances évident au sujet de cette nouvelle altérité.

3 La médiatisation de ce phénomène au Maroc contraste avec l'absence de travail scientifique notable sur le sujet. Toutefois, la thématique des migrations chinoises contemporaines en Afrique a bien été abordée par les chercheurs, mettant en lumière certaines caractéristiques communes à ces nouvelles tendances. C'est le cas de Park, qui emploie le terme de "séjourneur» pour désigner les nouveaux migrants chinois contemporains rencontrés sur le continent (Yoon Jung Park, 2009). Leur profil se rapproche de celui de "résidents temporaires", qui acquièrent grâce à l'entrepreneuriat une position sociale et des gains économiques importants dans un temps très réduit. Ils présentent la particularité de construire très peu d'attaches dans 
les lieux où ils s'installent, «ce qui leur permet de se " transposer " et de migrer une deuxième, voire une troisième fois" (Yoon Jung Park, 2009, p. 136). Les difficultés rencontrées lors de la migration « ne valent la peine et ne sont surmontables que parce qu'elles sont temporaires » (Yoon Jung Park, 2009, p. 136).

4 En focalisant notre attention sur les migrations chinoises installées à Casablanca, l'objectif de cet article est de fournir des éléments de compréhension sur un courant migratoire spécifique, de par son origine et son profil, et de le comparer aux caractéristiques des migrations entrepreneuriales internationales chinoises contemporaines observées dans d'autres pays africains. Les Chinois du Maroc peuventils être considérés comme des « séjourneurs »?

5 Les résultats présentés dans cet article s'appuient sur une enquête de terrain réalisée à Casablanca du 28 février 2014 au 31 mai 2014, qui a fait l'objet d'un mémoire réalisé sous la direction d'Hubert Mazurek et Saïd Belguidoum (Taing, 2014) au sein du Laboratoire Population- Environnement-Développement (LPED) dans le cadre du Master 2 en Géographie à l'Université de Marseille.

\section{Derb omar, un quartier de commerçants}

6 Le quartier de Derb Omar est situé en plein centre de Casablanca, dans l'arrondissement de Sidi Belyout de la préfecture de Casablanca- Anfa. Si son nom est aujourd'hui souvent associé aux commerçants chinois qui s'y sont installés, il s'agit avant tout de l'une des places marchandes les plus importantes de la métropole et du pays qui doit son identité marchande aux vagues successives de commerçants venus transformer les fonctions de ce quartier (Abdelkader Kaouia, 1996). Les grands commerçants fassis (originaires de la ville de Fès) ont été les premiers à s'y installer au début du XXe siècle, suite à la concentration des activités commerçantes du pays autour de Casablanca. Ils furent par la suite rejoints par les commerçants berbères originaires de la région du Souss au sud du pays. Ces deux grands groupes ont su marquer de leur empreinte les activités commerçantes du quartier. à l'heure actuelle, on trouve à Derb Omar de la soierie, du tissu ou encore du thé, des segments de marché historiquement occupés par les Fassis, tandis que les articles de maison, les jouets, l'habillement ou la vaisselle sont généralement proposés par les Berbères.

7 L'apparition au début des années 2000 des commerçants chinois à Derb Omar peut de ce fait être considérée comme la troisième vague de commerçants dans le quartier. Leur présence nous paraissait néanmoins de prime abord surévaluée par les médias et nos observations sont venues conforter ce pressentiment.

8 Les commerces tenus par les entrepreneurs chinois sont localisés autour de la Place de la Victoire, dans la partie sud-est du quartier. La rue Mohammed Ben Ahmed Lakrik, une ruelle parallèle à la Place de la Victoire, symbolise leur présence dans le quartier. La rue des chinois, comme la désigne la population locale, doit son sur nom à la kissaria (galerie marchande) qu'elle abrite, l'une des deux galeries marchandes du quartier exclusivement occupées par des commerçants chinois. Peu d'efforts ont été consentis pour mettre en valeur la kissaria, comme les box occupés par les commerçants ni même les marchandises proposées. Ces caractéristiques visuelles accentuent inconsciemment l'idée que l'on se fait à propos des marchandises chinoises, à savoir qu'il s'agit d'articles bon marché mais également de piètre qualité. Les produits qui reviennent le plus fréquemment dans les boutiques chinoises sont les foulards, les chaussures enfant et 
femme et les sacs à main. On trouve également des valises, des casquettes, du linge de maison et, ponctuellement, des reproductions de tableaux, des luminaires, des articles de quincaillerie ou encore des drapeaux, des produits tous importés de Chine. La plupart des segments de marché investis par les commerçants chinois n'entrent pas directement en concurrence avec l'offre proposée par les commerçants marocains de Derb Omar.

9 La renommée du "quartier chinois " auprès de la population locale contraste avec l'absence totale d'indications concernant sa localisation. Il nous a d'ailleurs fallu demander notre chemin à plusieurs reprises à des commerçants locaux avant de trouver son emplacement. Sur place, la visibilité des commerces chinois dans le paysage est tout aussi discrète. Seuls quelques rares éléments décoratifs comme des lanternes chinoises accrochées sur la devanture de quelques boutiques suggèrent la présence de commerçants chinois dans les quartiers, mais ils disparaissent aussitôt les rideaux baissés.

10 Sur la base de notre enquête de terrain, nous avons recensé 90 boutiques tenues par des commerçants chinois. Leur présence numérique et leur ancrage territorial sont relatifs à l'échelle de l'aire commerciale de Derb Omar, d'autant plus que soixante d'entre elles sont situées à l'intérieur de l'une des deux kissarias chinoises. Derb Omar fait office d'espace commercial mais aussi résidentiel, avec des lieux de résidence localisés à proximité de la zone commerciale et accessibles à pied. Nos estimations font état d'environ 500 ressortissants chinois installés à Derb Omar. Certains entretiens recueillis évoquent la présence de plus de 1000 Chinois dans le quartier, une estimation qui nous paraît cependant très large compte tenu des observations réalisées sur le terrain.

\section{Historique et profil de l'immigration chinoise à Casablanca}

11 C'est en 2003 que les premiers commerçants chinois se sont installés à Derb Omar. Le courant migratoire n'était alors pas directement originaire de Chine, mais du Sénégal, où ils s'étaient rendus à la fin des années 1990. Poussés à chercher de nouveaux marchés où écouler leurs marchandises en raison de la concurrence accrue entre les commerçants chinois dans cette région, quelques-uns d'entre eux ont alors ciblé Casablanca comme nouvelle étape de leur migration entrepreneuriale. Casablanca présentait en effet à l'époque de sérieux atouts : il s'agissait d'une grande métropole, dans un pays francophone, comme le Sénégal, qui bénéficiait d'un rayonnement à l'échelle régionale et nationale et qui surtout était encore vierge de commerçants chinois.

12 L'installation de ces premiers commerçants chinois à Derb Omar a en quelque sorte permis de défricher le terrain pour les nouveaux migrants entrepreneurs chinois. La concentration de boutiques chinoises et la valorisation d'une galerie marchande à destination des commerçants chinois ont progressivement fait de Casablanca une destination potentielle au sein de la géographie des migrations entrepreneuriales chinoises. Des migrants venus de Chine, mais aussi d'autres pôles de la diaspora chinoise ont été attirés par ces nouvelles opportunités offertes à Casablanca. Cantonnés à une frange du quartier mais aussi à un marché très restreint, la population de 
commerçants chinois a rapidement atteint la saturation, pour stagner autour de l'année 2010.

13 La majorité des Chinois installés à Derb Omar sont originaires de la province du Fujian, un des foyers d'émigration historiques des migrations chinoises à travers le monde. Viennent ensuite les ressortissants de la province du Zhejiang, puis de la province du Hebei. On recense plus ponctuellement des ressortissants originaires d'autres provinces de la Chine comme le Guangdong, le Sichuan ou encore le Hubei. Il s'agit de migrations entrepreneuriales qui suivent une logique familiale et qui constitue le cœur des activités économiques. Les commerces sont gérés en famille ou en couple et génèrent très peu d'emplois pour la communauté chinoise. Cependant, seuls les membres en âge de travailler émigrent. La majorité des Chinois que l'on rencontre dans le quartier ont entre 20 et 50 ans. Souvent il arrive aussi que la gestion des activités fonctionne de manière transnationale, soit pour des raisons économiques, avec un des membres de la famille en Chine qui s'occupe de l'approvisionnement et des exportations de marchandises, soit pour des raisons familiales, avec un parent retourné en Chine pour s'occuper des enfants.

\section{Des profils de séjourneurs}

14 Les migrants chinois interrogés disent largement apprécier la vie au Maroc. Le cadre de vie, le sentiment de sécurité, les relations cordiales avec la société d'accueil, la qualité de l'environnement et des produits alimentaires sont des éléments qui réapparaissent souvent dans les entretiens, si bien que certains n'hésitent pas à avouer être plus dépaysés lorsqu'ils retournent en Chine. Cette douceur de vivre est parfois même perçue de façon négative, à cause de la monotonie et de l'absence de pression au quotidien.

Pourtant, aucune des personnes rencontrées n'envisage son avenir à long terme au Maroc. Si les conditions de vie sont jugées meilleures qu'en Chine et que dans beaucoup d'autres pays d'accueil, leur migration est dès le départ envisagée comme temporaire.

Les marques d'appropriations matérielles et symboliques des commerçants chinois à Casablanca sont rares. L'offre de services ethniques communautaires est marginale et se limite à Deb Omar, avec une épicerie chinoise et un point de vente de produits frais. Les mariages mixtes restent à l'heure actuelle des cas anecdotiques, tandis que le choix de renvoyer au pays les enfants nés au Maroc ou à l'étranger prévaut souvent, bien que nous ayons noté la scolarisation de quelques enfants dans des établissements privés à Casablanca. Enfin, la distance avec le pays d'origine est réduite par le développement des moyens de communication mais aussi par les déplacements physiques entre les deux pays, essentiellement pour des raisons économiques, ce qui rend plus supportable l'épreuve de la migration.

Les interactions entre les migrants chinois et la population locale se cantonnent le plus souvent à la sphère professionnelle et aux transactions commerçantes avec les partenaires économiques marocains, qu'il s'agisse des employés, des clients ou des intermédiaires. En dehors de ce cadre, les interactions s'avèrent extrêmement limitées. La barrière linguistique rend également difficile la communication avec la population locale. Si la majorité des migrants chinois s'attellent à leur arrivée au Maroc à l'apprentissage du français, en premier lieu, et du darija (l'arabe dialectal) de manière secondaire, leur maîtrise des langues se révèle très sommaire et difficilement audible 
en dehors du cercle des collaborateurs proches. Par ailleurs, le choix du français n'est pas du tout adapté aux activités économiques du fait que la clientèle est principalement composée d'arabophones ou de berbérophones. La langue française, acquise au Sénégal par les premiers migrants chinois installés au Maroc, est restée la norme auprès des nouveaux arrivants et souligne l'importance des réseaux relationnels chinois au sein du quartier chinois dans le processus d'intégration des migrants à leur contexte d'accueil.

La recherche entreprise sur l'immigration chinoise au Maroc avait pour ambition d'apporter quelques éléments de compréhension sur un phénomène migratoire largement médiatisé qui se révèle être, au final, très limité aussi bien spatialement que numériquement. C'est à Derb Omar, l'une des plus importante place marchande du pays, que ces petits commerçants se sont installés. Ils s'y sont spécialisés dans la vente en gros et en semi-gros sur quelques segments du marché de produits de consommation courante à destination des classes sociales les moins aisées.

L'émergence des migrations entrepreneuriales chinoises au Maroc résulte dans un premier temps d'une extension des réseaux migratoires en Afrique de l'ouest où l'offre proposée par les chinois était arrivée à saturation, avant d'attirer des petits entrepreneurs venus de Chine mais aussi d'autres pôles de l'immigration chinoise dans le monde. Ces migrations entrepreneuriales centrées autour de la famille et du réseau relationnel proche possèdent au final peu d'attaches avec les lieux investis et rappellent les profils de séjourneurs qui caractérisent les migrations chinoises contemporaines en Afrique.

Bien que nous manquions encore de recul pour caractériser le profil de ce phénomène migratoire, les caractéristiques de l'immigration chinoise observée à Casablanca semble correspondre au profil des séjourneurs décrit par Park pour caractériser les migrations chinoises contemporaines en Afrique. Pourtant, si à l'échelle individuelle, la présence des commerçants chinois peut être considérée comme temporaire, Casablanca n'en reste pas moins une destination potentielle pour de nouveaux séjourneurs chinois, avec une circulation migratoire des commerçants au sein du quartier chinois de Derb Omar.

\section{BIBLIOGRAPHIE}

A. Kaioua, Casablanca, l'industrie et la ville, tomes I et II, Tours, Urbama, 1996, fascicule de recherches $n^{\circ} 30$.

H. Ostbo Haugen et J. Carling, « On the edge of the Chinese diaspora: The surge of baihuo business in an African city ", Ethnic and Racial Studies, vol. 28 - 4, 2005, p. 639-662.

Y. J. Park, « Les Chinois résidant temporairement en Afrique. Les séjourneurs », Hommes et migrations (en ligne), n 1279, 2009, consulté le 29 mai 2013, http://

hommesmigrations.revues.org/340

L. Roulleau-Berger et Lu Shi, « Routes migratoires et circulations en Chine : entre mobilités intracontinentales et transnationalisme ", Revue européenne des migrations internationales, vol. 20, $\mathrm{n}^{\circ} 3,2004$, p. 7-27. 
J.-P. Taing, Dynamiques des migrations chinoises au Maghreb. Comparaison des migrations chinoises à Alger et à Casablanca, mémoire de géographie sous la direction d'Hubert Mazureket Saïd Belguidoum, Université d'Aix-Marseille, 2014. 


\title{
Le personnel des ONG
} internationales au Maroc : l'expérience cosmopolite à l'épreuve?

\author{
Chadia Boudarssa
}

1 Le Maroc est souvent présenté comme un pays d'émigration et rarement comme une terre d'accueil pour des migrants. C'est pourtant aussi un pays d'immigration pour des étrangers venus d'Europe, d'Afrique subsaharienne ou du Maghreb. Selon le recensement de la population de 2014 (Haut-Commissariat au Plan), le Maroc compte environ 86206 étrangers vivant sur son territoire, soit $0,25 \%$ de la population marocaine.

2 Au cours de ma recherche de thèse, je me suis attachée à analyser une catégorie particulière d'étrangers au Maroc: le personnel des Organisations Non Gouvernementales (ONG) de solidarité internationale, italienne, française, espagnole et canadienne, installées et intervenant au Maroc. Lors de mon enquête de terrain entre 2008 et 2012 (Rabat et Tanger), j'ai réalisé des entretiens semi-directifs avec cinquantecinq acteurs humanitaires étrangers (de neuf nationalités différentes) et treize marocains, âgés entre seize et cinquante-neuf ans. Mon objectif était d'analyser les catégories du personnel des ONG internationales (volontaire de solidarité internationale et du service civique européen, salarié, stagiaire et bénévole) ainsi que les pratiques d'engagement et de travail.

Tout d'abord, ces acteurs de solidarité internationale se définissent comme " cosmopolites", ce qui renvoie à une appétence forte à la fois pour la mobilité internationale et la connaissance de l'autre. Afin de sonder la réalisation de cette "rencontre cosmopolite", je me suis donc intéressée à leurs modes de vie et à leurs relations avec le pays d'accueil. Seront ici questionnés, le choix du Maroc comme pays d'expatriation et les conditions de séjour rencontrées par ces expatriés, afin d'analyser leurs attentes et "expériences réelles" dans les relations entretenues avec les 
Marocains. Il est à préciser que le personnel marocain s'exprime peu sur ses relations avec les expatriés.

\section{Le Maroc : une destination pas toujours choisie mais de fortes attentes de rencontres}

Dans les ONG agissant à l'international, l'engagement des individus s'oriente vers « l'autre lointain » (Stangherlin, 2005, p. 9). Ces acteurs sont amenés à s'expatrier à plus ou moins long terme sans pour autant se considérer comme des migrants, ce que vient contredire leur situation objective. Ils se désignent comme des "volontaires", «humanitaires » ou « expats» et tentent de se différencier à la fois des travailleurs migrants et des expatriés des entreprises étrangères et des coopérations internationales, se positionnant ainsi régulièrement dans une posture «intermédiaire». Pendant leur séjour, ils souhaitent et tentent de vivre des expériences cosmopolites avec la population autochtone.

Les résultats de l'enquête menée montrent que près de la moitié des personnes interrogées (vingt-sept) disent ne pas avoir choisi le Maroc. Vingt ont accepté la mission par défaut au moment de leur recherche d'emploi ; certains déclarant préférer l'Afrique Subsaharienne ou l'Amérique Latine comme destination. D'autre part, sept personnes ont suivi leurs conjoints mutés au Maroc et neuf un conjoint(e) de nationalité marocaine, sénégalaise ou française, déjà installé(e) dans le pays. Vingt-huit d'entre eux ont choisi le Maroc, connu pour certains lors de voyages ou dans le cadre de stages antérieurs. Enfin, certains expatriés ont choisi cette destination pour sa proximité géographique permettant de s'éloigner le moins possible du conjoint resté en France tout en ayant une carrière internationale.

D'après mon enquête, ces expatriés ont de fortes attentes quant à la qualité de la relation cosmopolite avec les Marocains. Les discours recueillis renvoient à un imaginaire associé au Maroc, entre exotisme et mysticisme, et une projection dans des relations amicales, chaleureuses et hospitalières. Les descriptions qu'ils font du « Maroc authentique " sont nourries, d'une part, des représentations liées au cinéma, à la télévision et à la littérature et, d'autre part, par des expériences personnelles de voyages et de rencontres. Dans les entretiens, les couleurs (ocre et bleu), les paysages (désert, mer), le soleil, l'Afrique - voire l'Orient pour certains -, sont des items utilisés de manière récurrente pour décrire le Maroc. Certaines descriptions évoquent des souvenirs personnels liés à « l'expérience du Sud »(Stangherlin, 2005, p. 8) vécue grâce à des voyages familiaux, des relations amicales et amoureuses avec des Français d'origine marocaine.

7 Pour ce qui est de l'autorisation de séjour, le personnel étranger des ONG ne rapporte aucune difficulté à son obtention, et est généralement accompagné dans ces démarches par les ONG ou structures d'accueil ou d'envoi. En ce qui concerne la durée de séjour au Maroc, deux profils se détachent : les nouveaux arrivants (moins d'un an pour $38 \%$ de ces expatriés) et les anciens (une durée de séjour supérieure à trois ans pour $20 \%$ d'entre eux). Bien que les employés des ONG soient recrutés majoritairement en contrat à durée déterminée, certains réussissent à cumuler des contrats et pour $11 \%$ d'entre eux, cela fait plus de sept ans qu'ils vivent au Maroc, pour des motifs professionnels et/ ou personnels. 
Les volontaires, qui ne sont juridiquement pas salariés, reçoivent des indemnités qui varient de $70 €$ (service civique européen) à environ $500 €$ (volontariat de solidarité internationale). Les autres, par contre, perçoivent des salaires qui vont de 250 à $3000 €$ selon l'ONG et le type de contrat. De plus, certaines ONG participent au loyer, aux frais d'installation et de transport. Alors que l'indemnité de la majorité des volontaires est supérieure au salaire minimum en vigueur dans le pays, son niveau est considéré par les concernés comme bas, tout en reconnaissant une qualité de vie meilleure au Maroc qu'en Europe.

9 Même si le choix du Maroc n'est pas systématique et que la durée de séjour est déterminée, les attentes exprimées sont fortes en termes de rencontres cosmopolites. Celles-ci sont liées à l'injonction de réussir leur rencontre de l'« Autre », conformément au discours normatif des ONG internationales, et en se différenciant ainsi en pratique des autres expatriés.

\section{Le Maroc : entre un mode de vie communautaire et « un autre chez soi »}

10 Le type de logement, les pratiques alimentaires, les loisirs, les amitiés, etc., nous informent sur les modes de vie des employés des ONG étrangères au Maroc et des relations qu'ils entretiennent avec les autochtones. Les expatriés se répartissent à Rabat (selon la classification faite par Edogue Ntang et Peraldi, 2011, p.1), entre Oudayas, Océan, Salé (dans des quartiers populaires) et Agdal, Hassan ou Centre-ville (quartiers en majorité des classes moyennes). Certains de nos enquêtés choisissent leur quartier dans le souci de "vivre parmi les Marocains", excluant ceux considérés comme fréquentés par les expatriés. Pourtant, la plupart d'entre eux vit en colocation, généralement avec des personnes de la même nationalité et dans des logements qu'ils se transmettent. Ils recréent alors de fait une enclave d'étrangers, à l'intérieur d'un bâtiment situé dans un quartier marocain, ce qui ne correspond pas au désir d'intégration exprimé.

11 L'observation des pratiques alimentaires renseigne aussi sur cette dualité. Les personnes interrogées affirment consommer tant des aliments appartenant au régime marocain (dans les restaurants, par le biais de l'employée de maison, etc.) que des produits en provenance de leur pays d'origine. Une jeune volontaire raconte: «Je me réveille et je regarde les Maternelles, une émission sur France 5 en prenant mon petit déjeuner français : tartines à la boulangerie pâtisserie française, des céréales. On a essayé le régime marocain mais on est tombé malade ».

Pensant que le sport pourrait être un moyen de rencontres, beaucoup des enquêtés mènent une activité sportive dans l'association du quartier d'habitation, dans l'espoir de favoriser des contacts avec les voisins. Le soir, après le travail, des sorties au café et au restaurant sont organisées entre volontaires, salariés expatriés, mais rarement avec le personnel local. Ce constat de vivre en communauté fait dire à une volontaire française : "on a foiré notre intégration ». Pour pallier à cela, certaines associations organisent régulièrement des repas, invitant alors parfois le personnel étranger et local autour d'un déjeuner.

L'enquête de terrain et l'analyse des modes de vie montrent que le personnel étranger des ONG mène en grande partie une vie en communauté, malgré les tentatives d'aller à 
la rencontre des Marocains. Ils ont ainsi quasiment tous suivi des cours d'arabe marocain, offerts par l'association d'envoi ou d'accueil. Cette compétence semble être considérée comme un signe distinctif par rapport aux autres expatriés réputés «non cosmopolites ", comme les employés des agences onusiennes et des entreprises. Ces derniers, percevraient des rémunérations jugées indécentes, se sentiraient moins concernés par le pays et ses habitants et mèneraient un train de vie "occidental». Cette représentation s'oppose aux visions d'engagement, de terrain et de proximité cosmopolite véhiculées par les ONG de solidarité internationales et que leurs employés semblent vouloir incarner.

14 Comme l'explique une salariée française : «cette légitimité me concernant passe par le fait que je parle arabe, que j'ai 10 ans d'expérience au Maroc et que je sais de quoi je parle quand je parle du Maroc, le fait que j'ai côtoyé de près et vécu de près avec certains de mes groupes cibles». Pourtant, les personnes avec qui les employés étrangers des ONG pratiquent le marocain sont surtout leur employée de maison, les chauffeurs de taxi, les serveurs, les primeurs et parfois les conjoints. Ce sont parfois les seuls Marocains avec qui ils entretiennent des relations non professionnelles et avec lesquels ils peuvent échanger. C'est ainsi qu'une volontaire française et une salariée espagnole insistent sur leur intérêt pour l'expérience cosmopolite : «L'international est en toi, j'ai une vocation à voyager et pour les rencontres interculturelles. Pourquoi l'expatriation? J'aime voyager, connaître des pays nouveaux, des gens ».

15 Les employés étrangers des ONG sont donc souvent déçus par le peu de relations qu'ils ont avec les locaux et regrettent notamment de n'avoir que peu d'amis marocains. Une volontaire française constate qu' " au bout de 2 ans je n'ai pas d'amitié marocaine ». Ses amis sont généralement de sexe masculin: des militants associatifs, des artistes, des journalistes et des fonctionnaires fréquentant les mêmes lieux de loisirs ou de travail. Pour les enquêtés, cet échec à avoir des amies marocaines s'explique par des modes de vie différents et un manque de liberté chez les Marocaines.

16 Toutefois, certains réussissent à développer des relations plus soutenues, notamment avec des collègues, des militants ou au travers de rencontres amoureuses. Des couples se forment donc, et sur les dix-neuf couples mixtes recensés, sept comptent un conjoint marocain rencontré sur place. Certains expatriés considèrent le Maroc comme un " autre chez soi », revendiquant ainsi une intégration réussie. Dans le cadre de notre enquête, il s'agit surtout de personnes d'origine sicilienne, andalouse ou encore kabyle qui perçoivent des proximités entre leur région d'origine et le Maroc. Une salariée italienne explique : « Le Maroc c'est trop similaire à l'Italie. Il n'y a rien d'exotique pour moi au Maroc. Moi je ressemble aux Marocaines. Quand je marche dans la rue, les gens me parlent en darija marocain. C'est plus distant entre Paris et le Sud de l'Italie que le Sud de l'Italie et le Maroc. Je trouve de l'exotisme à Londres mais pas au Maroc ». Pour d'autres, cette relation particulière au Maroc découle de relations personnelles avec des personnes d'origine marocaine ou algérienne.

\section{Le Maroc : des rapports différenciés en fonction du genre, de la nationalité et du lieu de rencontre}

17 Le rapport au Maroc change selon le sexe, la nationalité et le lieu de rencontre. Certains types d'interaction évoqués dans les entretiens (le harcèlement, les pratiques racistes 
et les visites du pays ou mission de terrain) vont me permettre de mettre en avant certaines de ces différences.

Le harcèlement se traduit par des interpellations diverses, des sifflements ou des injures. Il est plus ou moins mal vécu et les employées étrangères des ONG, qui en sont régulièrement victimes, oscillent entre agacement et colère. Les réactions peuvent également évoluer dans la durée du séjour, comme le rapporte une volontaire française : «Au bout de deux ans, je me sens capable de mettre une jupe et un collant opaque ». Certaines adoptent des tactiques d'évitement: "baisser la tête", «les écouteurs dans les oreilles » et «ne pas marcher dans la rue». Et, si elles doivent marcher dans la rue, elles adaptent alors leur manière de se vêtir : " pas de vêtements courts, porter des manches longues» et certaines de leurs habitudes "ne pas fumer dans la rue toute seule... ». Le malaise est tel que la rue est considérée, par certaines femmes, comme inaccessible et devient alors un lieu à éviter. Une volontaire italienne révèle que "mon rêve est de marcher dans la rue", tandis qu'une salariée belge raconte qu'elle "marche dans la rue la nuit quand il n'y a personne " à Tanger. Les enquêtés ont rapporté des cas de harcèlement et des tentatives insistantes de séduction de la part d'hommes mais aussi de femmes et ce notamment dans les bars. Un couple français expose deux perceptions différentes de leur séjour au Maroc. Pour le conjoint, "les gens sont accueillants, chaleureux, lien qu'il n'y a pas en France. C'est mon ressenti et je me sens très bien. ». Mais pour la conjointe : "J'ai pas mal souffert d'être une femme. Je me suis fait suivre, siffler, j'ai tout le temps des incidents». La perception du harcèlement semble donc bien moindre pour les hommes expatriés et traduit des rapports sociaux de genre différenciés sous-jacents à ces interactions.

Des pratiques de discrimination raciale ont également été rapportées. Elles visaient des acteurs humanitaires d'origine subsaharienne et des couples mixtes françaissénégalais, notamment dans la recherche de logement. Un volontaire sénégalais témoigne : «À Rabat, les locations d'appartement ne sont pas nombreuses car les noirs ont mauvaise réputation ». Soulignons qu'il y a très peu de volontaires subsahariens au Maroc.

Malgré ces difficultés de la vie quotidienne, tous sont enchantés par les visites du pays et par les missions sur le terrain dans les villages et en dehors des grandes villes. Selon les enquêtés, les Marocains y sont beaucoup plus accessibles, ouverts à la rencontre, font preuve d'hospitalité et sont disponibles pour faire découvrir leur pays, échanger en arabe dialectal, conformément aux représentations que les expatriés se font du «Maroc authentique ». Les habitants de Rabat, par contre, sont décrits comme peu réceptifs à l'échange et plutôt indifférents à la rencontre que tente d'établir l'étranger.

Les employés étrangers des ONG semblent osciller entre déception, qui les oriente vers un mode de vie communautaire, et satisfaction quant à leurs relations avec les Marocains, quand ils évoquent leur intégration réussie ou le sentiment d'« un autre chez soi ». Ils développent des stratégies d'intégration à la société d'accueil et de rencontres vers "l'autre lointain", tentant d'abolir les distances sociales (Wagner, 2007, p. 88) dans l'objectif de ne pas être considéré comme étranger et de partager une commune humanité au-delà du statut d'immigré. Pourtant beaucoup d'incompréhensions et d'attentes déçues ponctuent ces séjours et suscitent de la frustration à l'encontre des Marocains, comme le regrette une volontaire française : "Je sais qu'ils me traitent en tant qu'étrangère, à part ». Alors qu'une salariée italienne s'interroge : «Ici je me considère comme étrangère. Je ne sais pas si c'est le Maroc. En 
Espagne, je ne me sentais pas comme ça (...). Je n'en pouvais plus. Les gens te traitent non pas seulement comme femme mais comme étrangère ».

Situés entre deux temps sociaux (Cicchelli, 2012, p. 106) à la fois touristes (quand ils sont en mission sur le terrain) et immigrés (dans leur ville de résidence), les expatriés travaillant pour les ONG internationales souhaitent réussir leur mission dans l'objectif principal d'être au plus près des bénéficiaires et des habitants, conformément à l'injonction prégnante dans le milieu de la solidarité internationale. Les interactions avec les Marocains les renvoient à de la réserve ou à de l'indifférence et ne leur permettent pas toujours de parvenir à la rencontre cosmopolite imaginée et attendue. Cette distance renvoie les expatriés à leur étrangéité, malgré leurs tentatives de s'y soustraire.

\section{BIBLIOGRAPHIE}

V. Cicchelli, L'esprit cosmopolite. Voyages de formation juvéniles et cultures européennes, Paris, Presses de Sciences Po, coll. Académique, 2012.

J.-L. Edogue Ntang, M. Péraldi, « Un ancrage discret. L'établissement des migrations subsahariennes dans la capitale marocaine ", dans D'une Afrique à l'autre : migrations subsahariennes au Maroc, Paris, Karthala, 2011.

Recensement Général de la Population et de l'Habitat 2014, « Note sur les premiers résultats du Recensement Général de la Population et de l'Habitat 2014 », http://rgph-2014.hcp.ma/Note-surles-premiers-resultats-du-Recensement-General-de-la-Population-et-de-l-

Habitat-2014_a369.html

G. Stangherlin, Les Acteurs des ONG. L'engagement pour l'autre lointain, L'Harmattan, coll. Logiques Politiques, 2005.

A.-C. Wagner, Les classes sociales dans la mondialisation, Paris, La Découverte, coll. Repères, 2007. 
Mobilités religieuses au Maroc: religion en migration et tourisme spirituel 


\title{
Les églises de maison congolaises de Rabat : la participation du secteur informel à la pluralisation religieuse au Maroc
}

\author{
Bernard Coyault
}

1 L'intensification des flux migratoires entre les pays d'Afrique subsaharienne et le Maroc relève de causes multiples. Ces flux ne sont pas seulement dus aux crises politiques, économiques ou sociales que traversent certains pays du continent. Ils sont aussi la conséquence de la politique africaine du Maroc qui, au gré des accords bilatéraux de coopération, amène dans le Royaume de nouvelles catégories de résidents : étudiants, stagiaires, malades en soins, militaires, hommes d'affaires. À cette diversification des populations migrantes, correspondent de nouveaux comportements vis-à-vis du pays d'accueil : d'une part, une tendance à la sédentarisation, d'autre part, une augmentation de la circulation des personnes, souvent pendulaire, entre leur pays d'origine et le Maroc. Ces phénomènes sont liés tout à la fois aux opportunités de régularisation, de travail ou d'étude rencontrées sur place, mais également aux facilités de déplacement accordées aux ressortissants de certains pays.

2 "Loin d'être uniquement un lieu de transit, le Maroc est un espace migratoire où s'organisent la rencontre et la confrontation d'anciennes et de nouvelles migrations. Il articule différentes strates, révèle des clivages entre vagues, groupes et nationalités. Il présente de manière combinée et non simplement opposée mobilités et ancrages, passages et installations. » (Timera, 2009, p. 177).

Cette reconfiguration de l'espace migratoire marocain a des conséquences importantes sur le plan religieux. Dans le champ du christianisme, elle a entraîné tout à la fois la revitalisation des églises officielles reconnues par les autorités du Maroc (Coyault, 2014), et l'émergence d'un secteur religieux chrétien informel. Le phénomène s'observe en particulier à Rabat et à Casablanca. Une enquête de terrain (deuxième semestre 2013) dans les quartiers périphériques de Rabat où résident la plupart des migrants, m'a permis d'identifier un réseau bien structuré d'une trentaine d'églises de maison, 
francophones (25) ou anglophones (5), dont la genèse remonte à 2003. Ces églises, pour la grande majorité d'initiative congolaise (surtout de la RDC), regroupent chacune de 20 à 100 participants, voire 150 pour les églises nigérianes. Elles sont souvent aménagées dans des sous-sols ou à l'étage supérieur de petits immeubles, dans des espaces exigus, équipés de chaises en plastique, d'un pupitre pour prêcher et de ventilateurs. Sans statut légal, mais tolérées par le voisinage pourvu qu'elles adoptent une pratique discrète, elles sont dirigées par des "pasteurs migrants » qui, lorsqu'ils se préparent à voyager, transmettent leur charge à un successeur désigné. En dépit de la précarité des personnes et des lieux, du turn-over important des leaders, ces communautés perdurent dans le temps, maintenant leur identité spécifique (nom, localisation, style de prière) par tuilage entre anciens et nouveaux membres, et formant ainsi un réseau religieux structuré. Le travail d'enquête réalisé en parallèle au sein de l'Église protestante officielle - l'Église évangélique au Maroc (EEAM)- montre que le champ religieux chrétien connaît une partition nette des publics sur la base du profil sociologique : ceux disposant d'un statut légal au Maroc (étudiants, stagiaires, salariés, etc.) se retrouvent très majoritairement dans les églises officielles (y compris catholique) tandis que ceux en situation irrégulière fréquentent surtout le secteur informel. Pour l'ensemble de l'EEAM, les migrants irréguliers ne représentent que $15 \%$ en moyenne de l'assistance du dimanche, avec un maximum de $24 \%$ pour la paroisse de Rabat (questionnaire du 13/10/2013).

4 Après avoir reconstitué la genèse de ces groupes de maison, je présenterai les dynamiques majeures qui sous-tendent la structuration et l'élargissement de ce secteur religieux informel, entre mobilité et ancrage. L'activité religieuse qui s'y déploie est orientée sur le projet de migration vers l'Europe des membres et des leaders, mais ces églises constituent aussi une forme d'insertion locale organisant la circulation d'acteurs et de ressources particulières, offrant même l'opportunité de carrières religieuses. Cette territorialisation progressive dans un environnement musulman où la liberté religieuse est strictement contrôlée, impose un équilibre complexe entre visibilité et invisibilité. Les modalités d'existence et de transmission du message chrétien s'en trouvent aussi affectées par rapport à la situation classique de pluralisme et de compétition religieuse ouverte qui prévaut dans le pays d'origine.

\section{Genèse des communautés de maisons congolaises de Rabat}

5 La pratique religieuse chrétienne se répartit, spécifiquement sur le terrain étudié à Rabat, entre : $1^{\circ}$ Églises officielles - Église catholique et EEAM ; $2^{\circ}$ Églises semi-officielles: une Église internationale anglophone et une Église pentecôtiste-charismatique, l' Assemblée chrétienne - AC (issue d'une scission avec l'EEAM en 2005) ; $3^{\circ}$ Églises de maison (tableau récapitulatif in Coyault, 2014). Pour le domaine francophone, ces églises, presque toutes congolaises, dans l'encadrement et pour la majorité des membres (19 églises sur 25), avec aussi 2 églises ivoiriennes et 1 camerounaise, totalisent au minimum 1200 personnes, soit le double de la population des églises protestantes instituées (EEAM et AC) qui comptent 300 personnes environ chacune. Ces églises de maison, localisées dans les quartiers où résident les migrants, balisent un deuxième espace religieux en marge des grandes églises. Cet espace constitue une sorte de réplique marocaine du champ religieux congolais dans sa diversité, hormis les églises 
traditionnelles d'institution missionnaires (catholiques et protestantes). Y sont représentés les christianismes dits d'initiative africaine: les groupes pentecôtistes/ charismatiques de la deuxième génération appelés aussi «Églises de Réveil », d'une part (pour les 3/4), et d'autre part, les églises prophétiques (endogènes), pour le $1 / 4$ restant, intégrant des éléments culturels traditionnels et considérées par les premières comme syncrétistes et déviantes sur le plan doctrinal.

D'après les divers interviews menés, la première église de maison, aujourd'hui disparue était Le Temple de Rabat, créée en 2003 au quartier J5, comme une première tentative d'autonomisation des migrants congolais par rapport à l'EEAM, jugée trop européenne et «non réveillée ». Trois autres églises ont suivi en 2005, dans 3 quartiers différents : Péniel (aujourd'hui disparue) à $\mathrm{J} 5, \mathrm{La}$ Manne cachée à Hay El Fath et La Grâce à Sidi Moussa. Le paysage s'est ensuite progressivement enrichi par des scissions internes et la diversification de l'offre, avec l'apport d'aventuriers religieux important au Maroc telle ou telle innovation du pays. Près de la moitié de ces églises de maison ont été créées avant 2008 et leurs effectifs se sont maintenus, voire accrus dans le temps, en dépit de quelques fermetures temporaires en 2010, du fait d'une intensification des contrôles par les autorités marocaines. Pour illustrer ces processus, voici quelques exemples d'églises anciennes ou récentes.

7 Ex.1 L'Église La Manne cachée, fondée en 2005 dans le quartier Hay El Fath, s'est déplacée à Bouitat en 2009. Elle compte 100 membres. Le nom même de l'Église, d'inspiration biblique (Apoc. 2.17) évoque la dialectique visible/invisible spécifique au contexte marocain. Quatre "pasteurs" s'y sont succédés. Le fondateur est parti en France et entretient toujours des liens avec la communauté. Le pasteur actuel a tenté de « voyager » à plusieurs reprises.

8 Ex.2 Le Ministère chrétien du combat spirituel (Maman Olangi). Le premier noyau a été créé en 2011 par une femme, arrivée de Mauritanie et repartie depuis. Ce mouvement religieux, fondé en 1991 en RDC et répandu mondialement (200 implantations sur quatre continents), est basé sur le « ministère de délivrance ». En 2012, la fondatrice du mouvement avait d'abord refusé de transformer cette cellule en Église, après avoir envoyé pour enquête des « missionnaires » du groupe de Casablanca. La reconnaissance a finalement eu lieu le 9/8/2014. Cette Église en croissance (40 participants actuellement) loue une grande maison précédemment utilisée par une Église nigériane.

Ex.3 L'Église prophétique EJCEV Bima, implantée depuis 2012 dans un appartement du quartier de Kama Saba, compte déjà plus de 100 membres (visitée le 27/10/2013). Son pasteur-missionnaire, le "docteur » É. S. dit avoir été envoyé par l'Église-mère de Kinshasa, après avoir accompli le même travail d'implantation dans quatre autres pays (Tchad, Togo, Cameroun, Nigéria). L'Église se développe rapidement autour d'une équipe dirigeante élargie (docteurs, prédicateurs, chantres, prophètes) avec une pratique cultuelle/rituelle exigeante (réunions journalières, jeûnes, etc.) et des séances de prophétie individualisées qui attirent un public extérieur. L'Église de Rabat a été officialisée par l'Église-mère.

Ex.4 L'Église El Shaddaï, la plus récente, fondée en 2013, dans le quartier J3. Née d'une scission avec l'Église Midi Miracle (fondée en 2006), et rassemblant environ 60 personnes, l'Église est animée par le jeune "prophète Osée " (25 ans). Renommé pour " passer beaucoup de temps dans la prière ", le leader attire du public par ses charismes de guérison et de prophétie. Initiative isolée d'un acteur religieux indépendant, l'Église est caractérisée par un habitus religieux hybride, avec la double influence des 
pentecôtismes exogènes et des prophétismes endogènes. Durant l'été 2014, le prophète a échoué lui aussi dans sa tentative de passage en Espagne. Depuis son retour, il a organisé un "séminaire" (conférences, prières) invitant des membres des autres églises. Il a également effectué un aller-retour en RDC, cherchant à établir un lien avec des réseaux religieux du pays.

\section{Entre carrières individuelles et logiques institutionnelles : dynamiques circulatoires}

11 À partir de ces quatre illustrations, on notera en premier lieu que l'implantation de ces églises relève de deux logiques conjointes, celle des individualités et celle des institutions.

12 Les acteurs concernés sont des entrepreneurs/aventuriers du religieux, hommes ou femmes, parvenus au Maroc après un itinéraire parfois complexe (Mauritanie, Libye, Nigéria, etc.). En créant une Église ou en prenant la direction vacante d'une communauté déjà existante, ils confirment une vocation religieuse - initiale ou acquise en cours de route - qui donne sens à leur parcours migratoire. Dans cette perspective, le champ religieux informel constitué à Rabat depuis dix ans, représente une pépinière et un tremplin pour ces nouvelles carrières religieuses. Les "places qui se libèrent " lorsque les pasteurs, prophètes, évangélistes, etc., en place voyagent, rendent ce champ très attractif. L'analyse bourdieusienne du champ comme espace concurrentiel où les différents acteurs, anciens (les tenants) et nouveaux-venus (les entrants) luttent pour la maitrise de l'habitus et la définition légitime du religieux est ici infléchie dans un sens collaboratif. Les tenants - les pasteur-migrants des premières vagues, sont aussi des sortants qui doivent nécessairement s'allier à de nouveaux acteurs entrants. Ces derniers assureront la succession, garantissant ainsi la pérennité de chaque Église, et, par ricochet, l'aura des pasteurs fondateurs qui poursuivent ailleurs leur carrière, en Afrique ou en Europe.

13 Même si la dimension concurrentielle, voire conflictuelle (scissions), participe aussi de la constitution de ce champ, la logique collaborative domine. Elle se manifeste notamment par les invitations que s'adressent entre eux les responsables d'églises pour assurer enseignements, séminaires de prière ou de louange, etc. Ces micro-événements évitent l'entre-soi et l'asphyxie de petites communautés qui n'ont quasiment aucune relation avec l'environnement extérieur. L'entente est aussi favorisée par un fort sentiment national partagé, comme l'atteste la création début 2014, de l'Union des Serviteurs de Dieu congolais au Maroc (USDCM).

14 Le but est de «travailler ensemble dans l'épanouissement et le développement de l'œuvre de Dieu au Maroc (...) développer les liens de fraternité entre les SD (...) promouvoir et défendre les droits et le respect des SD congolais en cas de litige avec l'ambassade de la RDC ou avec la colonie congolaise au Maroc (...)» (préambule et article 5).

Ce réseau d'églises de maison s'organise ainsi autour d'un cartel de pasteurs qui gèrent, plutôt à leur avantage, les attentes religieuses d'un public « captif ».

16 À côté de l'agencéité des acteurs religieux, l'émergence de ces communautés s'éclaire aussi par des logiques institutionnelles. Les églises du pays d'origine (Congo Brazza, RDC) voient dans l'établissement d'une antenne marocaine, ou la récupération a 
posteriori d'un groupe existant au Maroc, l'occasion de satisfaire leur stratégie d'expansion continentale ou même extracontinentale (vers l'Europe). Le Maroc recèle une charge symbolique forte, de par sa situation de passerelle entre deux mondes, mais aussi par l'imaginaire qu'il convoque, entre prospérité économique et défi missionnaire à relever (le monde musulman).

Qu'il s'agisse des logiques individuelles ou institutionnelles, la spécificité de ce réseau religieux congolais au Maroc tient donc aussi à sa dimension transnationale. Il participe d'un territoire circulatoire au sein duquel, dans cet entre-deux marocain, des liens se tissent et des échanges s'organisent tant vers l'Europe que vers l'Afrique. Les pasteurs "passés en Europe » gardent des liens avec «leur» Église du Maroc. Vue du côté européen, celle-ci prend alors le statut d'« œuvre missionnaire » : certains envoient de l'argent, reviennent au Maroc pour y assurer un séminaire, etc., ce qui contribue en retour au prestige et à l'attractivité de la communauté bénéficiaire. D'autres échanges s'organisent aussi entre Afriques méditerranéenne et subsaharienne. Les opportunités, tant missionnaires qu'économiques, que représente ce champ religieux marocain intéressent quelques grandes organisations religieuses telles que la grande Église pentecôtiste La Borne de Kinshasa qui multiplie des contacts pour tenter de s'implanter.

\section{Adéquation de l'offre religieuse aux besoins des personnes migrantes}

18 Le discours et la pratique rituelle de ces communautés sont ajustés aux besoins et attentes de leur public, préoccupé par la survie au jour le jour (nourriture, abri, santé, sécurité) et focalisé sur le passage en Europe. Les thèmes des prédications et enseignements dispensés sont aussi directement liés avec ce quotidien (ce qui n'est pas le cas au sein de l'EEAM), y compris dans la gestion pratique et «théologique » de l'échec.

19 La mobilité des fidèles d'un groupe à l'autre est parfois une réponse aux tentatives de captation des leaders, en particulier lorsque les demandes de contributions financières se font trop pressantes. Elle est aussi liée aux divers charismes et dispositifs prophétiques/ divinatoires déployés dans chacune de ces églises qui constituent un important facteur d'attraction. Qu'il s'agisse de prophéties individuelles (Église Bima), de "paroles de connaissance", d'explications sur les causalités (sorcellaires) des malheurs et les rituels de délivrance qui y sont associés, on vient chercher dans ces groupes une orientation concrète pour le parcours migratoire.

20 Enfin, un autre facteur déterminant dans la fidélisation des membres tient aussi à la présence, dans la quasi-totalité de ces églises, d'une personne ressource, appelée connexion, qui établit le lien avec les réseaux des passeurs, ouest-africains ou marocains. Dans ces espaces religieux informels s'échangent non seulement les biens de salut, mais également informations et conseils sur la poursuite de la route - les savoir-faire de la circulation.

\section{Les Congolais, « peuple missionnaire »}

La vitalité de ce réseau informel d'églises congolaises est directement liée au dynamisme de la colonie congolaise (expression employée par les intéressés) au Maroc. 
Les relations politiques et économiques entre les deux pays remontent à l'indépendance de l'ex-Zaïre, lequel est aussi l'un des premiers pays à avoir bénéficié des accords de coopération universitaire (Goldschmidt, 2004). Le nombre de ressortissants de la RDC, réguliers ou irréguliers, résidant au Maroc se situe probablement entre 6000 et 10000 personnes. La diaspora congolaise est donc un élément clé de la diffusion et de la "mise en réseau » du christianisme en Afrique et dans le monde. Jean M., ex pasteur migrant et fondateur de l'église Péniel en 2005, précise: "Nous, les Congolais, sommes un peuple missionnaire: partout où nous passons, nous créons des églises!». Jean $M$. travaille aujourd'hui comme agent de proximité pour le Comité d'entraide de l'EEAM, église dont il est devenu membre. Il reste néanmoins l'un des acteurs majeurs de ce réseau religieux congolais au Maroc. Initiateur de l'USDCM (supra), il est aussi l'un des organisateurs de la journée de prière en faveur de la RDC organisée chaque année à l'occasion de la fête nationale (30 juin). Cette cérémonie se déroule dans le temple de l'EEAM à Rabat (signe du rôle régulateur de l'Église officielle dans la structuration du champ religieux chrétien au Maroc) et rassemble des représentants des diverses communautés de maison. En 2014, au moment le plus intense de la cérémonie, une dizaine de pasteurs s'étaient regroupés pour la prière autour d'un drapeau géant aux couleurs du Congo, intercédant à haute voix, dans un état quasi-extatique. À noter que cette même année, une partie des pasteurs boycottait l'événement, organisant une contre cérémonie à l'Église mission chrétienne mondiale de Hay Nahda (fondée en 2006). L'anecdote révèle bien la velléité d'autonomisation du réseau informel congolais vis-à-vis de l'EEAM.

\section{Le contexte de l'islam}

Le discours et la pratique internes des communautés congolaises véhiculent de forts préjugés concernant la culture et la religion du pays d'accueil. Dans le contexte africain, la cohabitation religieuse revêt diverses formes d'échanges possibles: évitement, conflictualité, hybridation, imitation, distinction (Lasseur et Mayrargue, 2011).

23 Au Maroc, où se conjuguent l'empreinte sociale d'un islam ultra majoritaire et une stigmatisation généralisée à l'encontre des Africains subsahariens, ces échanges sont quasi-inexistants. Si le contexte musulman participe à l'élaboration de l'identité religieuse, c'est toujours par la négative. Dans le discours des pasteurs et de leurs fidèles, islam et société marocaine, comme deux réalités confondues, sont diabolisés et intégrés dans le système symbolique du combat spirituel et de la délivrance. Beaucoup pensent que la raison profonde justifiant leur présence dans ce pays est «que la puissance de l'Évangile pénètre cette société et que les liens des ténèbres soient brisés " (Coyault, 2014). Une perception plus positive a vu néanmoins le jour suite à la politique de régularisations menée dans le Royaume en 2014. Dans des églises où certains membres ont bénéficié de la mesure, on entend des prières positives pour le pays d'accueil : "Que le Maroc soit béni! Que Dieu bénisse l'économie du Maroc! Qu'Il bénisse le Roi ! ».Cette manifestation inédite de la bienveillance royale est réinterprétée dans des catégories bibliques: Dieu a infléchi le cœur de Mohammed VI, comme il l'avait fait jadis pour le Pharaon ou le roi des Perses (Esaïe 45). Ce sont néanmoins les registres négatifs qui dominent. La vision reçue durant l'été 2012 par un pasteur de $L a$ Manne Cachée est révélatrice à cet égard. Dieu lui aurait révélé ce message à transmettre 
à toutes les communautés de maison selon lequel les musulmans, durant le mois de ramadan, volaient les bénédictions des chrétiens. Il était donc urgent, argumentait le pasteur, d'organiser dans chaque communauté de maison des prières spéciales pendant le ramadan pour contrer cette menace. Dans les lieux où sont implantées les communautés de maison, les relations avec la population environnante sont très réduites. Les églises s'abstiennent de toute action de prosélytisme, laquelle est rendue d'autant plus difficile par la barrière linguistique. En dépit de quelques cas de dénonciation ou de malveillance, on observe de la part du voisinage marocain une forme de consentement, fut-il passif et marqué de préjugés, à cette expression religieuse alternative organisée par les personnes migrantes. Une ethnographie fine au niveau des quartiers concernés, permettrait de relever les interactions qui s'opèrent inévitablement entre les deux univers. Si l'ancrage marocain de la colonie congolaise ou celui d'autres groupes nationaux se confirment dans l'avenir, on assistera sans doute à l'émergence progressive, et à bas-bruit, du pluralisme religieux dans ces périphéries urbaines du Maroc. C'est aussi ce que laisse entrevoir l'étonnante déclaration du 21/11/2014 de M. Yazami, président du Conseil national des droits de l'homme (CNDH), qui préconise la construction de nouvelles églises pour répondre aux besoins spirituels des ressortissants subsahariens installés au Maroc, et éviter ainsi tout phénomène de clandestinité religieuse, comme ce fut le cas dans les années 1970 pour les musulmans d'Europe, avec le phénomène des « mosquées des caves » (Assabah, 22-23/11/2014).

\section{BIBLIOGRAPHIE}

B. Coyault, « L'africanisation de l'Église évangélique au Maroc : revitalisation d'une institution religieuse et dynamiques d'individualisation ", L'Année du Maghreb, nº 11, 2014, p. 81-103.

É. Goldschmidt, « Étudiants et migrants congolais au Maroc : politiques d'accueil et stratégies migratoires ", dans S. Wippel et L. Marfaing (éd.), Les relations transsahariennes à l'époque contemporaine, Paris, Karthala, 2004, p. 149-173.

M. Lasseur et C. Mayrargue, « Le religieux dans la pluralisation contemporaine. Éclatement et concurrence », Politique africaine, $n^{\circ} 123,2011$, p. 5-25.

M. Timera, «Aventuriers ou orphelins de la migration internationale. Nouveaux et anciens migrants 'subsahariens' au Maroc », Politique africaine, $\mathrm{n}^{\circ}$ 115, 2009, p. 175-195. 


\title{
Quelques enjeux du soufisme au Maroc : le tourisme religieux sénégalais et la construction d'un imaginaire sur l'amitié
}

\author{
Nazarena Lanza
}

1 Dans la société marocaine contemporaine les transformations en lien avec la présence d'étrangers, et plus particulièrement avec la construction d'imaginaires liés à "l'autre », peuvent arriver - du moins en partie - par « le haut », suivant les stratégies politiques, économiques et religieuses du pays. C'est le cas des politiques orientées vers l'Afrique de Mohammed VI, lesquelles s'appuient notamment sur le bagage symbolique commun de l'islam malikite et du soufisme confrérique visant à relier l'Afrique occidentale sous une même bannière religieuse, celle du Royaume chérifien.

2 La présence de plus en plus importante, au Maroc, de pèlerins africains subsahariens appartenant à la confrérie soufie de la Tidjaniyya constitue l'une des facettes de cet investissement sur le patrimoine religieux marocain et sur la promotion des « relations séculières » qui le lieraient à certains pays du sud du Sahara, notamment au Sénégal.

À partir d'un survol de la place du soufisme - et plus particulièrement de la confrérie Tidjaniyya - dans les stratégies politiques et économiques du Maroc en Afrique subsaharienne, je voudrais questionner les discours et imaginaires produits dans deux contextes différents mais en lien avec la présence de Sénégalais au Maroc. Je me réfère, d'une part, aux pèlerins des groupes « clé en main » organisés par un nombre croissant d'agences dakaroises et, de l'autre, aux Sénégalais résidant au Maroc, qu'ils soient étudiants, travailleurs ou migrants «en transit». Si les premiers semblent faire écho aux discours promus au niveau interétatique (et repris par les médias) présentant le Maroc comme un pays "frère" dans l'islam et comme le berceau de la tarîqa Tidjaniyya, les deuxièmes dévoilent un décalage important par rapport à ce type d'imaginaires, exprimant une certaine déception à l'égard de l'islam pratiqué au Maroc et dénonçant un racisme ordinaire à leur égard. Les faits divers rapportant les épisodes de violence - jusqu'au meurtre - visant des ressortissants sénégalais et en général 
d'Afrique subsaharienne de la part de la police et de citoyens marocains ont fait la une tant au Maroc qu'au Sénégal, questionnant la relation "privilégiée » entre les deux peuples.

4 Les deux discours existent cependant, chacun dans son contexte plus ou moins restreint, et semblent loin de converger. Comment appréhender ce décalage entre discours pèlerin et discours «ordinaire »? Est-ce qu'on peut parler de construction, par le haut, d'un imaginaire «enchanté » du Maroc, repris par les groupes de pèlerins, qui contribue à mitiger les expériences plus ou moins déroutantes des Sénégalais résidant au Maroc? Est-ce que ce tourisme religieux en provenance d'Afrique subsaharienne a un impact sur la manière de voir les Sénégalais et, plus globalement, les « Noirs » au Maroc?

\section{Les enjeux du soufisme au Maroc. Quelle place pour la Tidjaniyya?}

5 Le soufisme au Maroc fait l'objet, depuis une dizaine d'années, d'une grande exposition médiatique, au point qu'on peut y voir un phénomène de société et un investissement fort, de la part du Royaume, sur ses ressources spirituelles. Celles-ci sont mises en exergue, entre autres, dans les relations diplomatiques avec l'Afrique subsaharienne. Déjà, sous le règne d'Hassan II, l'appartenance au rite malékite et le caractère confrérique de l'islam marocain étaient utilisés comme un canal privilégié de communication avec plusieurs pays africains se réclamant de la même tradition islamique. Ces connexions religieuses fournissent un champ de partage qui facilite la coopération sous ses différents angles : politique, économique, social. Dans ce cadre, le titre d'Amir al Mouminine (Commandeur des Croyants) du souverain marocain est mis constamment en exergue, ainsi que le leadership spirituel du Maroc dans la région. $\mathrm{Ce}$ positionnement ne se fait pas sans une politique économique et de coopération forte, qui lui confère également un statut de partenaire économique incontournable pour un nombre croissant de pays africains.

6 Aujourd'hui toute rencontre politique, économique, culturelle ou religieuse entre le Maroc et le Sénégal se tient sur le fond d'un discours uniforme : les deux pays sont liés depuis des siècles grâce à leurs affinités religieuses au point qu'ils peuvent se définir, plus que comme des pays " amis », comme des pays « frères ".

7 Ces relations politiques sont soignées aussi lors des multiples rencontres religieuses organisées des deux côtés du Sahara, comme lors des annuelles «Journées culturelles islamiques Tidjanes" de Dakar, qui accueillent toujours d'importantes délégations marocaines du ministère des Habous et des Affaires islamiques, ou à l'occasion des conférences islamiques promues pas le roi Mohammed VI à Rabat, durant le mois du ramadan, auxquelles sont invités les chefs religieux des plus importantes confréries religieuses subsahariennes.

8 L'organisation de conférences internationales de la Tidjaniyya à Fès (en 2007, 2009 et 2014), tout particulièrement, répond à plusieurs soucis politiques et économiques : raffermir le Maroc en tant que berceau de la tarîga (en opposition aux tentatives identiques de l'Algérie); promouvoir l'image d'un islam marocain soufi, ouvert et tolérant, en opposition aux islamismes étrangers; établir et consolider des relations privilégiées avec les pays subsahariens avec une présence tidjane plus ou moins 
importante; favoriser les investissements économiques dans ces pays et relancer le tourisme religieux.

9 Participer à ces rencontres contribue à donner une idée de la puissance symbolique déployée par le Royaume et des effets produits sur ses invités. La dernière réunion générale de la tarîqa Tidjaniyya, organisée à Fès en mai 2014 par les ministères des Habous et des Affaires islamiques et de l'Intérieur et sous le haut patronage du roi, est à ce propos très instructive. Mise en place à l'occasion du 200e anniversaire du décès du fondateur de la confrérie, le coup d'œil en arrivant au Zalagh Place de Fès est étonnant : des centaines de cheikhs de la Tijaniya en grands boubous ou djellabas, aux phénotypes et styles vestimentaires différents selon le pays d'origine, sont réunis dans les jardins et dans le hall de ce grand hôtel cinq étoiles où la majorité d'entre eux est logé et où se tiennent les conférences. Les invités se réjouissent de l'accueil (ils sont entièrement pris en charge par le Royaume) et de la possibilité d'établir des contacts avec les représentants de la Tijaniya d'autres pays.

10 Lors de cette occasion, Fès a vu défiler plusieurs milliers de cheikhs (1 500 à 2000 selon les sources) majoritairement du continent Africain. L'économiste, dans un article intitulé «Fès prête à dérouler le tapis rouge aux tijani » (12/05/2014) en parlait comme du " probable plus grand pèlerinage qu'ait jamais connu Fès ». Le même journal, depuis le début de l'année 2014, a consacré toute une série d'articles au tourisme religieux au Maroc, après avoir relevé que, lors de la dernière tournée royale en Afrique en mars 2014, le secteur du tourisme religieux figurait parmi les priorités de l'agenda économique du Royaume.

\section{Discours pèlerin...}

11 Le pèlerinage à Fès date de plus d'un siècle mais, à partir du début des années 2000, il a pris une autre forme et une autre consistance. Durant cette période le nombre de pèlerins sénégalais à se rendre à Fès a commencé à se faire de plus en plus important et à prendre la configuration de voyages "clé en main». La multiplication d'agences offrant ces ziyara se traduit par un changement substantiel non seulement dans le nombre de pèlerins, mais aussi sur les caractéristiques socio-économiques de ces derniers. La plus grande accessibilité au voyage, en termes de prix et d'organisation, motive au départ des catégories de personnes auparavant non concernées par l'idée de ziyara: les personnes trop âgées pour entreprendre seules le voyage, les nouveaux commerçants «à la valise » et les touristes pèlerins, qui voient favorablement la possibilité de lier pratique religieuse, commerce et découverte touristique. Participant à certaines de ces ziyara organisées, j'ai pu observer la production et la reproduction de discours et d'imaginaires sur le Maroc comme terre mythique et pôle religieux de la Tidjaniyya.

$12 \mathrm{Au}$ sein des groupes, les guides qui accompagnent les pèlerins jouent un rôle déterminant dans la diffusion du discours sur les liens sacrés unissant les deux pays (Lanza, 2014). Tout au long des circuits qui touchent différentes villes marocaines (Casablanca, Marrakech, Rabat, Fès...) leur narration - à la fois touristique et religieuse des différents sites visités alimente des imaginaires positifs sur le Royaume chérifien, considéré par les tijanes sénégalais, avant tout, comme le pays ayant accueilli le fondateur de la confrérie et qui abrite son mausolée. 
Les circuits balisés et la dimension fermée de ces groupes met les pèlerins à l'abri d'expériences plus ou moins malheureuses, leur permettant de profiter de l'accueil qui leur est réservé dans chaque site visité et du plaisir de découvrir « le plus beau pays du monde ».Les infrastructures nouvelles flambantes du Maroc et le décor des villes et des hôtels sont particulièrement appréciés et constituent un important sujet de conversation.

Personne n'ignore certains des épisodes d'actualité concernant des migrants sénégalais au Maroc, surtout ceux qui ont fait la "une " des journaux comme les meurtres d'Ismaila Fall en août 2013 et de Charles Ndour quelques mois plus tard. Toutefois, pour la majorité des pèlerins, les vicissitudes des "migrants" sont très loin de leurs préoccupations quotidiennes et réflexions sur le Royaume chérifien.

Ils font généralement partie de la classe moyenne aisée et ne sont pas confrontés à la problématique de la migration. Au contraire, ils tiennent à souligner la distance entre eux et les «migrants » avec lesquels ils ne partagent que la nationalité. Plus sensibles à la question sont, bien évidemment, les parents qui ont des enfants émigrés ou qui étudient au Maroc, pour lesquels le souci pour leur sécurité prévaut sur tout.

Comme les autres touristes, les pèlerins sont aussi l'objet de stéréotypes, qui se démarquent cependant de ceux qui concernent, généralement, les « Noirs » au Maroc: ils sont considérés comme moyennement riches ou du moins comme de bons acheteurs. Les plus âgés sont appelés « hajj ", titre réservé à ceux, en islam, ayant déjà accompli le pèlerinage à la Mecque, informant implicitement sur le statut de musulman qu'on leur accorde. Les commerçants dans les rues de la médina de Fès et de Casablanca connaissent tous quelques mots en wolof pour établir de manière sympathique le contact avec les pèlerins. Ils connaissent leurs goûts et les produits que ces derniers recherchent le plus.

Dans l'ensemble, après leur première expérience au Maroc, les pèlerins souhaitent revenir, si possible tous les ans. Les raisons sont multiples et différentes mais toutes découlent d'impressions positives liées aux sites visités, au " ressourcement » sur les lieux fondateurs de la Tidjaniyya, à la possibilité de faire du commerce et au prestige qui découle du fait d'avoir voyagé au Maroc et accompli la ziyara à Fès.

\section{... et contre-discours « migrant »}

8 En se rapprochant du vécu quotidien des Sénégalais au Maroc, on constate des relations beaucoup plus désenchantées avec le pays et les "locaux" qui se manifestent, au premier abord, dans les appellations que nombre d'Africains subsahariens affirment subir de la part de Marocains.

Interpellés sur les plus communes, comme « azi » ou «mon ami », les Marocains nient généralement qu'il y ait du mépris. « Azi », en dialecte marocain, signifie «noir ». Pour beaucoup de Marocains, il s'agit d'une manière amicale et issue de la plaisanterie pour appeler les Noirs, "pour casser la glace, en ne sachant pas comment les appeler " (entretien, Rabat, juillet 2013). Cette défense à outrance de leur bonne fois dans l'usage de ces termes, informe néanmoins sur une modalité de relations assez répandue dans la société marocaine, basées sur une conception du respect qui se manifeste par la crainte révérencielle vers le haut de l'échelle sociale et la minoration ou subordination vers le bas. Les "Noirs", de par le vécu encore trop récent de leur condition servile, se 
trouvent souvent automatiquement assignés au rang plus bas. L'esclavage, ayant persisté au Maroc jusqu'au début du XXe siècle, fait notamment partie des pages noires de l'histoire commune marocco-sénégalaise qui tendent à être effacées des discours tant de l'un que de l'autre pays.

Selon l'historienne Rita Aouad, en commentaire aux agressions aux Africains subsahariens à Tanger, "l'histoire récente éclaire en partie le rapport particulier des Marocains à l'esclavage et aux Noirs » (Telquel, 6/9/2014). L'auteure met en relation une attitude décomplexée au racisme avec le fait que l'esclavage n'a jamais été formellement aboli au Maroc. Le protectorat français avait pris certaines mesures, comme la circulaire de 1922 qui interdisait la vente d'esclaves dans les marchés, mais la pratique avait persisté jusqu'aux années 1940 .

Concernant la pratique religieuse, Mahamet Timera remarque qu'au sein même du discours sur "l'islam en partage ", l'expérience ordinaire révèle une dévalorisation de la pratique religieuse de l'autre, et ce dans les deux sens (2011). L'auteur considère que le mépris dont les Sénégalais sont l'objet, va avec une dévalorisation de leur "islamité » en tant que "non arabes » ou "récemment islamisés », tandis que les Sénégalais considèrent ces discours et pratiques de dénigrement comme "non islamiques » et, partant, remettent en cause « l'islamité véritable » des Marocains.

Plusieurs Sénégalais installés au Maroc depuis longtemps tiennent cependant à souligner que le racisme relève surtout de certains milieux défavorisés et d'une profonde méconnaissance de l'Afrique. L'un d'entre eux rapporte comment, dans un café où passait à la télévision un documentaire sur la forêt équatoriale africaine, tout le monde se mit à le regarder prétendant à une traduction de ce que se disaient deux pygmées, repris par la caméra, qui parlaient entre eux. Son témoignage informe autrement le problème et montre la place tenue par l'ignorance dans la construction d'images de l'autre avilissantes ou du moins simplistes.

\section{Ré-enchantement ou désenchantement?}

Si la promotion de la Tidjaniyya, des « liens sacrés » avec l'Afrique subsaharienne et du tourisme religieux contribue, d'un côté, à la création d'imaginaires "enchantés " concernant le royaume chérifien, d'un autre côté, les violences ordinaires vécues par les Sénégalais du Maroc et rapportées par les médias contrebalancent radicalement ces perceptions. Au point que M. Alioua, dans son « coup de gueule » contre le meurtre de Charles Ndour à Tanger et l'expulsion presque immédiate de certains témoins écrit : " on pourrait presque croire que c'est du sabotage volontaire des excellentes relations entre le Maroc et le Sénégal » (Tribune, 5/09/2014).

Il ne s'agit pas de sabotage mais de vécus et de discours parallèles qui agissent sur les imaginaires de manière divergente. La volonté du Royaume de promouvoir, par les discours et les images, les liens « sacrés » qui unissent le Maroc au Sénégal se heurte à une certaine mentalité qui résiste à cette " éducation forcée " par le haut. Les groupes de pèlerins, dans leur forme close et leur manière fugace d'appréhender le Maroc semblent, par contre, constituer un espace interstitiel dans lequel le discours interétatique trouve son application. Partant, en tant que touristes et pèlerins, ils offrent une image qui, si elle ne révolutionne pas le regard que les Marocains portent 
sur les Africains subsahariens, contribue néanmoins à complexifier le champ de la présence d'étrangers au Maroc.

\section{BIBLIOGRAPHIE}

M. Alioua, «Si le racisme s’installe, pas de démocratie possible au Maroc », Tribune, 5/09/2014.

R. Aouad-Badoual, «Esclavage et situation des Noirs au Maroc dans la première moitié du XX siècle ", dans L. Marfaing, S. Wippel (éd.), Les relations transsahariennes à l'époque contemporaine, Paris, Karthala/ ZMO, 2004, p. 337-359.

N. Lanza, «Pèleriner, faire du commerce et visiter les lieux saints : quelques enjeux du tourisme religieux sénégalais au Maroc », L’Année du Maghreb, 2014.

M. Timera, « La religion en partage, la "couleur" et l'origine comme frontière. Les migrants sénégalais au Maroc », Cahiers d'études africaines, n 201/1, 2011. 


\title{
Mobilité des Musulmans ivoiriens au Maroc : entre formation islamique et tourisme religieux
}

\author{
Mamadou Bamba
}

1 L'avènement du Roi Hassan II au pouvoir dans le Royaume chérifien en 1961 marque un tournant nouveau dans l'histoire des relations ivoiro-marocaines, comme l'illustre l'ouverture d'une ambassade du Maroc en Côte-d'Ivoire en 1981. L'on assiste depuis à une revitalisation des relations entre ces deux pays, au travers des secteurs tels que la formation islamique, la culture, l'économie et le tourisme. Cette revitalisation a été soutenue par la volonté des différents régimes ivoiriens, du président Houphouët Boigny depuis 1973 au président Alassane Ouattara en 2011, qui ont toujours entretenu des liens cordiaux avec le Maroc.

Dans le cadre de la présente réflexion, l'intérêt portera sur les mobilités d'étudiants et de religieux musulmans qui se rendent au Maroc pour profiter des formations islamiques et du tourisme religieux. La question nodale de cette étude est la suivante : pourquoi le Maroc exerce-t- il une telle attractivité sur ces catégories spécifiques d'Ivoiriens? De cette question principale se dégagent des interrogations secondaires: peut-on parler d'impact de ces religieux ivoiriens sur la société marocaine ? Y a-t-il des répercussions de ces formations islamiques et de ces séjours religieux sur le pays d'origine, la Côte-d'Ivoire? Peut- on parler de contribution sociale et académique du Maroc vis-à-vis des musulmans ivoiriens, via ces échanges ?

\section{Quelques facteurs explicatifs de la mobilité des étudiants et religieux ivoiriens au Maroc}

Plusieurs facteurs, politiques, religieux et socio-culturels expliquent les déplacements des étudiants et religieux vers le Royaume chérifien. Lors de son indépendance, en août 1960, la Côte-d'Ivoire est devenue un État laïc, avec le français pour langue officielle. Ce jeune État de l'Afrique de l'ouest, ancienne colonie française depuis 1893, adopte alors 
des institutions sur le modèle de l'ex-puissance coloniale, notamment pour ce qui est de son système éducatif. Son baccalauréat, cinquante ans après son indépendance, est régi par des lois d'inspiration française et des conventions de reconnaissance des diplômes ivoiriens et français permettent des équivalences (article 13 de l'accord de coopération entre la république ivoirienne et la république française du 24 avril 1961).

La formation islamique est mise au second plan, même si certains dirigeants ivoiriens, à l'instar du président Houphouët Boigny, n'ont pas eu une position univoque vis-à-vis de l'islam et de son enseignement. Au contraire, elle a varié en fonction des intérêts du moment. Cette position ambivalente a eu pour conséquence la mise en place d'un nombre très limité d'établissements confessionnels islamiques sur l'ensemble du territoire ivoirien. Exceptions faites du centre islamique d'Ar-el-Hadisse de Bouake, du centre islamique de Williamsville et d'une école islamique au stade embryonnaire nommée Itratou à Yopougon, il n'existe pas de véritables structures d'enseignement supérieur islamique en Côte-d'Ivoire. à ces éléments, il faut ajouter que les bacheliers des écoles confessionnelles islamiques ne sont pas admis dans les universités publiques car le ministère de l'Enseignement supérieur en Côte-d'Ivoire ne reconnaît pas ces diplômes. Les étudiants ivoiriens en sciences islamiques se dirigent ainsi, pour la plupart, vers les ambassades du Niger et surtout du Maroc, qui offrent une gamme variée de formations qui semblent répondre à leurs besoins (Binate, 2012).

Concernant ce dernier pays, il faut souligner que les liens religieux entretenus avec la Côte-d'Ivoire relèvent du processus d'implantation de l'islam, depuis le Moyen Âge. L'islamisation de l'Afrique s'est faite notamment du nord vers le sud, du Maghreb vers les pays au sud du Sahara au XVe siècle. Cette progression de l'islam s'accompagne, à partir de la fin du XIXe siècle, de l'expansion confrérique, notamment de la Qadiriyya et de la Tidjaniyya (Bamba, 2009, p. 106-107).

6 La Tidjaniyya semble être la confrérie la plus populaire en Côte-d'Ivoire contemporaine. Les ziyara de Seydou Nourou Tall (1864-1980), grand marabout sénégalais soutenu par l'administration coloniale française, participent considérablement à la mise en place de zaouïas tidjanes sur toute l'étendue du territoire ivoirien à partir de 1920.

7 En mai 2000, la famille du cheikh Hamed Tidjani nomme cheikh Moustapha Sonta coordonnateur de la Tidjaniyya pour la Côte-d'Ivoire, qui devient ainsi l'interlocuteur de la zaouïa-mère de Fès pour le pays. Ce lien est à l'origine des voyages périodiques de nombreux fidèles ivoiriens vers la ville sainte de Fès. Ces déplacements sont par ailleurs facilités par la dispense de visas d'entrée dont bénéficient de manière bilatérale les ressortissants des deux pays.

8 À ces raisons religieuses s'ajoutent d'autres déterminants, plus proprement politiques, qui contribuent à expliquer les mobilités actuelles en direction du Maroc.

9 Au début des années 1980, le roi Hassan II se rapproche d'un certain nombre de présidents de pays subsahariens, notamment du Zaïre, du Sénégal, du Gabon et de la Côte-D'ivoire. Des relations se concrétisent par la mise en place de plusieurs ambassades marocaines en Afrique, notamment au Zaïre en 1983, en Côte-d'Ivoire en 1981 et au Nigeria en 1982. Les relations amicales entre le roi Hassan II et le président Houphouët Boigny ont été à la base d'échanges commerciaux et du développement d'une coopération spécialement dans le cadre de la formation supérieure. Le début des 
années 1990 est marqué par le départ d'étudiants ivoiriens en sciences islamiques vers les villes de Casablanca, Rabat, Marrakech et Fès.

\section{Les étudiants et les religieux ivoiriens au Maroc}

10 Le service socioculturel de l'ambassade du Maroc en Côte-d'Ivoire, en collaboration avec le ministère de l'Enseignement supérieur et le ministère de l'Intérieur ivoirien interviennent pour faciliter le voyage des étudiants ivoiriens sélectionnés sur analyse de dossier. Ces étudiants ivoiriens, par le biais de l'Agence marocaine de coopération internationale (AMCI), s'inscrivent dans les universités marocaines pour des formations en théologie, études orientales, civilisation arabo-musulmane, droit islamique, gestion islamique de l'économie, commerce international et bien d'autres filières non islamiques.

11 Les étudiants peuvent choisir entre le " cycle court ", qui prend fin avec la licence (BAC + 3), et le «cycle long» qui se termine avec le doctorat. Dans les universités marocaines, ces jeunes ivoiriens bénéficient d'une éducation formelle, c'est-à-dire une formation qui répond aux normes reconnues par l'UNESCO, dans des centres de formation ou des universités qui bénéficient plus ou moins d'une bonne réputation. Sur une vingtaine d'universités que compte le Royaume, les étudiants ivoiriens en études religieuses choisissent généralement les universités de Fès, de Marrakech, de Casablanca, de Tanger et de Tétouan. Ces étudiants sont souvent confrontés à des difficultés sociales (problèmes de logement, d'insertion dans la ville et le quartier d'habitation), économiques (retard dans le paiement de la bourse) et académiques (difficile adaptation au système éducatif marocain) auxquelles ils doivent faire face et qui font partie de leur expérience du Maroc. Certains d'entre eux intègrent le soufisme par l'adhésion à des ordres confrériques. D'autres, par contre, s'engagent plus largement dans l'islam malékite, sans nécessairement s'affilier à une confrérie. Cette volonté de connaissance et de pratiquer l'islam amène certains étudiants à visiter les lieux historiques et prestigieux du culte musulman au Maroc comme les mosquées, les médersas et les mausolées des saints. Selon Konaté Arna (2008, p. 67), ces sites religieux attirent presque la moitié des étudiants ivoiriens en formation au Maroc. Pour cet auteur, "le tourisme religieux est devenu une formation complémentaire pour les étudiants musulmans au Maroc ». à titre d'exemple, des musulmans ivoiriens appartenant à la Tidjaniyya s'organisent chaque année pour visiter le mausolée du fondateur de la confrérie et d'autres sites d'intérêt religieux. Le Maroc a toujours utilisé l'atout religieux pour se rapprocher des pays de l'Afrique de l'Ouest, notamment du Sénégal, du Mali, de la Côte-d'Ivoire et du Niger. Les musulmans ivoiriens, de leur côté, ont bénéficié de cette ouverture pour se rendre régulièrement au Maroc. Cette situation est favorisée par la promotion du rite malékite, notamment dans ses dimensions de tolérance et d'ouverture, que le Maroc exporte dans un bon nombre de pays subsahariens. Ainsi, grâce à sa politique religieuse et à la valeur touristique de ses sites patrimoniaux, le Maroc est devenu une référence, voire un modèle, aux yeux des musulmans ivoiriens et plus particulièrement de la communauté des Tidjanes.

Du côté marocain, l'office du tourisme prend des dispositions pour faciliter la visite de ses sites touristiques, telles que le soutien à l'obtention des autorisations et le suivi de certaines démarches administratives. Du côté ivoirien le ministère de l'Intérieur, qui gère les questions religieuses et des cultes, s'implique au plan administratif, 
diplomatique et médical dans l'organisation des voyages. Des accords ont été signés entre Moustapha Sonta et les responsables de la compagnie Royal Air Maroc, prévoyant que les adeptes ivoiriens de la Tidjaniyya puissent bénéficier de facilités sur les tarifs et les transports entre Abidjan et Fès. Selon Driss Benhima « le transport aérien marocain se met à la disposition de la tarîqa Tidjaniyya à travers le monde » (Fraternité Matin, 12 mai 2014, p. 7). Parmi les sites visités, la ville de Fès est la plus convoitée puisqu'elle fait partie des principaux centres spirituels et intellectuels de la Tidjaniyya en Afrique. La ville est un lieu de "pèlerinage" pour bon nombre de musulmans subsahariens, notamment les Tidjanes ivoiriens qui y vont pour se ressourcer et revigorer leur foi. Le site le plus important est représenté par le sanctuaire du maître de la tarîqa Tidjaniyya, sidi Hamed Tidjani, suivi par la mosquée Qaraouiyine et la mosquée des Andalous. D'autres sites touristiques, notamment à Casablanca, attirent également les musulmans ivoiriens: le boulevard Houphouët Boigny, le tombeau de Sidi Bousmara, la grande mosquée Hassan II, la qubba (tombeau à coupole) du marabout Sidi Abderahmane, le bastion de la Sqala, le quartier Anfa avec ses architectures modernes, etc.

\section{L'impact des formations islamiques et du tourisme religieux sur le Maroc et sur la Côte-d'Ivoire} constituent l'un des aspects des relations diplomatiques qu'entretient la Côte-d'Ivoire avec le Royaume. Au cours des deux dernières décennies, le Maroc a multiplié les dons et les aides au profit des organisations islamiques, notamment le Conseil supérieur islamique (COSIM), le Conseil national islamique (CNI) et la Ligue islamique des prédicateurs de Côte-d'Ivoire (LIPCI) (Bamba, 2009, p. 370).

Sur le plan économique, les formations de ses étudiants au Maroc coûtent à la Côted'Ivoire environ un demi-milliard de francs CFA (environ 750000 euros). Pour Kone Adama (entretien, 26 juillet 2014), cette somme représente une enveloppe colossale pour un pays en voie de développement. Il faut cependant rappeler que seuls les étudiants sélectionnés sur des critères de mérite bénéficient du soutien de l'État. En plus de ces étudiants boursiers, d'autres se déplacent au Maroc à leurs propres frais, de manière autonome de l'AMCI.

15 Au plan socioculturel, les étudiants ivoiriens qui reviennent du Maroc sont supposés avoir un bagage intellectuel solide et une formation théologique de haut niveau car, selon la perception communément admise par les musulmans ivoiriens, pendant leur séjour marocain ils s'imprègnent considérablement de la culture islamique.

En Côte-d'Ivoire ces étudiants se présentent parfois comme de véritables érudits des sciences islamiques et participent, à leur tour, à la propagation de l'islam malékite dans le pays. Toutefois, ils sont aussi régulièrement confrontés à des problèmes d'insertion socioprofessionnelle, puisque les diplômes des formations islamiques délivrés au Maroc sont souvent en déphasage avec les réalités ivoiriennes. Ces jeunes diplômés souffrent d'un sentiment d'incompétence face à d'autres étudiants issus du système éducatif national - francophone - qui ont plus de facilités à intégrer la fonction publique. Il en est de même des étudiants ivoiriens ayant suivi au Maroc un cursus francophone, qui leur permet de s'insérer aisément sur le marché de l'emploi national. Pour trouver des débouchés professionnels certains étudiants arabophones s'investissent alors dans le 
commerce, dans le transport ou dans le secteur informel. Quant à leurs voyages motivés par des raisons religieuses, ils ne leur apportent que de l'expérience, non «monnayable » dans la perspective d'une insertion professionnelle.

Du côté du Maroc, l'accueil de nombreux étudiants subsahariens soutient les bonnes relations entretenues avec l'Afrique subsaharienne et permet au Maroc de se présenter comme un pays attractif, ainsi qu'un important lieu de formation en Afrique du nord, notamment grâce à son système éducatif et à ses infrastructures universitaires et techniques. De plus, le Maroc se présente comme un pays stable pour l'acquisition du savoir et des enseignements liés à l'islam, contrairement à ses voisins magrébins où l'environnement social est rythmé par des violences et des tensions récurrentes.

Enfin, sur le plan économique, la convergence d'étudiants étrangers et les activités du tourisme participent au dynamisme de l'économie du Royaume. L'absence de données statistiques ne nous permet pas, cependant, de dégager la contribution réelle des étudiants et des religieux dans l'économie marocaine, laquelle semble pourtant indéniable. Des travaux et enquêtes pourront nous situer dans l'avenir.

19 Au terme de cette analyse il faut souligner que les relations ivoiro- marocaines ont été scellées par le roi Hassan II et le président Houphouët Boigny en 1961, avant d'être matérialisées en 1973 par la signature d'un traité d'amitié et de coopération portant principalement sur la création d'une grande commission mixte ivoiro-marocaine. Cependant, les difficultés dans l'insertion professionnelle rencontrées par les étudiants arabophones revenus du Maroc atténuent l'impact potentiellement positif de ces mobilités. C'est particulièrement vrai si l'on pense aux fonctions administratives et politiques, inaccessibles aux arabophones, qui se voient ainsi nier la possibilité d'obtenir un travail rémunéré à la hauteur du diplôme acquis. Ces formations, finalement, ne donnent une relative satisfaction qu'aux plans académique et religieux.

Pour finir, ce réseau de tourisme religieux représente aussi une succursale des activités commerciales entre les fidèles de la Tidjaniyya en Côte-d'Ivoire et leurs condisciples de l'Afrique et du monde entier. Le soutien marocain récent apporté pour l'encadrement de certains religieux, notamment les prédicateurs, quelques imams et surtout guides des tidjanes ivoiriens situe le Maroc comme référence en la matière et contribue à positionner le Maroc comme une plaque tournante de l'islam en Afrique.

\section{BIBLIOGRAPHIE}

M. Bamba, La communauté musulmane et les mutations sociales et politiques en Côte-d'Ivoire de 1946 à 1999, doctorat nouveau régime, Université de Côte-d'Ivoire, U.F.R SHS, Histoire, 2008.

I. Binate, Histoire de l'enseignement islamique en Côte-d'Ivoire: dynamique d'évaluation d'une éducation communautaire (fin XIX ${ }^{e}$ siècle - 2005), thèse de doctorat unique, Université Félix-HouphouëtBoigny, Abidjan, département d'histoire, 2012.

Entretien du 26 juillet 2014 avec A. Kone, sociologue à l'université Peleforo Gon de Korhogo et chargé de communication au Conseil national islamique (RCI). 
A. Konate, Le circuit des étudiants ivoiriens en formation dans les pays du Maghreb de 1981 à 2002, mémoire de DEA en histoire contemporaine, Institut d'histoire, d'arts et d'archéologie-africains (IHAA), Université de Cocody, 2008.

UNESCO, Les relations historiques et socioculturelles entre l'Afrique et le monde arabe de 1935 à nos jours, colloque de l'Unesco, Paris, 1984. 
De la prise en compte de la présence étrangère au Maroc 


\title{
Immigration estudiantine subsaharienne : quel enjeu pour le Maroc?
}

\author{
Lionel Nzamba
}

1 L'actualité brûlante de la présence subsaharienne au Maroc mobilisait déjà plusieurs acteurs bien avant l'engouement médiatique suscité depuis l'annonce du changement de la politique migratoire marocaine qui s'appuie principalement sur la régularisation des «sans-papiers ». Loin d'être le modèle en matière de respect et de protection des Droits de l'Homme, le Maroc a consenti à cette démarche à un moment où la gestion des migrants clandestins aux portes de l'Europe est de plus en plus critiquée. Cependant, la présence subsaharienne révèle aussi d'autres aspects de l'immigration, occultés par les préoccupations sécuritaires, que la « nouvelle politique migratoire » tente d'humaniser.

2 Cette nouvelle donne politique vient renforcer une coopération Sud-Sud qui trouve ses fondements dans une amitié entretenue au plus haut niveau avec certains chefs d'États africains depuis les indépendances; ce qui a le mérite d'encourager les échanges, le dialogue culturel, politique, économique entre les entreprises, les gouvernements et les peuples de ces pays (Gabon, Sénégal, Mali...). À majorité francophone, ces États subsahariens ont une communauté implantée au Maroc pour diverses raisons. L'aspect qui retient notre attention dans le cadre de la présente contribution sur les présences étrangères concerne l'attractivité qu'exercerait l'enseignement supérieur marocain sur les jeunes Africains subsahariens. Cet aspect a rarement fait l'objet d'études rigoureuses, bien qu'il en existe quelques-unes.

3 À l'heure où le Maroc renforce sa coopération en Afrique par le biais de plusieurs accords économiques, commerciaux et diplomatiques avec les États francophones - que le Roi du Maroc a visité entre février et mars 2014 à l'occasion d'une tournée « africaine »- il est difficile pour le chercheur de ne pas voir dans cette démarche un positionnement stratégique visant à participer à la reconfiguration de la géopolitique africaine. 
Chaque année, des centaines d'étudiants subsahariens sont accueillis au Maroc dans le cadre d'une migration estudiantine, qui prend de l'ampleur au niveau mondial puisque, entre 1999 et 2007, le nombre d'étudiants scolarisés dans les établissements supérieurs hors de leur pays d'origine a augmenté de $53 \%$ (plus 2,8 millions d'étudiants en mobilité en 2007 dont environ 5,8\% viennent de l'Afrique subsaharienne) selon l'Institut Statistique de l'UNESCO.

5 Encouragés par un cadre juridique et institutionnel favorable, les établissements d'enseignement supérieur participent à une immigration subsaharienne légale. Ils mettent en avant les atouts du Maroc, notamment la proximité ou la diversité de l'offre de formation directement liée au développement de l'Afrique. Ils multiplient ainsi leur chance d'accueillir les futurs dirigeants d'États, d'organisations régionales et internationales ou d'entreprises. De ce fait, si la formation de l'élite subsaharienne constitue un enjeu pour le Maroc, quel rôle pourraient jouer les établissements d'enseignement supérieur marocains pour assurer l'intégration des étudiants subsahariens?

6 Notre contribution est un éclairage sur les motivations des étudiants subsahariens pour l'enseignement supérieur marocain, en posant comme hypothèse une configuration où les choix des uns (étudiants) servent les intérêts stratégiques des autres (les États), le tout sur fond de compétition que se livrent les États dans leur construction économique avec des répercussions sur le social.

\section{La formation en question}

7 Le Maroc a ouvert depuis des années les portes de ses établissements supérieurs aux subsahariens, en s'appuyant sur trois principaux axes: la formation des cadres, la formation professionnelle et la formation supérieure. Le durcissement des conditions d'admissions des Africains dans certains États, en particulier européens et nordaméricains, a permis à d'autres États de révéler leur potentiel et de concurrencer l'hégémonie occidentale en matière de transmission du savoir. Le Maroc devient ainsi une alternative aux coûts élevés des études dans ces pays, qui restent néanmoins des destinations privilégiées de familles aisées.

Ce changement de tendance est dû au croisement de deux facteurs non négligeables dans la politique internationale: la reconsidération des rapports Nord-Sud et l'encouragement de la coopération Sud-Sud. À ce constat, viennent s'ajouter les moyens déployés par le Maroc pour développer les secteurs de l'économie, du social et de la formation dans le but notamment de rayonner sur le continent.

Parmi les instruments mis en place pour faciliter l'accueil des étudiants subsahariens, l'Agence marocaine de coopération internationale (AMCI) a assuré, depuis sa création en 1986, des milliers d'inscriptions en faveur d'étudiants subsahariens dans les établissements publics d'enseignement supérieur. Elle assure la répartition de ces étudiants sur l'ensemble du territoire et constitue le support administratif pour leur orientation et gestion. Elle a contribué à l'ouverture de nouvelles facultés dans les petites villes, comme c'est le cas de Settat, Mohammedia ou El Jadida. Cette ouverture a aussi profité aux établissements d'enseignement supérieur privés. En quête de nouveaux étudiants, ces établissements sont allés plus loin en développant des 
campagnes actives de recrutement directement dans certains pays subsahariens (Guinée, Sénégal, Gabon pour l'école Sup de Co Marrakech en 2014).

10 Les premiers étudiants subsahariens formés au Maroc étaient envoyés principalement dans les années 70 pour des formations professionnelles ou des stages de perfectionnement. Pour la formation militaire par exemple, le Maroc n'était autrefois qu'une étape dans le circuit de formation devant mener les élèves-officiers à Saint-Cyr, en France. Il a ainsi formé plusieurs officiers subsahariens, principalement artilleurs et médecins.

11 Les universités marocaines connaissent moins de crises que leurs homologues francophones subsahariennes, depuis les réformes initiées en 2000 et la mise en place $\mathrm{du}$ plan d'urgence des universités. Les universités francophones subsahariennes tournent, pour la plupart, au ralenti, en général victimes de mauvaise gestion et du désintéressement des pouvoirs publics dans l'amélioration des conditions d'études. Entre grèves des étudiants, des professeurs et problèmes de gestion, les jeunes subsahariens se sont rendus compte que la crise habite l'université. Le Maroc l'a compris et s'est attelé à différencier ses établissements, de manière à ce que les étudiants ne suivent pas le même parcours d'une ville à une autre ou d'une faculté à l'autre.

12 Quand il s'agit de réformer l'université, les questions de fond sont soigneusement évitées afin de ne pas mener une réflexion engageant réellement les universités dans le devenir de l'État et l'évolution de la société. Par exemple, l'adoption du système LMD (Licence Master Doctorat) a été très tardive en Afrique subsaharienne. Si les pays du Maghreb ont entamé ce processus au début des années 2000, au Sud du Sahara il a fallu attendre 2006-2007 pour voir les premières expériences (Cameroun).

Pour pallier la défaillance du système, les États s'en remettent à l'initiative privée pour la création d'établissements supérieurs qui, dans la plupart des cas, ne résolvent pas les problèmes de sureffectif et d'échecs dans certaines filières. Une spirale dans laquelle étudiants et enseignants sont pris en otage.

14 L'ancien ministre, Saâdeddine El Othmani, révélait en 2014 que plus de 12000 étudiants subsahariens étaient inscrits au Maroc, dont 8000 dans les établissements publics et 4000 dans les établissements privés. 40 pays africains sont représentés dans ces établissements, ainsi que 91 autres nationalités. Ces trente dernières années, plus de 30000 cadres ont été formés au Maroc via cette coopération entre le Maroc et les pays d'Afrique subsaharienne.

\section{Les étudiants en marge de la recherche scientifique}

15 La migration estudiantine s'organise de mieux en mieux depuis le Maroc avec la consolidation de réseaux et d'associations communautaires de stagiaires et étudiants qui participent au renforcement des liens avec les pays d'origine de ces étudiants (Berriane, 2009). Pour ces raisons, la solidarité estudiantine se trouve encore plus renforcée que celle d'autres groupes de migrants appartenant à la même communauté. Elle se poursuit en général hors de la vie estudiantine en permettant de nouer des relations et de faciliter l'accueil des nouveaux arrivants au Maroc. presque l'assimiler à la fuite des cerveaux, tant l'analyse rappelle la relation Nord-Sud. 
Or, en réalité, la présence d'étudiants subsahariens au Maroc revêt des enjeux économiques et diplomatiques non négligeables, si l'on considère les entrées de devises apportées par ces étudiants et l'influence que le Maroc y gagne sur le continent. De plus, la mobilité estudiantine est nécessaire au développement des États d'Afrique et au partage d'expériences.

Quant à la question du départ, elle est toujours présente bien que les expériences d'étude et de vie soient radicalement différentes d'un étudiant à un autre (Infantino, 2011). La décision de quitter le Maroc répond à une série de questions telles que l'adaptation sociale, les conditions de vie, etc., et prend en considération les débouchés au Maroc, la possibilité de poursuivre les études ou de s'engager dans une activité professionnelle. Mais là encore, on ne sait pas ce qu'il advient des lauréats formés au Maroc : sont-ils facilement intégrés sur le marché de l'emploi ? La législation marocaine ne facilite pas l'accès à l'emploi pour la majorité des étrangers, notamment d'Afrique subsaharienne, à l'exception des Sénégalais et de certaines catégories particulières d'étrangers (conjoints de marocain(e), footballeur, etc.).

Pour ceux encore en formation, le départ du Maroc est parfois précipité et justifié pour certains par des évènements personnels ou académiques (degré de satisfaction de l'enseignement reçu, suppression de la bourse, etc.). Ceux dont la volonté de rester au Maroc est plus forte nagent à contre-courant et poursuivent leurs études dans le public ou le privé sans aucune bourse, ni de l'AMCI, ni même de leur État. Alors, partir ou rester? Pour les étudiants, c'est une question soit de détermination, soit de moyens financiers. Il ne serait donc pas étonnant de trouver d'anciens étudiants en « situation administrative irrégulière » toujours au Maroc.

19 L'université marocaine pourrait contribuer au rayonnement du Maroc en participant à la réflexion sur le développement de la société, et ainsi éclairer les choix stratégiques des décideurs sur ce que pourrait être par exemple la nouvelle politique migratoire. Elle pourrait ainsi s'interroger sur les moyens d'améliorer les conditions d'étude et de séjour des étudiants (autorisation de séjour couvrant tout le cursus universitaire, augmentation des places en campus universitaires), ou le moyen d'en faire un vivier de personnes hautement qualifiées qui pourrait servir de pont entre le Maroc et l'Afrique subsaharienne, ne serait-ce que pour les grandes entreprises marocaines implantées dans les pays tels que le Mali, la Côte-d'Ivoire ou le Gabon.

Les travaux universitaires n'ont pas manqué d'attirer l'attention des institutions publiques sur les risques d'une passivité de l'État dans le traitement de la présence des migrants subsahariens. Les orientations sécuritaires et humanitaires ont renforcé la position de certains médias sur les «dangers » de l'immigration subsaharienne, alors qu'un tout autre traitement pourrait contribuer à mettre en valeur l'importance d'encourager l'intégration sur le marché du travail des jeunes subsahariens, notamment ceux formés au Maroc. À terme, cela pourrait concerner l'ensemble des ressortissants subsahariens vivant au Maroc. On a noté quelques rares incursions à la télévision marocaine (2M, Medi1TV) où des reportages évoquaient le récit de vie d'Africains subsahariens ayant trouvé les moyens de s'adapter et de s'intégrer dans la société marocaine (création d'entreprise, emploi, mariage).

21 Aucun article (de presse ou scientifique) ne fait mention des avantages que le Maroc pourrait tirer de la présence subsaharienne, que ce soit économiquement ou socialement. Les chercheurs se laissent entraîner dans un conformisme de la réflexion sur cette présence. Pourtant, comme le souligne les conclusions du rapport du CNDH de 
septembre 2013, les migrations humaines constituent un «facteur d'enrichissement pour les sociétés de départ et d'arrivée, un stimulant de l'activité économique et une source de leur développement culturel ». Ainsi, certaines catégories de ressortissants subsahariens sont écartées des recherches sur les migrations ou les présences étrangères au Maroc (étudiants, malades, chefs d'entreprise, etc.) au profit d'une catégorie englobante - les « migrants » - sur laquelle l'attention des hommes politiques, des citoyens et des médias est facilement focalisée.

Le cosmopolitisme marocain s'enrichit de nouveaux profils, si l'on tient compte des récents changements dus à la mondialisation et à l'internationalisation de l'enseignement et de la formation. Les notions de circulation et d'échange sont fondamentales pour la compréhension des mécanismes d'influences réciproques à l'œuvre entre États et dans les transformations qui se révèlent dans la redéfinition des identités individuelles ou collectives. L'expérience au Maroc des étudiants subsahariens ne peut se limiter à l'analyse des aspects académiques, car ceux-ci se nouent avec des aventures, professionnelles et personnelles, qui ont donné naissance à d'autres dimensions (mariages mixtes, clandestinité). Les étudiants subsahariens ne parlent pas du Maroc comme d'un "eldorado", ou une terre promise, mais comme un moyen d'arriver à une fin : la réussite.

\section{BIBLIOGRAPHIE}

J. Berriane, «Les étudiants subsahariens au Maroc : des migrants parmi d'autres ? ", Méditerranée, 113, 2009, p. 147-150 http:// mediterranee.revues.org/3843 (consulté le 11 janvier 2015).

F. Infantino, « Les mondes des étudiants subsahariens au Maroc », dans M. Peraldi (éd.), D’une Afrique à l'autre. Migrations subsahariennes au Maroc, Paris, Karthala, 2011, p. 101-120.

J.-B. Meyer, S. Laouali, « Mobilité internationale des étudiants étrangers vers le Maroc : quelles particularités?", Études \& Essais, Rabat, Centre Jacques Berque, n 10, octobre 2012.

Conseil National des Droits de l'Homme (CNDH), Étrangers et droits de l'homme au Maroc pour une politique d'asile et d'immigration radicalement nouvelle, conclusions et recommandations, septembre 2013.

Recueil de données mondiales sur l'éducation, Statistiques comparées sur l'éducation dans le monde, Institut statistique de l'UNESCO, 2009 http://www.uis.unesco.org/Education/Documents/

ged-2011-fr.pdf.pdf (consulté le 7 août 2015). 


\title{
Labour market situation of sub- Saharan migrants in Morocco : the case of call centers
}

\author{
Silja Weyel
}

1 Today, sub-Saharan migrants are found in a big variety of jobs in Morocco, ranging from journalism and engineering to nursing, construction work and street vending. Some of these jobs are typically associated with disadvantaged migrant workers in countries worldwide, like domestic work or construction work. Others, like journalism or teaching, are activities that are less specific for migrants' positions. Compared to European countries, where migrants' integration into the labour market typically started with lower level jobs, Morocco, at its beginning of becoming an immigration country, shows a different picture: migrants are entering the labour market from below and at the same time in mid-level and higher level positions which require specific skills and education.

Drawing on fieldwork in Rabat and Casablanca in 2013, the paper will look at some key points around migrant work in call centers and then turn to the question how these phenomena relate to what the concept of labour market segmentation has described for western immigration countries. Rather than representing a thorough analysis of the applicability of segmentation theory to the Moroccan case, the paper puts together some points for discussion. In this context the term «migrant» does not refer, as is common in French language publications on Morocco, to vulnerable migrants in precarious situations but is used in its broad sense to designate people who have moved from their country of origin to another country and have stayed there for a certain amount of time. 


\section{Call centers as one major employment sector for migrants}

3 There seem to be two sectors that are dominant and integrate more migrants than others: the construction sector and that of call centers. The work in call centers primarily asks for an ease in speaking French and, for most positions with outbound calls, some sales talent.

4 Official numbers are not available but according to estimations of the association of Senegalese call center workers in 2013 around 10.000 Senegalese nationals are working in Morocco's call centers-to which nationals of other sub-Saharan African countries need to be added - and who represent more than 20 per cent of the number of (mainly Moroccan) people officially employed in the sector. This compares to a country wide percentage of foreigners of less than one percent and shows the job wise importance of call centers for sub-Saharans. To many migrants, call centers are the only sector where they can find work despite an educational background suited for other fields.

Call centers represent one of the well-functioning and growing sectors of the Moroccan economy in need of workers and since their introduction to Morocco about 15 years ago their sales figures have been growing. While other areas of foreign direct investment have not been extremely successful in creating jobs in Morocco (El Wazani and Souaf, 2006), this does not hold true for call centers. Their number reaches almost 500 and the Moroccan association of client relation (AMRT) estimates that they employ more than 45.000 people - which only includes registered centers and official contracts. The need of workers is visible through the call centers' numerous advertisements as well as in their recruitment strategies: some of the bigger centers use the so called " parrainage » system offering their Moroccan and foreign employees bonuses of 1000 dirhams (around $90 €$ ) if they recruit a new successful employee. Several centers recruit parts of their staff via websites and skype calls directly in Senegal, at times even paying for their plane tickets to Morocco.

6 Given the high unemployment rate in the country, specifically among the "chômeurs diplômés ", the Moroccan government aims at keeping numbers of foreign workers low and giving jobs to Moroccan nationals in the first place. The labour code stipulates that employers are allowed to recruit foreign nationals only if special skills are needed and no Moroccan can fill the job - with the exception of Tunisians, Algerians, Senegalese and the foreign spouses of Moroccan citizens. However, the interest of call center employers shows to be different from that of the government as they recruit numerous non Moroccans anyway. This situation leads to employment of many sub-Saharan national despite a high unemployment rate among Moroccans and to many different ways of circumventing the law.

\section{Migrants' employment conditions in call centers}

7 Employment conditions vary a lot among centers. However, with the exception of Senegalese nationals who have the same employment rights as Moroccans, only few sub-Saharan call center workers get an officially recognised work contract. One major reason for this is the Moroccan labour code which makes it difficult for call centers to legally employ sub-Saharan nationals other than Senegalese (or spouses of Moroccan 
citizens) if they work in the most common position of a "téléopérateur " or " téléconseiller ", i.e. the person that talks to clients on the phone. In sum, the practice ranges from not giving a contract at all and paying cash to giving contracts that are recognised by the Ministry of Labour and that include all social security payments. The practice does not necessarily depend on the size of the center.

Some small centers give contracts to their sub-Saharan employees and pay social security contributions while some big and well known centers don't allow their employees to take a copy of their contract home and ask them to sign pay slips in the center without handing out a copy to the employee. The aim of these call centers seems to be to not leave any traces of the employment of sub-Saharan nationals. In consequence, the workers are unsure what kind of contract they have signed and if health insurance and taxes are taken from their salary or not. Other centers give internship contracts to their employees, transfer their salaries to bank accounts, pay health insurance and social security contributions to the CNSS (caisse nationale de sécurité sociale), taxes are taken from the employees' salaries - which means that their situation is a good example of what some authors call «semi- legal» (Kubal 2012). Semi-legality, as Kubal (2012) uses it, refers to the many different nuances that exist between the often used simple dichotomy of «legal / illegal» with reference to migrants and their relation to the law. For example, while a migrant might not have the right to work, he or she might still pay taxes, insurance contributions and sign work contracts as is the case for many sub-Saharan call center workers in Morocco.

9 Some centers request from their sub-Saharan employees that their papers are "en règle ", i.e. that they have a valid residence permit. This causes a problem for many migrants since a work contract and a rental agreement are required to get a residence permit. A common practice of those workers is to sign in private educational institutions so they officially have a status as a student and can ask for a student residence permit. This can be quite costly for the concerned "students " as private educational institutions ask up to 2000 dirhams (around $180 €$ ) for inscription.

\section{Migrants' background and working conditions}

Sub-Saharan nationals working in call centers in Morocco have various backgrounds, are overwhelmingly in their twenties and come from West or Central African countries. The most represented nationalities seem to be Senegalese, Cameroonian, Congolese and Ivorian. Some are current students wanting to earn money beside their studies, others are former students waiting to find a job that fits their university education while others again come to Morocco to earn some money and find out about possibilities that the country can offer them. Educational backgrounds range from uncompleted high school to university degrees. Most see their work in call centers as a temporary situation which helps them earn some money for a certain goal or until a better opportunity is found. However, specifically Senegalese nationals come to Morocco explicitly in order to work in call centers and to many migrants their call center job means they can send back remittances to their families. Among Senegalese employees, there are numerous ones who used to work in call centers in Senegal before but chose to migrate to Morocco since payment was much higher there.

11 Like employment practices, working conditions vary a lot between centers and many interviewees mention the routine they feel from their daily work. Adding to the 
routine, a major concern mentioned by interviewees is the stress they experience regularly. In order to reach the target number of sales or successful calls that call agents are required to do, supervisors closely monitor the activities of subordinated staff and immediately give feedback or ask for personal meetings if they are not satisfied by communication techniques or sales numbers. Some supervisors send messages with feedback and suggestions to the screen of a call agent while he or she is talking to a client. This constant control creates a feeling of stress to employees, especially if supervisors mention that they might be released if sales figures do not go up.

12 Job stability varies and depends, next to an employee's sales ability, on the center. Some Senegalese migrants who have work contracts and are employed in big and wellknown centers that have long time relationships with their partner companies in Europe have had their jobs for several years and are likely to keep it. Other interviewees who used to work in call centers that do not give proper contracts report about being laid off with one day's notice and being asked to write a letter of resignation themselves if they wish to receive the last month's salary.

13 For some migrants, however, their main concern is to keep the job they started and getting their salary at the end of the month. Specifically in what are commonly called «small centers" in Casablanca, i.e. centers that are known to accept various nationalities without giving contracts to their employees, migrants report about difficulties of staying employed. When starting a new job in a call center, workers usually get a short training on techniques how to talk to their potential customers on the phone and about the product they are going to sell.

14 At times, workers do the training and start their calls to potential customers but are fired after only a few weeks, sometimes without receiving any payment at all or a lower sum than was agreed on originally. It is obvious that centers take advantage of the informal employment situation and fire as they like without regarding workers' rights or the personal situation of their employees. Some migrants continue searching for a stable call center jobs for months, starting in various centers and being sent off after the training or a few weeks work.

\section{Signs of segmentation?}

15 How does this snapshot of migrants' work in Morocco relate to explanations on labour market integration in the literature? One approach to explain minorities' integration into the labour market is that of labour market segmentation and of dual labour markets. Processes of labour market segmentation refer to the fact that people's chances of getting jobs are not equal and do not only depend on their human capital but also their gender, race, ethnicity and legal status.

16 Some have defined segmentation as «...the failure of the labour market to treat its participants even-handedly, in that it accords significantly different opportunities to otherwise comparable people » (Ryan 1984, in Leontaridi 1998 p. 77).

17 One of the well-known predecessors of the segmentation approach is Micheal Piore (1979) who posited that international migration is caused by a permanent demand for immigrant labour that is inherent to the economic structure of developed countries. In his studies on the functioning of labour markets and migrants' positions within them, 
Piore draws on the concept of dual labour markets and combines it with several other arguments. The dual labour market hypothesis posits that the labour market is split into a capital intensive primary sector and a labour intensive secondary sector - which gives rise to a divided labour market and creates distinctions among workers. The primary sector of the labour market is characterised by stable jobs where career advances are possible. Jobs in the secondary sector are unsecured and usually lie at the bottom of the job hierarchy. Jobs that migrants are concentrated in tend, according to Piore, to be unskilled, low paying and to carry inferior social status. They often involve hard or unpleasant working conditions, rarely offer chances of advancement toward better-paying, more attractive job opportunities and are usually performed in an unstructured work environment, involving informal relationships between supervisor and subordinate.

While today the idea is regarded as too simplistic and migrants are thought to be found in different labour markets that are part of one continuum, it is Piore's understanding of the coexistence of lasting rates of unemployment together with a demand for migrant labour and his explanations about why migrants can be found in these jobs that seem interesting in the Moroccan case. In order to further explain segmentation phenomena, Piore draws on migrants' motivations: while native workers are associated with motivational problems in these jobs since they carry little prestige and give a small salary, migrant workers do not necessarily face the same problem, since they come as target earners and, in the beginning of their migratory career, keep the origin country as social reference.

19 The un employment in Morocco has been high for many years, specifically among the youth, but the economy asks for foreign workers, specifically if we look at call centers (and some other areas like the construction sector). Jobs in call centers, as recruiters describe their experiences, are not seen as proper jobs by Moroccans and are often not accepted as a good way of breadwinning.

20 Some university graduates refuse jobs as call center agents. Migrants, many of whom dispose of a university degree make their way to Morocco in order to do this work and can be considered target earners. Many migrants have a specific goal in mind and have a family in their origin country that depends on them or don't have any family support to ensure their survival in Morocco.

21 The working conditions in some centers recall what Piore describes as secondary sector jobs : they involve unpleasant working conditions, do not dispose an outlook for career advances and are unsecured, mainly due to the legal situation for foreign workers. However, this is not the case in all centers and specifically Senegalese nationals can be found in more secure positions where, on top of regular contracts, advancement to a better position within the company is possible.

22 A point that is specific to the Moroccan setting is that of language in call center work. Unlike the jobs that Piore refers to in his work and migrant jobs that are often taken as examples in other works referring to segmentation theory (cleaning, jobs in hotels, nursing), call center work requires some skills that are not a given ability for all Moroccans, i.e. fluency in the French language. Call center staff in most cases does not require specific diploma and high school graduation (baccalauréat) is not systematically asked for, however, fluent French is a must in the overwhelming part of call centers. 
While schooling in (francophone) sub-Saharan countries is exclusively in French and French language fluency is therefore not considered a special skill, this proves to be different in Morocco where schooling is overwhelmingly in Arabic. The question is in how far we can qualify call center work as low skilled as is usually the case with jobs analysed in segmentation approaches. We should also ask whether this specificity of the French language in this setting is linked to some positive stigmatisation of subSaharan migrants. Stigmatisation is often seen as one factor that contributes segmentation and the concentration of migrants in certain jobs. Among call center recruiters in Morocco, sub-Saharan migrants seem to have the reputation of speaking good French which could contribute to migrants being easily recruited in call centers. Call center work in Morocco also does not figure among the lowest paid jobs as is the case with the jobs analysed and argued by Piore with regard to native workers' motivation. The average salary is usually around 3500 dirhams (if centers pay as promised) while the minimum salary is about 2200 dirhams. It needs to be taken into account if we want to analyse motivational factors of employees and social status of the job.

\section{BIBLIOGRAPHIE}

Y. El Wazani, M. Souaf, « La création d'emplois par les investissements directs étrangers au Maroc : un apport limité à la réduction du chômage et des flux migratoires ", Autrepart, 37, 2006, p. 19-35.

A. Kubal, « Conceptualizing semi-legality in migration research », in Working Papers, Paper 58, Oxford, International Migration Institute, 2012.

M.-R. Leontaridi, « Segmented labour markets : Theory and evidence ", Journal of economic surveys, $12(1), 1998$, p. 63-101.

M.-J. Piore, Birds of passage. Migrant labour and industrial societies, Cambridge, London, New York, Melbourne, Cambridge University Press, 1979. 


\title{
Loi sur l'entrée et le séjour des
} étrangers au Maroc : les conditions pour résider régulièrement au Maroc

\author{
Nisrine Eba Nguema
}

1 L'immigration désigne l'entrée dans un pays de personnes étrangères pour y séjourner à plus ou moins long terme. Selon la rapporteuse spéciale des Nations Unies, trois catégories de migrants sont identifiables: «les personnes qui se trouvent hors du territoire de l'État dont elles possèdent la nationalité ou la citoyenneté, mais qui ne relèvent pas de la protection juridique de cet État; les personnes qui ne jouissent pas du régime juridique général inhérent au statut de réfugié, de résident permanent, de naturalisé ou d'un autre statut octroyé par l'État d'accueil; les personnes qui ne jouissent pas non plus d'une protection juridique générale de leurs droits fondamentaux en vertu d'accords diplomatiques, de visas ou d'autres accords" (Rodriguez Pizarro, 2002). Il s'agit d'un phénomène très ancien qui s'est développé pour des raisons de survie, de rapprochement familial, de travail, d'études, d'avantages fiscaux ou de santé.

Le Maroc n'échappe pas à la donne mondiale. Recevant depuis longtemps des migrants de différentes origines, et en particulier européens, il est devenu, depuis quelques années, un pays de destination de nouvelles migrations. Si certains migrants s'y installent après avoir tenté d'atteindre sans succès l'Europe, d'autres optent pour le Maroc comme destination. Le Maroc facilite l'immigration de certaines catégories d'étrangers, notamment en concluant des accords de libre circulation comme dernièrement avec le Gabon (projet de loi $n^{\circ} 17-14$ ) ou en augmentant le nombre de places octroyées aux étudiants étrangers dans ses universités.

3 À ce titre, quelles sont les conditions prévues par la loi pour s'installer au Maroc ? Sontelles empreintes de cette volonté du Maroc d'accueillir une population cosmopolite ? La loi n 02-03 (2003) relative à l'entrée et au séjour des étrangers au Royaume du Maroc, à l'émigration et à l'immigration irrégulière et son décret d'application n 2-09-607 
constitueront les principaux outils de cette étude. Il sera question d'analyser les conditions d'acquisition, de perte, de renouvellement et les sanctions liées à l'absence de titres de séjour.

4 Dans le cadre de cette contribution, l'analyse de ces textes a été complétée par des questionnaires remplis par des étrangers (étudiants des universités publiques et travailleurs) afin d'analyser leur vécu dans le cadre de cette procédure. Ces questionnaires à questions ouvertes et semi-directes ont été soumis à une cinquantaine d'étrangers de différents pays entre mars et juin 2014, afin de recueillir leurs impressions et difficultés.

5 Ainsi, dans une première partie, il sera question de l'analyse des conditions de séjour régulier au Maroc, puis en seconde partie, des cas de refus ou d'exclusion du statut de résident.

\section{Les conditions du séjour régulier au Maroc}

6 De manière générale, les articles 3 et 4 de la loi 02-03 soumettent les étrangers traversant les frontières marocaines à un contrôle exercé par les autorités. Tandis que l'article 3 porte sur le contrôle de validité du passeport et du visa, l'article 4 prévoit un contrôle dont la nécessité, et dans une certaine mesure, les contenus sont laissés à l'appréciation des autorités. Ce contrôle concerne la vérification des ressources financières des immigrés, leurs motifs d'entrée et les garanties de leur retour au pays. Dans le cas où l'intéressé ne remplit pas ces conditions, il peut se voir refuser l'entrée sur le territoire et être renvoyé immédiatement. Toutefois, l'article 4 prévoit certains droits à l'étranger dont l'entrée sur le territoire est refusée, tels que ceux de prévenir la personne qui devait l'accueillir, avertir son consulat et prendre contact avec un avocat.

7 L'étranger remplissant les conditions d'entrée est admis à séjourner sur le territoire marocain pendant la durée de validité de son visa. Lorsque son séjour est supérieur à trois mois, il doit avant l'expiration de son visa ou avant quatre-vingt-dix jours s'il est exempté de visa, se rendre auprès de la préfecture de police de sa ville de résidence pour accomplir les formalités permettant l'établissement d'un titre de séjour. Dans la pratique cependant, il s'agit d'une disposition qui n'est pas toujours observée par les autorités marocaines et par les étrangers. Selon nos constatations, la demande intervient régulièrement après l'expiration du visa. Les étrangers interrogés ont confirmé qu'ils ne procédaient à cette formalité qu'entre trois et quatre mois après leur entrée au Maroc et qu'ils n'avaient jamais été sanctionnés à ce titre.

8 Ce retard est souvent lié aux difficultés à fournir les documents exigés. Au moment de l'établissement du titre de séjour, l'étranger peut être amené, soit à établir une carte d'immatriculation, s'il est résident de courte durée ou étudiant, soit une carte de résidence, s'il est installé depuis au moins quatre ans. La loi n ${ }^{\circ}$ 02-03 prévoit à l'article 17 que ce titre n'est délivré qu'à certaines catégories d'étrangers pour une durée de dix ans, renouvelable. Il s'agit du/de la conjoint(e) de marocain(e), de l'enfant étranger ou apatride d'une mère marocaine, de ses ascendants étrangers et de ceux de son conjoint qui sont à sa charge. Sont également concernés l'étranger parent et tuteur ou représentant légal d'un enfant marocain, le conjoint et les enfants mineurs d'un étranger titulaire de la carte de résidence, le réfugié et l'étranger résidant régulièrement depuis dix ans. 
9 La carte d'immatriculation constitue donc le principal titre auquel tous les étrangers ont accès. S'agissant de la procédure d'établissement de ce titre, l'article 4 du décret d'application de la loi $n^{\circ} 02-03$ prévoit que les intéressés doivent remplir des formulaires et y joindre certaines pièces justificatives variant selon le statut de l'étranger. À ce titre, les formalités concernant l'établissement des titres de séjours sont devenues plus contraignantes depuis deux ans, et sont vécues par les étrangers comme un frein à l'immigration. Outre les formalités précédentes, l'intéressé doit désormais déposer une copie de sa carte consulaire, un certificat médical de non affection de maladies contagieuses et un extrait du casier judiciaire.

Lors de la première entrée au Maroc, le certificat médical et le casier judiciaire de l'étranger sont exigés afin de vérifier s'il présente une menace pour l'ordre public. Soulignons que selon l'article 25 de la loi $\mathrm{n}^{\circ} 02-03$, l'expulsion d'un étranger peut être motivée par un risque pour l'ordre public. Au-delà, les frais liés à l'établissement de la carte de séjour sont largement critiqués par les étudiants qui doivent désormais déposer un montant de 100 dirhams au moment de la remise du récépissé en remplacement du timbre fiscal de 60 dirhams, auxquels s'ajoutent les frais liés au certificat médical, au timbre du casier judiciaire, aux photos, aux légalisations de documents et aux frais de déplacement, soit 300 à 400 dirhams dépensés chaque année. Toutefois, la plupart des étrangers interrogés ont souligné que la nécessité de fournir un contrat de bail était le principal obstacle à leur immatriculation, car les propriétaires ne veulent ni «s'encombrer» de démarches administratives contraignantes, ni payer d'impôts pour la location de leur logement. S'agissant des autres catégories d'étrangers pouvant bénéficier d'un titre de séjour, il est plus facile de résider au Maroc au moyen de ses propres ressources financières qu'en tant que travailleurs ou conjoints de marocains. S'intégrer à chacune de ces catégories implique des procédures en amont qui ne sont pas aisément accessibles. S'agissant des étrangers qui souhaitent travailler au Maroc, il est très difficile pour eux de faire valider leur séjour au titre d'un emploi trouvé, car l'employeur souhaitant recruter un étranger doit obtenir une attestation dite ANAPEC prouvant que le profil recherché ne peut être trouvé auprès des demandeurs d'emploi nationaux (Khrouz, 2013). La procédure doit être menée dans les trois mois de leur entrée et nécessite deux publications d'annonces d'emploi dans deux journaux, l'un arabophone et l'autre francophone dont la liste est fixée au niveau national. à ce titre, trois travailleurs européens ont précisé que cette formalité se chiffrait à près de 5000 dirhams. Un montant qui n'encourage pas les employeurs à recruter des travailleurs étrangers. Certaines catégories d'étrangers sont cependant dispensées de cette attestation selon l'arrêté du département de l'emploi $\mathrm{n}^{\circ} 05.350 \mathrm{du} 9$ février 2005. Par ailleurs, le mariage avec un(e) marocain(e) est également très encadré, car il est soumis à une autorisation du juge. Une enquête peut être menée par la police afin de s'assurer de la situation administrative régulière et financière du futur conjoint et $\mathrm{du}$ "bien-fondé » du mariage. De plus, la conversion à l'Islam est obligatoire, lorsque la conjointe est musulmane.

11 Une fois que l'étranger a fourni les documents demandés, il lui est remis, selon l'article 5 du décret d'application de la loi n 02-03, un récépissé qui doit être renouvelé tous les trois mois jusqu'à ce qu'il soit statué sur sa demande. En pratique, les étrangers interrogés ont précisé que le récépissé était remis dans un délai de deux semaines et la carte d'immatriculation entre un et trois mois. La demande de renouvellement de la carte d'immatriculation doit intervenir dans les deux semaines qui suivent l'expiration 
du titre de séjour dont la validité est généralement d'un an, sous peine de reconduite à la frontière, d'amende et/ou d'emprisonnement. Toutefois, en pratique, la plupart des étudiants étrangers procèdent au renouvellement de leur titre un à trois mois après son expiration du fait des nombreuses formalités à accomplir. Il arrive même que certains étudiants passent près d'une année sans renouveler leur carte d'immatriculation. Cette situation concerne surtout les étudiants qui ont déménagé et qui n'arrivent pas à trouver un logement avec un contrat de bail.

Dans certaines conditions, l'étranger peut se voir refuser un titre de séjour et être contraint de quitter le territoire marocain ou se retrouver en séjour irrégulier.

\section{L'étranger « dangereux » ou en situation irrégulière}

L'entrée sur le territoire marocain peut être refusée à toute personne ne présentant pas les pièces administratives ou les justificatifs demandés ou qui fait l'objet d'une mesure d'expulsion ou d'une décision judiciaire d'interdiction d'entrée sur le territoire en vertu de l'article 4 de la loi $n^{\circ} 02-03$. Pour ce qui est du refus de délivrance ou de renouvellement d'un titre de séjour, cette loi prévoit la possibilité pour l'étranger concerné de formuler un recours devant le président du tribunal administratif dans le délai de quinze jours suivant la date de notification de la décision du refus ou du retrait du titre. Dans le cas où une décision de reconduite à la frontière est prise, l'intéressé peut dans les quarante-huit heures suivant la notification, demander l'annulation de cette décision au président du tribunal administratif qui statut dans un délai de quatre jours. Selon l'article 23, l'audience est publique et l'étranger peut avoir accès au dossier, à un interprète et à un avocat. Dans la pratique cependant, certains étrangers sont reconduits à la frontière sans avoir pu exercer de recours, soit parce qu'ils n'ont pas reçu de notification, soit du fait du manque d'information concernant la procédure à suivre.

Dans tous les cas, l'étranger qui n'a pas de titre de séjour en règle - à l'exception des réfugiés reconnus par l'Agence des Nations Unies pour les Réfugiés - doit quitter le territoire dans un délai de quinze jours (article 11), sous peine :

- d'être reconduit à la frontière, s'il est entré irrégulièrement sur le territoire, si son visa a expiré et qu'il s'est maintenu sur le territoire marocain, s'il n'a pas procédé au renouvellement de son titre de séjour ou s'il est condamné pour contrefaçon ou falsification du titre de séjour (article 21);

- d'être expulsé du territoire marocain, s'il constitue une menace grave pour l'ordre public (article 25).

15 À ce titre, la loi $n^{\circ}$ 02-03 insiste sur «l'étranger qui constituerait une menace pour l'ordre public », en y faisant référence aux articles $4,14,16,21$ et 25 . Il n'y a toutefois aucune définition ou précision par rapport au type de danger dont il est question. C'est le juge administratif qui a précisé dans un arrêt de 2005 que l'expulsion ne peut être prononcée qu'à l'égard des étrangers coupables de crimes constituant un «danger effectif ", tels que le meurtre, le proxénétisme, les coups et blessures volontaires, le trafic de drogue, l'occupation illégale de lieux, la prise d'otages, le transport d'armes ou le vol avec voie de faits.

16 Enfin, différentes sanctions sont prévues à l'égard des étrangers qui sont en situation irrégulière ou qui ne respectent pas les conditions fixées par la loi n 02-03. À ce titre, 
l'article 42 dispose que l'étranger qui s'est maintenu sur le territoire marocain au-delà de la durée de son visa encourt une amende de 2.000 à 20.000 dirhams et une peine de prison d'un mois à six mois ou l'une des deux peines. En cas de non renouvellement du titre de séjour dans le délai imparti, sans justificatif valable, l'étranger doit s'acquitter d'une amende de 3.000 à 10.000 dirhams et encourt une peine de prison d'un mois à six mois, ou l'une des deux sanctions (article 44). Aussi, l'étranger qui change de résidence et ne le déclare pas à la préfecture de police de son lieu de résidence est punissable d'une amende de 1.000 à 3.000 dirhams (article 47).

17 En définitive, le cadre normatif en vigueur au Maroc vise plus à autoriser l'étranger à séjourner pendant une courte durée, qu'à y résider. Les conditions liées au travail, au mariage et les contraintes religieuses ont tendance à décourager les étrangers à vivre de manière permanente au Maroc. De nombreux étrangers ont d'ailleurs souligné le caractère " méfiant », « dur ", «fermé », « non accueillant » des autorités marocaines qui sont chargées de les recevoir lors du dépôt du dossier concernant l'établissement ou le renouvellement du titre de séjour.

18 Toutefois, la loi marocaine apparait plus sévère dans les textes que dans la pratique. De nombreux étrangers ont à ce sujet souligné le fait de pouvoir circuler librement sans crainte, même lorsqu'ils ne sont pas en règle. De même, la condition relative à la nécessité de déclarer automatiquement sa nouvelle résidence est peu connue par les étrangers qui, pour certains, continuent à déclarer leur ancienne résidence ou déclarent leur nouvelle adresse seulement au moment du renouvellement du titre de séjour. En somme, il existe une rigueur ou une souplesse apparente en fonction de la préfecture de police d'accueil de l'étranger, avec un différentiel apparent selon les étrangers concernés.

\section{BIBLIOGRAPHIE}

Code relatif à l'entrée et au séjour des étrangers au Royaume du Maroc, à l'émigration et à l'immigration irrégulière, loi nº2-03, Bulletin officiel, $n^{\circ} 5162$ du jeudi 20 novembre 2003.

Décret $n^{\circ}$ 2-09-607 pris pour l'application de la loi n 02-03 relative à l'entrée et au séjour des étrangers au Royaume du Maroc, à l'émigration et à l'immigration irrégulières, avril 2010.

G. Rodriguez Pizarro, Special Rapporteur of the Commission on Human rights, Human rights of migrants, A/57/292, Note by the Secretary- General, 9 August 2002.

N. Khrouz, « "Politiques" publiques et présence des étrangers au Maroc », Blog Farzyat du CJB, 30 août 2013. 


\title{
De la respécification de la notion de transit
}

\author{
Nadia Khrouz
}

1 Le Maroc, important pays d'émigration, ne s'est que récemment perçu comme pays de transit puis d'immigration. Cette question de la migration ou des migrants «de transit » a pris de l'importance dans les années 2000, rendue particulièrement visible à l'occasion d'événements comme le drame de Ceuta et Melilla en 2005.

2 Utilisée de manière récurrente par la presse et les discours politiques, jusqu'à en constituer une catégorie qu'il semblait difficile de réinterroger, les migrants en transit ont été institués en population à part entière, tout en ne désignant quasiment que ceux qualifiés de "subsahariens", induisant le risque d'une stigmatisation de cette population. Le transit est appréhendé comme séjour temporaire dans un ou plusieurs pays en vue d'atteindre une autre destination plus ou moins lointaine.

3 La notion de transit reste donc bien vague et renvoie à des situations diverses. Être en transit sous-tend, pour la personne concernée, le projet de ne pas s'établir sur un territoire. Elle interroge de fait les projets migratoires des étrangers au Maroc, dans un contexte d'une immigration diversifiée et complexe à appréhender. Je souhaiterai ici revenir sur la catégorie du transit telle que constituée au Maroc et sur les modalités par lesquelles celle-ci a été promue, a influé sur le traitement juridique des mobilités et est rendu visible au travers des pratiques, notamment discursives, de certains acteurs de l'administration et de la justice marocaines.

\section{Des « migrants en transit » vers l'Europe}

4 La mise en place de l'espace Schengen et de dispositifs de contrôle à l'entrée dans cet espace ont amené certains pays frontaliers de l'Union Européenne (UE) à être considérés comme espaces de transit par lesquels passeraient les migrants pour rejoindre le territoire européen. Ces pays frontaliers de l'UE ont alors renforcé le contrôle à leurs frontières. 
5 Dans le transit de l'un de ces État vers l'UE, l'attention était focalisée vers les restrictions à atteindre irrégulièrement le continent européen, d'abord via l'émigration irrégulière pour l'Europe, puis par le durcissement des contrôles à l'entrée de ces pays associés au transit des migrants. Différentes recherches soulignent l'européocentrisme marquant l'émergence et l'importance prise par cette catégorisation de «transit » qui s'intègre à la représentation du territoire européen et de son voisinage (Collyer, Düvell and de Haas, 2012).

6 L'argument du transit a de plus été utilisé, dans le contrôle des migrations, comme monnaie d'échange de l'aide au développement, du rapprochement avec l'UE et intégré dans différentes négociations notamment économiques, commerciales et liées à l'accès de nationaux au territoire européen.

7 L'intérêt porté à cette migration de transit vers l'Europe et les financements accordés par les partenaires européens ont de fait orienté nombre de programmes, notamment d'ONGs ou de recherche vers la question du transit et des migrants dits "clandestins " au Maroc, bloqués dans leur tentative de se rendre en Europe.

8 La présence de migrants est régulièrement justifiée par le projet de se rendre en Europe et alors présentée comme "par défaut». Le postulat posé est donc que le Maroc n'intéresserait pas ces étrangers qualifiés de « migrants ». L'image d'un afflux massif de migrants subsahariens en transit pour rejoindre l'Europe "coûte que coûte » a contribué à présenter les États maghrébins comme œuvrant pour soulager l'Europe et non pas pour gérer une migration qui les concernerait aussi, temporairement ou à plus long terme.

Ce rôle de "gendarme de l'Europe " a soutenu la déresponsabilisation des États concernés et de certains de leurs acteurs, institutionnels et non-institutionnels. Bien que le nombre d'étrangers constitue une proportion minime de la population et ne fasse pas encore réellement l'objet d'un intérêt global, le Maroc est bien aussi un pays d'immigration, que cette focalisation sur un transit présumé a contribué à camoufler.

Les recensements et différentes données officielles attestent de la présence d'autres catégories d'étrangers installés au Maroc, comme il en est des étrangers ayant obtenu un titre de séjour au Maroc:

\begin{tabular}{|l|l|l|l|l|}
\hline & 2002 & 2003 & 2005 & 2010 \\
\hline Afrique & 25262 & 23932 & 25486 & 28021 \\
\hline dont Algérie & 14392 & 11452 & 11581 & 11066 \\
\hline Europe & 28053 & 27682 & 28203 & 32518 \\
\hline dont France & 17175 & 17175 & 17792 & 21857 \\
\hline Asie & 5946 & 6414 & 6946 & 9584 \\
\hline Autres & 1576 & 1651 & 1713 & 4193 \\
\hline Total & 60837 & 59679 & 62348 & 74316 \\
\hline
\end{tabular}


11 Au-delà du peu d'importance accordé à la diversité des présences étrangères, les possibilités légales et concrètes de se stabiliser au Maroc ont été peu interrogées. Pourtant, l'étranger en transit est non seulement l'étranger de passage, se servant du Maroc comme «tremplin» ou "salle d'attente» avant d'atteindre le continent européen, mais également celui qui ne veut pas ou n'a pas pu se stabiliser et poursuit sa migration vers d'autres destinations. Un détour par les perspectives d'entrée régulière et de régularisation semble important.

\section{Le « transit » dans et par le droit positif}

En novembre 2003 est adoptée la loi $n^{\circ} 02-03$ «relative à l'entrée et au séjour des étrangers au Maroc, à l'émigration et à l'immigration irrégulières » dans un contexte de négociations pour que le Maroc contrôle davantage la migration sur son territoire, considérée comme susceptible d'être répercutée sur l'Europe. La notion de "transit » n'apparaît pas en tant que telle dans la législation marocaine. Cependant, certaines dispositions semblent, sans l'expliciter, y renvoyer. La loi no 02-03 dissocie, dans le cadre des sanctions pénales prévues, l'entrée et le séjour irréguliers des étrangers (titre 1 , chapitre 8), de l'émigration et l'immigration irrégulières (titre 2). Cette distinction instaure, selon la juriste Delphine Perrin, une confusion :

«L'immigration est entendue en tant qu'entrée sur le territoire, en vue d'un passage. Elle est liée à une volonté de sortie vers l'Europe » (Perrin, 2008).

13 Les conditions d'entrée et de séjour sur le territoire peuvent rendre l'installation plus ou moins accessible à certaines catégories d'étrangers et alimenter un transit qui n'est pas toujours initialement voulu. Si le Maroc a signé différentes conventions bilatérales de dispense de visa pour des séjours courts, cela ne signifie pas que tous les ressortissants de ces États peuvent y entrer librement. Outre l'obligation du passeport et du visa (ou la dispense de visa), le contrôle à la frontière peut porter sur les moyens d'existence, les motifs de la venue, les garanties de rapatriement (art. 4), et l'accès au territoire peut être refusé à tout étranger dont la présence constituerait une menace pour l'ordre public. Le manque de définition précise de cette notion alimente le pouvoir discrétionnaire de l'administration aux frontières, qui, en outre, a également le pouvoir d'annuler le visa de l'étranger qui « exerce au Maroc une activité lucrative, sans avoir été régulièrement autorisé, ou s'il existe des indices concordants permettant de présumer que l'intéressé est venu au Maroc pour s'y établir» (art. 40). L'opacité des normes appliquées quant à certains contrôles, concernant notamment les étrangers catégorisés comme "à risques" (" migratoire » et "terroriste " notamment) et les pratiques de corruption contribuent à entraver l'entrée de certains étrangers sur le territoire, quand bien même ils en remplissent les conditions formelles. Au-delà, la responsabilité imposée aux transporteurs de prendre en charge les étrangers ne remplissant pas (visiblement) les conditions d'entrée a amené au développement de pratiques de contrôle en amont et de refus d'embarquer qui n'ont pas toujours été légalement justifiées (art. 48).

14 À cela s'ajoutent les difficultés et l'opacité entourant l'obtention du visa marocain. La publication du décret $n^{\circ}$ 2-09-607 du 1 avril 2010, qui prévoit la demande du visa correspondant au motif de venue en amont de l'arrivée au Maroc, pourrait aussi durcir les conditions d'entrée et d'installation. Si les conditions d'entrée prennent de 
l'importance, c'est que l'entrée régulière conditionne la régularisation du séjour et l'accès à différentes procédures.

L'article 17 de la loi n 02-03 conditionne ainsi la délivrance d'une carte de résidence à l'entrée et au séjour régulier. Cette condition d'entrée régulière se retrouve dans les procédures d'autorisation de mariage avec un(e) marocain(e), d'accès au marché du travail ou de création d'une entreprise. Le séjour irrégulier sur le territoire prive l'étranger de l'accès à différents droits ou services (scolarisation, dépôt de plainte, etc.), au-delà des sanctions pénales (amende et/ou prison) et/ou administratives (reconduite à la frontière) prévues par la loi et de la vulnérabilité induite par ce statut administratif irrégulier. Le caractère restrictif de l'accès à certaines procédures, liées à des conditions rigoureuses posées par le droit positif et/ou à des difficultés pratiques, peuvent rendre les perspectives de stabilisation précaires (Khrouz, 2013). À cela s'ajoute la marge de manœuvre laissée dans certains domaines à l'administration, qui nous incite à orienter nos regards vers l'impact des catégorisations d'appartenance sur les pratiques du droit.

\section{La catégorie de « transit » comme qualification juridique}

16 La notion d'« étranger en transit » renvoie donc à différentes catégories d'étrangers. Si le transit n'apparait pas explicitement dans la législation marocaine, son recours s'est développé dans la pratique comme un référentiel permettant de qualifier et de catégoriser certains étrangers au Maroc. Le considérer s'intègre dans une démarche d'appréhension du droit en action. Je m'appuierai sur deux situations particulières de rencontre de l'étranger avec la justice dans l'une des premières étapes de cette rencontre : les procès-verbaux (PV) d'écoute de la police.

Celui que nous surnommerons Francis est entré régulièrement au Maroc avant de se trouver en situation administrative irrégulière à la fin de ses trois mois de séjour «touristique ». Deux ans plus tard, il est interpellé en accompagnant une femme à l'aéroport. Dans un courrier adressé au chef du service préfectoral de la police judiciaire, le commissaire de l'aéroport signale que Francis a «probablement servi de passeur ». Dans son premier PV d'écoute, Francis dit séjourner au Maroc de manière irrégulière parce que (selon le $\mathrm{PV}$ ) : «Je ne suis pas parvenu à avoir des documents pour établir ma carte de résidence ».

Pour l'officier de police, «le citoyen guinéen prénommé (Francis) [...] réside sur le territoire national de façon non réglementaire [...] en attendant que se présente à lui une occasion d'émigrer vers l'Europe ». Par ce renversement de catégorisation, l'affaire prend une place dans le registre de la lutte contre la migration irrégulière vers l'Europe et Francis passe d'étudiant n'étant pas parvenu à régulariser sa situation à « clandestin en transit ». Ce changement de catégorie accompagne donc une évolution des raisons ayant conduit à son irrégularité administrative, de ses motivations et de son intentionnalité qui le placent alors d'emblée comme déviant. Cela met en valeur non seulement l'importance de la pré-qualification et de l'assignation attribuées à l'inculpé, mais aussi le jeu moral de catégorisation qui influe sur la manière dont sera appréhendée la situation dans le cadre de la décision administrative et judiciaire. Si Francis n'est condamné par le juge «qu'à » de la prison avec sursis et à une légère 
amende, il sera en parallèle éloigné vers la frontière algéro-marocaine, pourtant officiellement fermée.

Dans la seconde situation, le projet de transit, dont cinq réfugiés reconnus par le HautCommissariat des Nations Unies pour les Réfugiés (UNHCR) semblent suspectés, justifie l'inculpation pour séjour irrégulier dont ils font l'objet. C'est ce qui ressort des PV de ces réfugiés inculpés pour "rassemblement armé, rébellion et violence contre un fonctionnaire public» et "séjour irrégulier». Dans leur PV d'interrogatoire, les réfugiés inculpés reviennent, en lien avec les probables questions posées par les officiers de police judiciaire, sur :

- Leur parcours migratoire, en soulignant leur volonté originelle de transiter par le Maroc pour rejoindre l'Europe et le caractère économique de leur exil : « à la fin de 2008, j'ai quitté mon pays pour immigrer en Europe à cause des problèmes économiques que connaît la Côte d'Ivoire ".

- L'entrée irrégulière sur le territoire marocain en recourant à un passeur : «Après avoir pris contact avec une personne sur place, qui nous a aidé moyennant une somme de 100 euros, nous avons traversé la frontière vers le Maroc ».

- La similitude de leur stratégie avec « le reste des migrants irréguliers » : « Après être entré au Maroc, je suis resté, comme le reste des migrants irréguliers dans une forêt au Nord du Royaume afin de préparer mon voyage à l'intérieur du Royaume du Maroc en attendant l'occasion de migrer vers l'Europe ».

- Les motivations de leur demande d'asile : «Afin de pouvoir circuler librement, je me suis adressé au Haut-Commissariat des Nations Unis pour les Réfugiés pour obtenir la carte de cette institution, sachant que je n'appartiens à aucun parti politique ou milice anti- gouvernementale ivoirien, mais c'est une manœuvre inventée par les migrants clandestins pour qu'ils puissent vivre dans les pays où ils séjournent ».

- Leur séjour « illégal » au Maroc : « Je vous confirme que je vis au Maroc de manière illégale, comme tous les autres migrants africains et que je ne possède aucun document officiel [...] Je sais que je séjourne au Maroc de manière illégale ».

20 Ces réfugiés y apparaissent comme de "faux réfugiés" qui auraient basé leurs demandes d'asiles sur des informations mensongères en vue de transiter "plus sereinement » par le territoire marocain. Les questions n'apparaissent pas dans le PV. Il est donc difficile d'envisager l'orientation donnée par les officiers de police à l'interrogatoire, ni même le différentiel entre ce que dit l'inculpé et ce qui est retranscris par l'officier de police dans le PV. L'extrême proximité des propos de ces cinq inculpés et les amalgames faits avec "tous les autres migrants africains" interpellent l'élaboration même de ces PV et leur constitution téléologique.

\section{Une nouvelle politique migratoire marocaine : vers une nouvelle perception de la migration?}

21 Si l'actualité autour de la migration au Maroc continue d'être focalisée sur la « figure, largement médiatisée mais réductrice, du subsaharien errant sur les routes, acculé à recourir à la charité publique ou s'attaquant régulièrement et en groupe, aux frontières des deux enclaves espagnoles » (CNDH, 2013), la diversité des présences d'étrangers est aujourd'hui rendue plus visible. Le constat est fait de la présence d'étrangers européens, asiatiques ou des pays arabes, installés au Maroc sous différents statuts administratifs et à plus ou moins long terme. En septembre 2013, le soutien royal à une 
nouvelle politique migratoire et à une opération de régularisation d'étrangers de différentes nationalités en séjour irrégulier sur le territoire, constitue un tournant dans la posture du Royaume comme pays d'immigration. Pourtant, depuis son lancement, cette opération de régularisation est régulièrement présentée comme concernant les dits subsahariens clandestins, et une grande partie des étrangers au Maroc notamment en situation administrative irrégulière - ne semblent pas être visés directement par les programmes prévus par cette nouvelle politique. Dans les faits, l'adoption de nouvelles dispositions législatives et la mise en place de certains programmes impacteront pourtant formellement l'ensemble des étrangers au Maroc. Cela interroge les dispositions de la population marocaine et des différents acteurs intervenants sur ces questions à prendre en compte l'ensemble de la réalité migratoire au Maroc, à l'envisager dans sa complexité, intégrant catégorisations de sens commun, catégorisations administratives et diversités de situations vécues par les étrangers au Maroc. Il semble important d'entamer un travail de respectification de différentes notions et catégories, trop souvent admises a priori, comme il en est du migrant en transit, du clandestin ou de l'étranger en séjour irrégulier. Un retour sur ces catégorisations, rattachées à l'étranger ou à la migration, ainsi que sur le déploiement pratique des procédures administratives et judiciaires permettraient une meilleure analyse des modalités de mise en œuvre du droit des étrangers suite à cette «nouvelle politique migratoire ", au travers des perspectives de pérennisation du séjour pour les étrangers et de la place donnée aux dispositions juridiques formelles.

\section{BIBLIOGRAPHIE}

M. Collyer, F. Düvell, H. De Haas, « Critical approaches to transit migration », Population, Space and Place, $2012, \mathrm{n}^{\circ} 18$, p. 407-414

D. Perrin, «L'étranger rendu visible au Maghreb - la voie ouverte à la transposition des politiques juridiques migratoires européennes ", Revue Asylon(s), n 4, mai 2008, Internationalisation de la xénophobie en France.

N. Khrouz, «"Politiques" publiques et présence des étrangers au Maroc », 30 août 2013, blog Farzyat, CJB.

« Foreign population residing in Morocco by country of nationality, 1936-2010 », CARIM (Consortium for Applied Research on International Migration). Source : Direction Générale de la Sûreté Nationale (DGSN), années 2002, 2003, 2005 et 2010.

CNDH, Étrangers et droits de l'Homme au Maroc : pour une politique d'acte et d'immigration radicalement nouvelle, conclusions et recommandations du rapport septembre 2013. 


\title{
Migration au Maroc et faits du "printemps arabe » : cas des Syriens
}

\author{
Bouchra Sidi Hida
}

1 Les soulèvements populaires au Maghreb et au Machrek ont contraint un certain nombre de personnes à la mobilité hors de leurs frontières. Les uns, ont choisi de traverser vers Lampedusa pour atteindre l'Europe. Les autres, ont préféré rejoindre des proches ou amis vers les Amériques (USA, Canada) ou vers l'Australie. Parmi les Syriens, certains se sont exilés en Turquie, au Liban ou en Jordanie, fuyant l'insécurité et la violence. D'autres se sont dirigés vers le Maroc, devenu aussi un pays de destination pour des Libyens et des Égyptiens. Cette communication s'appuie sur une recherche qui se penche sur les profils et parcours des migrants syriens arrivés au Maroc dans ce contexte pour y demander l'asile. Elle s'intéresse également à la stratégie du Maroc face à la migration syrienne et à l'impact de celle-ci sur la société marocaine. L'étude, menée à Marrakech, Rabat et Oujda, concerne des Syriens en « situation administrative irrégulière " vis-à- vis des autorités marocaines.

2 S'appuyant sur une approche sociologique de la migration, elle a été réalisée avec le concours de l'Institut de Recherche pour le Développement (IRD) et le Centre d'Études et de Recherches en Sciences Sociales (CERSS). Elle s'inscrit dans une démarche exploratoire et qualitative basée sur l'observation, une enquête de terrain et des informations issues d'articles de presse. Les entretiens semi-directifs ont visé une trentaine de Syriens, ainsi qu'une trentaine de Marocains afin de sonder leur opinion sur la présence des Syriens au Maroc. Les enquêtes ont eu lieu de mai à fin juillet 2014. Tous les Syriens rencontrés avaient déposé une demande d'asile auprès du Hautcommissariat aux réfugiés des Nations-Unies (UNHCR) à Rabat et attendaient une réponse. La majorité des personnes interrogées sont originaires de la région rurale de Hama, certains sont d'Alep ou de Damas. Au moment de l'enquête, les plus anciens de ces Syriens sont au Maroc depuis deux ans. 


\section{Itinéraires et profils migratoires}

$3 \quad$ S'inspirant des mouvements de protestation tunisien (révolution du Jasmin) et égyptien (révolution du 25 janvier), l'appel à manifestation en Syrie a été lancé en février 2011 par des opposants syriens de l'étranger. Certains étaient très actifs sur les réseaux sociaux pour dénoncer les répressions que subissent des Syriens par le régime en place. Ils ont réussi à avoir la sympathie des internautes qui demandaient le départ du Président et une intervention occidentale en Syrie. Les mobilisations effectives n'ont cependant commencé que le 15 mars 2011. Plusieurs familles syriennes, des régions d'Alep, de Damas, de Homs et de Hama, mais également de la région kurde, ruinées, craignant d'être torturées ou massacrées, ont alors quitté la Syrie. Le nombre de Syriens ayant fui le pays a atteint presque 4 millions en avril 2015, d'après l'UNHCR. Un grand nombre de ces exilés s'est réfugié dans les pays frontaliers, qui constituent pour certains la première étape d'un périple incertain. Plusieurs familles syriennes se sont dirigées vers le Liban, d'autres vers la Turquie, la Jordanie ou l'Irak. La migration forcée des Syriens s'est accrue avec l'intensification de la violence et le conflit en Syrie. En avril 2015, l'UNHCR a enregistré 2,2 millions de Syriens exilés au Liban, en Égypte, en Jordanie et en Irak alors qu'ils sont 1,7 millions en Turquie. Ils représentent plus de 24055 exilés au Maghreb, d'après la même source. Le parcours migratoire est souvent guidé par des relations familiales, d'amitiés, professionnelles ou religieuses dont ces réfugiés peuvent profiter dans les pays de destination (ORSAM, 2015).

Les migrants syriens portent en eux le sceau de l'étrangeté et l'incertitude du futur, laissant derrière eux toute une histoire, leur vie mais également des membres de leurs familles et leurs biens. Les deux tiers des personnes interrogées se posent des questions sur le devenir des membres de leur famille restés en Syrie. A., 50 ans, au Maroc depuis un an et demi, explique: "Je remercie Dieu de notre présence ici et je remercie les Marocains pour leur aide, mais je ne peux m'empêcher de penser aux autres membres de ma famille qui sont restés au pays. Que deviennent -ils? De penser au pays ». Deux femmes et un homme ont même exprimé des remord vis-à-vis de ceux restés dans le pays et de leur devenir. La rupture avec leur passé crée chez ces exilés un morcellement de l'espace et du temps, une perte de repères.

5 La crise nationale syrienne semble s'installer dans la durée. Les causes de son émergence paraissent multiples et complexes. Au régime politique totalitaire instauré par l'ex-président Hafez el-Assad, s'ajoute la paupérisation des campagnes et l'exode vers les villes, ce qui a contribué à créer des clivages et des inégalités sociales. Cependant, les déplacements des Syriens sont majoritairement motivés par leur fuite du conflit armé. « Nous étions assiégés plusieurs semaines à Alep, entourés de morts, sans nourriture, ni secours, ni même possibilité de sortir de la ville, de peur d'être attaqués ou bombardés ", raconte R., 35 ans, rencontrée à Bab el Had à Rabat. « Nous avons fui parce que nous avons peur, ma sœur, des persécutions de 'Saffah », explique M., jeune syrienne, 20 ans, originaire de Hama. Elle est installée au Maroc avec sa famille depuis deux ans en attendant d'avoir une réponse de l'UNHCR concernant leur demande d'asile. Elle et sa sœur demandent de l'aide aux passants devant un feu rouge à Marrakech. En juin 2014, près de 1000 Syriens avaient déposé une demande d'asile auprès de l'UNHCR, sans obtenir le statut de réfugié (Bentaleb, 2014).

6 Une partie des Syriens en fuite ont choisi d'aller vers les pays de l'Afrique du Nord. Certains ont opté pour l'Algérie, du fait de la fréquence des liaisons aériennes assurées 
par la compagnie nationale et de la dispense de visa d'entrée dont bénéficient les Syriens en Algérie. D'autres ont choisi la Libye ou la Tunisie mais, depuis 2012, les relations diplomatiques entre Tunis et Damas se sont interrompues et les visas ne sont plus délivrés par les ambassades de Tunisie (Sphyar et al, 2014). D'autres encore ont préféré le Maroc, du fait de sa stabilité politique, de sa bonne réputation, des relations familiales et professionnelles existantes entre les deux pays et de l'annonce de la régularisation des migrants par les autorités marocaines. La possibilité de traverser le détroit de Gibraltar pour rejoindre l'Europe motive aussi la présence de certains Syriens au Maroc. Zineb explique: "On nous a assuré qu'à partir de Ceuta, il serait possible d'obtenir le statut de réfugié et d'entrer en Europe » (Jeune Afrique, 2014).

7 Dès le début du conflit, le Royaume du Maroc a soutenu le peuple syrien, d'abord par la mise en place, en août 2012, d'un hôpital au camp Jâafari en Jordanie. De plus, au début du conflit, le Maroc offrait la possibilité d'entrer au Maroc en facilitant l'octroi du visa via les ambassades. Soulignons également que des Syriens résidaient déjà légalement au Maroc avant 2011, et ce depuis plusieurs années. Ceux- ci semblent bien intégrés sur le marché du travail (dans les secteurs du bâtiment, de la restauration, etc.) et certains ont créé leur propre entreprise (restauration, commerce, forage). Leurs enfants sont le plus souvent inscrits dans des établissements scolaires publics ou privés, mais tous ne parviennent pas cependant à s'inscrire à l'école, pénalisés par la situation administrative irrégulière de leurs parents. Le français, deuxième langue au Maroc, pénalise également les enfants syriens habitués davantage à la langue anglaise. Certains d'entre eux accompagnent alors leurs mères pour demander la charité près des mosquées, des feux rouges et des espaces commerciaux ou vendent des produits à la sauvette. C'est le cas de W., enfant de 7 ans, qui demande de l'argent aux passants à Bab el Had à Rabat.

8 Le séjour irrégulier contraint ces migrants au travail temporaire (Soussi, 2015), ou à la mendicité. La grande majorité des personnes interrogées pratiquent la mendicité et sont représentées presque uniquement par des femmes avec enfants. Ces exilées sont en position de vulnérabilité, frustrées et déçues de la réalité qu'elles vivent, éloignées de ce qu'elles avaient imaginée. Elles vivent dans l'incertitude et l'attente, même si le retour dans leur pays est un espoir lointain. Un Syrien à Marrakech témoigne : «Tant que le conflit persiste, nous ne pouvons retourner chez nous ».

9 Ces migrants ont tissé des liens avec la population locale, qui exprime un sentiment de solidarité mélangé de compassion. Une Marocaine s'exprime à ce sujet : «Que dieu les aide et nous préserve de leur situation ». La sympathie envers les Syriens permet à Mo, la trentaine, dentiste syrien en situation administrative irrégulière, de pratiquer son métier tout en s'appuyant sur la sympathie des gens d'un quartier périphérique à Marrakech. Ils font appel à lui et l'invitent chez eux. À Oujda, plusieurs femmes syriennes aident à faire le ménage chez des familles marocaines.

Ceux qui s'intègrent sur le marché du travail et acquièrent ainsi une position, peuvent toutefois susciter un ressentiment négatif de la part de Marocains qui les indexent de leur confisquer une place que eux n'ont pu avoir. Un ouvrier du bâtiment s'exprime au sujet d'un Syrien qui travaille dans la même entreprise que lui : « Il n'avait rien quand il est arrivé et déjà, il a pu avoir un poste, une voiture et paye les frais de scolarité de ses enfants qui sont inscrits dans une école privé ». Par contre, on peut remarquer une bonne solidarité entre Syriens anciennement installés et nouveaux arrivants, dans le cadre des procédures de demande d'asile, de recherche de logement, d'emploi, etc. 
11 Les Syriens en séjour irrégulier sont éparpillés sur le territoire, en lien avec leurs réseaux sociaux mais aussi du fait des autorités locales qui empêchent toute constitution d'un camp de réfugiés. La question du logement est donc primordiale chez les Syriens. A., 40 ans, assise devant une mosquée à Marrakech m'interpelle : « Aide-moi ma sœur, je dois payer mon logement et faire vivre mes enfants». Les personnes interrogées affirment payer un loyer variant entre 1500 et 3000 dirhams.

12 Les anciens Syriens constituent aussi une importante source d'information. C'est le cas notamment de S., 30 ans, et de sa femme, 22 ans, installés depuis deux mois à Marrakech. Originaire de Hama, ce couple et leur enfant de 6 mois est parti du Liban vers l'Algérie par voie aérienne. Ils sont ensuite passés par Maghnia pour traverser clandestinement la frontière maroco-algérienne vers Oujda. Soulignons que les réfugiés syriens, une fois en Algérie, mobilisent des pratiques et adoptent des stratégies déjà explorées par d'autres migrations, notamment celle des migrants de l'Afrique subsaharienne. Les uns tentent de s'installer au Maroc comme ultime étape de leur parcours, alors que d'autres continuent vers l'Europe. Plusieurs Syriens attendent à Nador l'opportunité de passer la frontière vers l'Europe, en recourant aux services de passeurs.

13 Les déplacements nécessitent l'appui des réseaux familiaux, d'amitiés ou professionnels. C'est le cas de Z. de Homs, 35 ans, rencontré à Oujda. Il attend le moment de traverser la frontière vers l'Espagne puis vers une autre destination européenne qu'il refuse de divulguer et où un membre de sa famille est supposé l'accueillir.

\section{Politique migratoire : évolution et blocage}

14 La visibilité des migrants syriens dans l'espace public marocain (mosquées, grandes surfaces, feux tricolores...), essentiellement par les jeunes femmes et leurs enfants, interroge aujourd'hui les pouvoirs publics sur les politiques migratoires, les stratégies et les moyens pour les mettre en œuvre.

15 Pays d'émigration, le Maroc devient une destination pour les migrants et réfugiés venant d'Afrique subsaharienne, des pays arabes et d'Europe. Par sa position géographique, il constitue aussi une porte d'entrée vers l'espace Schengen. Cependant, les dispositions sécuritaires prises par l'Union Européenne (UE) pour restreindre l'accès à l'espace Schengen contraignent un certain nombre de migrants à s'installer au Maroc.

L'arrivée de demandeurs d'asile syriens au Maroc est récente, comparée à d'autres communautés étrangères. Plusieurs d'entre eux ont déposés des demandes d'asile auprès de l'UNHCR.

La migration aujourd'hui est encadrée par des traités et des conventions internationales que le Maroc a ratifiés, ainsi que par des dispositions juridiques nationales en la matière. Suite à la publication en septembre $2013 \mathrm{du}$ résumé exécutif et des recommandations du Conseil national des droits de l'homme (CNDH) pour une « politique d'asile et d'immigration radicalement nouvelle » (CNDH, 2013), le Souverain marocain a réagi en annonçant une nouvelle politique migratoire, mobilisant différents ministères et prévoyant la mise à niveau du cadre juridique et l'élaboration d'une nouvelle politique migratoire. À la suite de cette annonce, 853 demandes de reconnaissance du statut de réfugié de l'UNHCR ont été examinées par une commission 
interministérielle. Depuis janvier 2015, la commission est en train de traiter 1100 demandes d'asile de syriens, dont 383 ont été déjà auditionnés.

Pour ce qui est de l'opération dite exceptionnelle de régularisation, jusqu'au 31 décembre 2014, 27332 demandes de régularisation ont été déposées, dont 17916 ont été acceptées. Cette régularisation a touché 116 nationalités, avec 6600 Sénégalais, 5250 Syriens, 2380 Nigériens et 2281 Ivoiriens. En parallèle, une commission nationale de recours a été instituée sous la présidence du CNDH pour traiter des personnes n'ayant pas reçu d'avis favorable dans cette opération de régularisation qui s'est terminée officiellement le 31 décembre 2014. De nombreuses demandes sont en attente des décisions définitives de cette commission de recours. L'augmentation des demandes d'asile, la lenteur de la procédure de traitement des dossiers et les contraintes pour y répondre accroissent le désarroi des demandeurs qui sont en situation administrative irrégulière. Tout en ayant ratifié la Convention de Genève de 1951 relative au statut de réfugié et adopté un décret fixant les modalités de son application (1957) qui prévoit la mise en place d'un Bureau marocain des réfugiés et apatrides, le Maroc ne dispose pas, dans les faits, de procédure effective d'asile nationale. C'est donc l'UNHCR qui se charge de la détermination et de l'assistance aux réfugiés au Maroc. Concernant les Syriens, le blocage par les autorités marocaines des dossiers de demande d'asile est justifié par les difficultés d'identification des demandeurs. Les autorités publiques déclarent les considérer comme des réfugiés même s'ils n'ont pas encore de statut de réfugiés, par égard à la situation de leur pays. Un certificat de dépôt de demande d'asile leur est octroyé par l'UNHCR pour une durée de 6 mois renouvelable.

En juin 2014, les Syriens demandeurs d'asile ont organisé un sit-in devant le bâtiment de l'UNHCR à Rabat. Ils dénoncent la lenteur dans les traitements des dossiers et demandent des subventions pour survivre. Ces questions font actuellement l'objet d'échanges, notamment entre l'UNHCR et les autorités marocaines, dans le cadre de la nouvelle politique migratoire. L'adoption d'une nouvelle loi sur l'asile est ainsi prévue mais n'a pas encore été présentée au parlement. La nouvelle politique migratoire nationale a été traduite par une stratégie adoptée par le Conseil gouvernemental en décembre 2014 qui renvoie aux dispositifs du " Processus de Rabat ». Elle concerne onze domaines essentiels, dont l'éducation et la culture, la jeunesse et le sport, la santé, le développement social, la formation et l'accès à l'emploi.

Le Maroc représente une étape cruciale dans les parcours migratoires des migrants en situation irrégulière, notamment Syriens. Malgré les efforts déployés par le pays pour mettre en place une nouvelle politique migratoire et d'asile, les retombées effectives restent faibles. En mars 2014, quinze Syriens clandestins ont été expulsés vers la Turquie. L'UNHCR, déplorant cette décision, a exhorté le Royaume à l'instauration d'une protection temporaire pour cette population. L'État marocain semble ainsi osciller entre le contrôle sécuritaire, le laisser- faire et la volonté affichée de rendre ses politiques plus cohérentes et respectueuses des droits des étrangers. 


\section{BIBLIOGRAPHIE}

Conseil national des droits de l'homme (CNDH), Étrangers et droits de l'homme au Maroc, pour une politique d'asile et d'immigration radicalement nouvelle, résumé exécutif, septembre 2013.

H. Bentaleb, « Le parcours du combattant des réfugiés au Maroc », Libération, 21 juin 2014.

ORSAM, The situation of Syrian refugees in the neighbouring countries : Findings, conclusions and recommendations, Ankara, Report $\mathrm{n}^{\circ}$ 189, April 2014.

Processus de Rabat, vers une nouvelle politique marocaine d'immigration, 2015 (consulté sur processusderabat.net le 20 mars 2015).

S. A. Soussi, « Le travail migrant temporaire : une figure hors normes de la division internationale du travail », dans M. D'Amours, S. A. Soussi, D.-G. Tremblay (dir.), Repenser le travail : des concepts nouveaux pour les réalités transformées, Québec, Presses de l'Université du Québec, 2015, p. 165-194. 


\title{
Quelle école sur le chemin de la migration? L'exemple de Caritas (Rabat, Casablanca)
}

\author{
Dorothée Barrière
}

1 La présente réflexion émane d'un stage de fin d'étude effectué en 2013 au sein de l'ONG Caritas dans le cadre du master «Communication, humanitaire et solidarité internationale » proposé par l'université Lyon 2. Enseignante, ayant exercé cinq ans au lycée français de Rabat, nous avions déjà travaillé avec Caritas pour un projet d'écriture mêlant jeunes subsahariens migrants et lycéens de Descartes (lycée français réputé pour la formation des élites). Bénévole, nous avions alors amené les élèves et éducateurs hors les murs du centre, dans des rencontres et ateliers que nous avions définis ensemble en compagnie d'autres intervenants (un écrivain et une danseuse en résidence d'artiste), dans le souci d'apporter à tous un enseignement ouvert sur l'autre et sur la réalité migratoire.

2 Stagiaire à Caritas, nous nous trouvions cette fois intégrée à l'institution, dans une équipe hiérarchisée et plurielle, à la fois marocaine, européenne, subsaharienne, engagée depuis peu dans le programme « Promotion du respect des droits des migrants subsahariens au Maroc». Ce dernier, liant trois centres d'accueil de migrant(e)s Rabat, Tanger et Casablanca -, établi sur trois ans et financé par l'Union Européenne, porte sur différents volets, dont l'éducation. Nous connaissions déjà en partie les éducateurs et les enfants, tandis que les responsables des centres voyaient dans notre expérience d'enseignante des compétences précises à solliciter. En effet, si l'enjeu du programme était de préparer les enfants à intégrer les écoles marocaines et à construire un plaidoyer en ce sens, les défis, au quotidien, semblaient davantage porter sur les préoccupations pédagogiques et la motivation des professeurs subsahariens. Nous étions donc supposés fournir des « recettes » pour améliorer leur pratique.

Dans ce cadre général, le choix de partir du conte, et notamment du conte africain, nous a progressivement amené à dépasser les classiques préoccupations pédagogiques. Derrière la préparation et la construction d'un cours ou d'une programmation, se jouait en fait le sens de l'école de Caritas. «Mettre en place quelque chose qui les intéresse 
vraiment », « comprendre leurs besoins et y répondre justement » furent les questions de l'équipe enseignante au cœur de notre coopération. Or, si cette quête s'appuyait sur de fortes affirmations - «nous connaissons nos enfants", "nous savons comment les éduquer » - les réponses n'en furent pas pour autant évidentes. Dans ce qui n'est pas " une vraie école » et au sein d'une équipe plurielle, elles opposèrent de façon sourde les différents acteurs au sujet de ce que doit être « le bagage » de l'enfant sur le chemin de la migration.

4 Nous nous proposons ici d'interroger quelques éléments, à savoir l'importance des origines, le terme revendiqué d'éducateur ou encore la recherche de légitimité, qui nous ont paru structurer les discours de l'équipe enseignante. Que disent-ils des enjeux de l'accueil des enfants, au carrefour des routes migratoires et des représentations culturelles? Quelles tensions révèlent-ils au sein de l'institution, prise dans la diversité des acteurs s'efforçant chacun de valoriser ses propres codes?

5 La majorité des intervenants auprès des enfants - de la crèche aux adolescents - sont d'anciens "bénéficiaires» ou étudiants d'Afrique centrale et de l'Ouest. De leurs parcours, nous connaissons des bribes qui ont émergé lors de discussions informelles. Pour tous, le séjour au Maroc s'est éternisé sans retour possible au pays et sans opportunité de gagner l'Europe. La plupart ont fondé une famille. Leurs enfants demeurent au pays d'origine vivent au Maroc ou sont confiés à un proche en Europe. $\mathrm{Au}$ CAM (Centre d'accueil des migrants - Rabat) comme au SAM (Services accueil migrantes - Casablanca), une professeure marocaine enseignant l'arabe est intégrée à l'équipe en vue de l'admission à l'école publique.

6 Dans l'effervescence de nos premières rencontres, les enfants, légèrement agités, entendaient cette parole: «N'oubliez pas que vous êtes Africains et que vous avez le respect de l'aîné ", là où nous ne percevions ni manquement, ni marque d'irrespect mais libre expression de l'enfant... « Vous, Européennes, à chaque fois que vous êtes là, les enfants en profitent car ils savent que vous ne criez pas », me lança une fois une éducatrice alors que nous nous trouvions par hasard dans le couloir, où chahutaient quelques élèves. Ce jugement nous a d'autant plus surprise que nous travaillions ensemble, dans une bonne entente...

7 La place donnée à l'enfant dans l'apprentissage est ainsi une importante source de conflit entre bénévoles et éducatrices du SAM, qui, de ce fait, peinent à collaborer. Être " sage ", les bras croisés sur la table, apprendre par cœur et répéter de façon collective la leçon sont autant d'impératifs qui heurtent les bénévoles, habitués à des approches pédagogiques jugées plus respectueuses du rythme de l'enfant. à l'opposé, la participation et l'expression des élèves, sollicitées dans les cours des bénévoles, sont perçues par les maitresses comme une forme de chaos corrupteur du lien enfant/ adulte. Dans une structure où les relations entre travailleurs et "bénéficiaires" demeurent asymétriques, entretenues par les réponses d'urgence aux besoins premiers des personnes (santé, logement...) qui dominent le travail des centres, l'expression des enfants apparait tenir peu de place. Or, la scolarisation des enfants s'inscrit dans une autre temporalité et donc dans un autre ordre. L'école, peu questionnée par les bénévoles dans son rapport à la culture, permet aux bénéficiaires et anciens bénéficiaires que sont les professeurs de se réapproprier une certaine maîtrise de leur situation, de se projeter dans l'avenir et de faire valoir une identité personnelle et collective. L'éducation donnée à l'enfant est affirmation de soi et du groupe qui ne saurait disparaître, même dans une condition d'extrême précarité. 
8 Nous avons, à notre tour, sollicité l'introduction de la culture africaine par le recours au support livresque et au conte africain pour des motivations diverses: amener les enfants vers les livres et fournir un outil concret aux enseignants pour construire des séances diversifiées. Aussi avions-nous sélectionné une dizaine de récits, les équipes s'en saisissant avec curiosité et enthousiasme. De cet engouement partagé, deux problématiques majeures ont émergé: comment (oser) dire l'Afrique, pourquoi dire l'Afrique ? La référence à une culture d'origine posait en effet question.

9 L'exploitation riche et diverse du matériau littéraire joua, certes, un rôle fédérateur au sein des équipes subsahariennes, qui montrèrent un véritable plaisir à travailler les contes, voire à les transcender par une réécriture mêlant imagination, souvenirs et histoires d'enfance.

10 Elle n'eut cependant pas le même écho chez les cadres européens du CAM. Le conte africain était perçu comme cruel et violent, donc peu adapté à un jeune public. Le choix du thème commun (l'Afrique), qui avait été longuement et vivement discuté par les éducateurs, fut, lui, questionné par les responsables dans sa pertinence et les conditions de son émergence. Que pouvons-nous comprendre de cette forte réserve qui pesa sur la construction de ces différents projets. Furent-elles perçues comme une attitude de repli des éducateurs s'opposant ainsi aux efforts développés par l'ONG pour intégrer les enfants à l'école publique marocaine et de façon plus large à la société marocaine? Dans un registre plus inconscient, elles pouvaient heurter le regard classique que nous portons très souvent sur l'émigré ; celui-là même, nous rappelle le philosophe Guillaume Le Blanc (2010), qui veut que l'étranger désirant être accueilli vienne vierge de toute histoire et de tout passé.

11 Quoi qu'il en soit, cette identité réinvestie auprès des enfants nés au Maroc ou sur le chemin de la migration semble rassurer. Nombreux furent les commentaires à l'occasion de l'exploitation des contes sur les racines et le pays d'origine, empreints d'une fierté non feinte, d'un soulagement d'être enfin en accord avec soi-même. "L'Afrique, c'est ce qui nous est familier ", « l'Europe, c'est ce qui est futur, c'est loin » expliquait une éducatrice. Il est apaisant de « revenir vers d'où l'on vient « au cours d'un projet migratoire empli d'incertitudes, de ne plus être « au pied du mur », dans un entre deux géographique et culturel.

12 En juin 2014, soit un an après notre stage, les éducateurs parlèrent avec beaucoup d'entrain des travaux autour du projet commun et des productions présentées aux parents. L'éducatrice chargée de suivre les enfants d'une dizaine d'années nous expliqua comme elle s'était sentie à l'aise dans l'enseignement de son continent : « Rien ne m'échappait et les enfants étaient motivés». Il y avait «le plaisir de savoir, de connaître les différents pays et les richesses de l'Afrique. On se questionne même sur le sens de l'immigration, des choses positives et négatives». Et de conclure que les enfants ont ainsi découvert que le Maroc était en Afrique et non dans un ailleurs entre continent d'origine et Europe...; autant de « connaissances qui les situent » et qu'ils pourront utiliser pour se défendre contre les propos et actes racistes. « Ils ont compris que nous étions tous Africains ». L'enseignement du continent dévoile ainsi une part d'identité commune, jette une passerelle entre les différences culturelles, linguistiques et/ou religieuses, dans une société d'accueil rétive.

13 Pour cette éducatrice, fort de ces connaissances - ses élèves n'ont- ils pas appris à compter sur le jeu d'awalé! - l'enfant peut aller sereinement vers la classe d'Anissa et apprendre l'arabe! 
14 Au fil de notre travail commun, la question de la dénomination des intervenants est apparue : «professeur » que nous employions plus volontiers ou/et «éducateur » que l'équipe préférait. Certes, tous, dans cette tâche de transmettre des connaissances, nous ont dit avoir apprécié le travail sur la méthode. Mais, rappellent-ils avec force, ils ne sont pas dans une école classique. Leurs élèves sont "des enfants à problèmes", la condition de migrant générant des difficultés telles que l'absentéisme, l'agressivité, le manque de concentration. Les parents se disent de passage au Maroc. Les enfants de même. Aussi, pour l'équipe éducative, s'agit-il aussi et surtout de prendre soin de ces élèves dans un contexte de carence de repères (du pays d'origine, de la famille, des parents peu disponibles car monopolisés par l'entreprise du passage en Europe) : les mettre en confiance et leur montrer qu'ils rencontreront des personnes qui veilleront sur eux, où qu'ils soient, car ils relèvent d'une même famille originelle.

Comment alors accompagner au mieux les enfants dans cette "deuxième vie »? En corrigeant quelques fautes d'orthographe et d'expression sur les copies d'expression libre dont le sujet, pour les plus grands, était «faire la rédaction de mon parcours jusqu'à l'arrivée au Maroc»? Mais l'essentiel se trouve sans doute dans les appréciations. "Yako!, courage!», pouvons-nous lire sur une des copies ou encore, dans la marge, "Ça va aller ", parmi d'autres remarques réconfortantes: "Être soi ", "C'est un journal, merci ", "Quel parcours de courage ", "Prends la vie du bon côté », «Bon maintenant tu es arrivé. Ton destin, ton avenir sont dans tes mains ».

Revenir sur le parcours, penser l'Afrique «berceau de l'humanité » et lui inventer un avenir serait entretenir le fil ténu, malmené par la migration et la société d'accueil, avec soi. L'une des éducatrices s'interrogeait ainsi : « Quand l'enfant va se forger, quelle notion aura- t-il de sa réalité à lui ? Entre l'Arabe et le Français, où se trouve la place de la langue maternelle, le Lingala, le Kikongo, langue qui porte le lien avec la terre d'origine et avec la mère ? Sans langue maternelle, il n'y a plus de confidentialité ». « La femme, fière de sa peau d'ébène, qui porte l'enfant, son fardeau. Malgré la souffrance et la difficulté, elle n'a jamais laissé son enfant...Il est attaché au dos » développait cette autre éducatrice participant à l'atelier conte mère-enfant. Est-ce là que réside le sens de l'école de Caritas?

Pour l'ancienne psychologue du CAM, la présence d'éducateurs subsahariens auprès des enfants peut favoriser l'entre soi et fragiliser l'ouverture sur la société marocaine. "L'école étant un vecteur d'intégration pour les enfants étrangers dans la société qui les accueille, si l'on était complètement cohérent il faudrait plutôt qu'une majorité de Marocains enseignent à nos enfants ». Pour elle, une autre question se pose : «Dans le même sens, le fait que les éducateurs soient eux- mêmes migrants, donc vivant des quotidiens douloureux, incertains et anxieux souvent face à leur avenir, peuvent-ils être suffisamment "solides ", " sécurisants » face à leurs élèves? N'est-ce pas une des bases pour transmettre dans les plus jeunes âges?».

Le danger de l'entre-soi a été perçu par les éducateurs, mais au sujet de leur image professionnelle, qu'ils entendent valoriser. Face à l'institution qui les emploie, en termes de statut, de rémunération et de perspective mais également face aux parents, ils doivent s'affirmer. L'école de Caritas, si elle n'est pas une «vraie école »- puisque non reconnue, ne délivrant pas de diplôme, et aux conditions de travail matérielles difficiles - n'est pas pour autant «une garderie». Les éducateurs construisent avec application les cours, sans programme officiel et sans manuel, corrigent les copies, font de multiples rapports sur leurs activités et les enfants. Ils leur apprennent à lire et à 
écrire, et, selon eux, "transmettent avec passion des connaissances, des valeurs universelles et plus spécifiquement africaines ». Or, ce travail serait peu reconnu par les parents dont le comportement nourrit un certain nombre de reproches. Ouvrir la classe aux familles pour qu'elles réalisent la qualité du travail et s'impliquent ensuite dans le suivi de leur enfant serait une solution. Cependant, les parents totalement engagés dans leur aventure migratoire, selon une éducatrice du CAM, se dispersent et oublient de "rassembler » le bagage nécessaire à l'enfant pour se construire comme personne. « On migre pour l'enfant mais l'enfant n'a pas sa place ou du moins on ne lui laisse pas sa place ». "L'éducation est à privilégier avant tout: on traverse à la fin de l'année sinon, tu fais du mal à ton enfant, tu mélanges tout dans sa tête... l'Europe, l'Europe, l'Europe !!!»; «On s'en va chercher notre avenir, disent les mamans, et l'avenir de l'enfant ?... ». L'école serait donc là pour donner à l'enfant un minimum de temps et de stabilité afin qu'il puisse investir sa propre construction. Aussi, un récent règlement avertit les parents que s'ils retirent l'enfant pour tenter un passage, il ne sera plus accueilli en classe.

Une ancienne salariée du CAM, mère de cinq enfants, soulignait aussi que la scolarisation de l'enfant restitue la femme dans son rôle et ses devoirs de mère, après qu'elle ait été maltraitée et dévalorisée pendant le voyage. Elle ouvre une nouvelle route à l'enfant et donne une autre perspective à la migration. Sinon, « toi, tu n'es pas en train de réussir... L'enfant n'est pas en train de réussir...Tu as raté ta vie ».

L'école de Caritas se trouve bien à la croisée de nombreux univers qui portent les représentations, les certitudes et les fragilités de chacun des acteurs : les éducateurs subsahariens tentant de se forger un avenir dans une migration contrariée, les travailleurs humanitaires européens et marocains contraints par les exigences des bailleurs de fond et la réalisation d'un programme, soumis aussi à leurs propres représentations plus ou moins questionnées, tout comme pour les bénévoles. La culture universelle des droits de l'Homme que d'aucuns, ici, pourraient penser au service d'un dessein géopolitique, contribue à opacifier ce « labyrinthe culturel » (Agier, 2013) dans lequel se trouve propulsé tout migrant, a fortiori ses enfants. L'enjeu est ce passage d'une rive à l'autre, d'un monde à l'autre, rendu d'autant plus difficile que le rivage d'accueil est incertain. Est-ce celui, souvent contraint, du Maroc ou celui de cette Europe qui se refuse? Quel sens revêt alors l'école? Que doit-on y apprendre? Comment faire émerger la figure du passeur des cultures (M.R. Moro, 2010) sécurisant les parents et l'enfant dans sa propre construction? Comment, à l'intérieur de l'ONG et plus largement dans les pays d'accueil, rompre cette relation forcément asymétrique entre l'hôte et l'accueilli? Quelle place construire pour accompagner les uns et les autres dans le respect de leur individualité et de leurs choix? «L'hospitalité serait la capacité à accueillir un récit qui n'est pas le nôtre, qui peut le cas échéant même le défaire en partie » (Le Blanc, 2010). Ces questionnements s'adressent en premier lieu à nous-mêmes, dans notre volonté de recueillir une parole «vraie » qui devient aussitôt un matériau de réflexion. Nous songeons ici à l'une des personnes avec laquelle nous avions beaucoup échangé à Caritas au sujet des élèves et de nos propres enfants qui, un temps, ont correspondu. Lors de notre dernière visite, à la fin d'un entretien sans doute un peu trop directif de notre part, elle eut cette phrase, ô combien révélatrice : "Je croyais que tu étais comme nous ». Nous nous apprêtions alors à monter dans un taxi plutôt que dans le bus... 
21 Sa remarque retentit comme un avertissement mais aussi comme un encouragement à continuer de penser les conditions du passage réussi d'un monde à l'autre.

\section{BIBLIOGRAPHIE}

M. Agier, La condition cosmopolite, l'anthropologie à l'épreuve du piège identitaire, Paris, Éditions la Découverte, 2013.

H. Lagrange, Le déni des cultures, Paris, Le Seuil, collection « Points essais », 2013 (deuxième édition).

G. Le Blanc, Dedans dehors. La condition d'étranger, Paris, Le Seuil, 2010.

M.-R. Moro, Grandir en situation transculturelle, Bruxelles, éditions Fabert, 2010.

Chaire Unesco de l'Université catholique de Lyon, L'humanitaire à l'épreuve des cultures, actes du colloque international, 19-20 octobre 2012, Études interculturelles, $\mathrm{n}^{\circ}$ 6, 2013. 
Le Maroc : une société plurielle au prisme de l'altérité 


\title{
Les étudiants subsahariens,
} nouveaux portraits de la présence étrangère au Maroc : l'exemple des Maliens de Fès

\author{
Touré Niandou
}

1 En raison de la densification des mouvements migratoires du et vers le Maroc, depuis une vingtaine d'années, le Royaume est désormais reconnu comme pays d'immigration et d'émigration (de Wenden, 2013). Les étudiants étrangers, dont la majorité provient d'Afrique subsaharienne, figurent parmi les catégories les plus représentées pour ce qui est de l'entrée sur le territoire marocain. En effet, leur nombre croît de façon constante depuis 1998, aussi bien en termes absolus qu'en proportion du nombre total d'étudiants inscrits dans les établissements d'enseignement supérieur du pays. D'après des estimations récentes, on en dénombrait plus de 15000 en 2010-2011 (Meyer, Laouali, 2012). Cette même année, nous estimions à 1800 le nombre d'étudiants maliens au Maroc. Pour illustration, la liste électorale réalisée en vue de la présidentielle 2012 par l'ambassade du Mali, recensait 1995 Maliens au Maroc dont près de 1900 étudiants arrivés avant cette date. 100 nouveaux boursiers maliens arrivent chaque année au Maroc et un nombre encore inconnu d'étudiants s'inscrivent simultanément dans les établissements supérieurs privés.

2 La plupart des étudiants étrangers dans les établissements marocains proviennent d'Afrique subsaharienne, d'où sont également originaires une proportion importante de migrants en situation administrative irrégulière installés au Maroc. Les données relatives à ces migrants se caractérisent par leur très grande variation suivant les organismes qui les produisent. Leur nombre se situerait ainsi entre 4500 - statistique invraisemblablement basse - et 40 000, estimation plus plausible (Human Rights Watch, 2014). Les étudiants subsahariens constituent une population de plus en plus importante au Maroc, cependant assez peu de publications scientifiques ont fait cas du phénomène (Berriane, 2012). 
3 Cette contribution analyse la présence d'étudiants subsahariens dans les villes marocaines à partir du cas des Maliens des quartiers d'Atlas et de Florence, à Fès. Dans le cadre de nos recherches de terrain, réalisées pour notre thèse de doctorat en 2012 et 2013, nous avons trouvé à Fès des spécificités qui font de ce lieu saint de la Tidjaniyya un intéressant terrain d'observation. On y trouve, agrégées, les différentes catégories historiques de la mobilité étudiante malienne: d'une part, les boursiers de la coopération aux statuts divers et, d'autre part, les étudiants non boursiers majoritairement inscrits dans les écoles privées. La présence de plus en plus importante de cette dernière catégorie découle des nouvelles mutations de l'enseignement supérieur marocain et de la demande de formation des étudiants subsahariens. C'est pourquoi notre propos sera focalisé sur Fès, ses écoles privées, sa nouvelle ville (Fès El Jdida) et sur ses étudiants maliens. Les résultats présentés sont issus de deux mois de terrain à Fès, quinze entretiens semi- directifs auprès des étudiants et une observation participante auprès de nos hôtes étudiants. La construction de notre échantillon a été faite de sorte que s'y retrouve la mosaïque des profils d'étudiants. Aidés en cela par notre hôte étudiant, nous avons pu rencontrer dix étudiants et cinq étudiantes suivant principalement des formations en sciences de l'entreprise (finance, gestion, marketing) et en NTIC (informatique, télécom). Les analyses présentées sont éclairées par une vue d'ensemble de la présence étudiante malienne au Maroc, qui a fait l'objet d'autres terrains de recherche dans le cadre de notre doctorat, à Rabat, Casablanca ou Mohammedia.

4 La présence d'étudiants subsahariens n'est pas un phénomène nouveau au Maroc. Cependant, c'est par son ampleur grandissante et par les mutations qui sont consubstantielles à la mobilité étudiante qu'elle invite à la réflexion. En effet, ces évolutions nous incitent à interroger l'impact du mode d'habitat et la visibilité croissante des étudiants dans l'espace public sur la nature de leurs perceptions de soi et d'autrui. En analysant les marqueurs de la présence étudiante malienne à Fès et la question de leurs rapports avec les autres populations en place, nous pourrons mieux comprendre le mécanisme plus général de la participation de la présence estudiantine dans la construction de la figure de l'étranger subsaharien.

5 Afin d'analyser les ressorts de cette présence, nous opérerons un bref retour historique sur la présence étudiante étrangère au Maroc. Nous nous intéresserons ensuite aux profils des étudiants maliens, avant de dévoiler leur environnement social, sorte de microcosme construit dans un espace géographique situé entre les écoles et les logements privés qui les accueillent. Ce diagnostic permettra, in fine, de dresser une analyse de la visibilité des étudiants étrangers et de son impact sur leurs représentations sociales de soi et d'autrui.

\section{Cinquante ans de présence étudiante subsaharienne}

6 La formation d'étudiants subsahariens au Maroc remonte aux années 60 (Belkadi, Charef, 2009). Elle constituait un volet clé de la coopération économique bilatérale liant le Maroc à ses voisins du Sud (accord de 1963 avec le Sénégal, de 1972 avec le Gabon). Dans d'autres cas, la formation des étudiants subsahariens était financée par des institutions spécialisées de l'ONU - comme l'Organisation mondiale de la santé (OMS) à travers leurs programmes de renforcement des compétences. 
7 Suite à son retrait définitif de l'Organisation de l'Unité Africaine (OUA) en 1985 et la création en 1986 de l'Agence marocaine de coopération internationale (AMCI), ces accords ont été systématisés afin de permettre au Maroc d'asseoir ou de maintenir son influence sur les pays au sud du Sahara. C'est ainsi qu'ont été signés des accords commerciaux de nature plus ou moins similaire avec le Mali et le Cameroun en 1987 et une demi-douzaine d'autres jusqu'en 1997 avec le Bénin, le Burkina Faso et la Guinée.

8 Le troisième temps de la mobilité d'étudiants subsahariens au Maroc se situe au début du XXIe siècle, avec la promulgation en 2000 de la loi $n^{\circ}$ 01-00 sur l'organisation de l'enseignement supérieur. Cette loi matérialise la volonté du Maroc de faire de l'enseignement supérieur privé un domaine complémentaire des établissements publics, grâce son innovation dans les programmes de formation et de recherche (article 39 de la loi). Ce terme renvoie aux espoirs que plaçait l'État dans l'essor de l'enseignement supérieur privé, à travers la diversification de l'offre pédagogique et l'élargissement des domaines de recherche scientifique. Depuis, on a assisté à une multiplication exponentielle des écoles supérieures privées accréditées dont le nombre est passé en trente ans, de 2 à 230 , dont 6 universités privées, d'après le ministère marocain de l'Enseignement supérieur. Les établissements privés accueillent un nombre considérable d'étudiants, encore difficile à dénombrer, les données de l'AMCI concernant essentiellement les boursiers. Dans certaines écoles privées de la Nouvelle Fès, dans les quartiers Florence et Atlas, les étudiants subsahariens représentent souvent deux-tiers à trois-quarts de l'effectif total.

\section{L'étudiant dans la ville, une figure différente de l'étranger}

9 Les étudiants des écoles privées sont issus de catégories sociales aisées, ce qu'atteste leur pouvoir d'achat élevé. En effet, les coûts de scolarité constatés auprès des étudiants maliens que nous avons interviewés, sont compris entre 25000 et 60000 dirhams par an, l'équivalent de 2200 et $5500 €$. À ces coûts de scolarité, il faut ajouter le coût de la vie dans les grandes villes marocaines, afin d'évaluer le coût financier supporté par les parents maliens qui assument les frais de séjour de leurs enfants. Par un croisement des informations recueillies auprès de nos enquêtés et des associations étudiantes, nous sommes parvenus à estimer le coût moyen du séjour annuel entre 5.000 à $9.000 €$ par étudiant. Ces montants dépassent les niveaux moyens de richesse économique au Mali, où le revenu national brut par habitant est seulement de $600 €$ par an.

10 À Fès, les étudiants habitent généralement près de leur école, chez des particuliers. Ils investissent ainsi un petit périmètre urbain qui rend leur présence d'autant plus notable. Ils sont visibles dans les grandes villes marocaines, comme dans le centre de Fès où toute leur vie est concentrée dans un microcosme social très dynamique. Les étudiants y mènent une vie associative dense, occupent des logements où ils cohabitent par groupes de quatre à six en moyenne, $y$ fréquentent leurs écoles et différents lieux de divertissement.

$11 \mathrm{Au}$ cours de notre investigation, nous avons essayé de déterminer le nombre d'étudiants maliens à Fès. D'après nos calculs approximatifs réalisés avec l'aide du bureau de l'association des stagiaires et étudiants maliens (ASEM), ils étaient, en 
2012-2013, entre 500 et 600, dont plus des trois-quarts inscrits dans des établissements supérieurs privés. Les sciences de l'entreprise (gestion, marketing, finance, audit) et les nouvelles technologies (informatique et télécoms) sont les principales disciplines dans lesquelles s'inscrivent les étudiants maliens, à l'instar de leurs homologues Sénégalais encore plus nombreux à Fès.

\section{Atlas et Florence, des quartiers « ouest-africains »}

Fès, HECF (Hautes études comptables et financières) et EPSIEL (École polytechnique supérieure en informatique et électronique). Ces trois institutions sont situées dans un périmètre à la frontière entre les quartiers Atlas et Florence. Elles ont des stratégies marketing plutôt tournées vers l'Afrique. C'est ce qui ressort de leur communication axée sur leurs importants réseaux internationaux ou la possibilité de délivrer des diplômes français et canadiens au Maroc. HECF a un accord de partenariat avec l'ESC de Pau, EPSIEL avec l'université de Franche-Comté et Sup'Management bénéficie d'un réseau mondial de collaborations, notamment en Espagne et aux États-Unis.

Sup'Management est également implantée au Mali, au Sénégal et en Mauritanie. Il n'empêche que l'antenne de Fès accueille des étudiants de tous ces pays, confirmant ainsi l'importance du label «diplômé du Maroc», valorisé sur le marché malien de l'emploi. Il l'est d'autant plus qu'il provient d'un pays en voie de développement et «si proche de l'Europe » nous dit Aicha, étudiante en informatique à EPSIEL. Les autres écoles surfent sur une communication, portée par certains étudiants, qui ont le statut de recruteurs officiels, et qui font des campagnes annuelles de recrutement toujours fructueuses dans leurs pays d'origine.

\section{Le microcosme social des étudiants maliens de Fès}

À Fès, le périmètre spatial et social de la vie des étudiants maliens du privé, est similaire à celui de la plupart de leurs homologues d'Afrique subsaharienne : ils vivent en communauté entre des logements partagés avec leurs compatriotes, des écoles où les étrangers sont souvent nombreux et se regroupent dans des associations nationales ou régionales. En grande majorité non arabophones, les étudiants des écoles privées côtoient très peu la population marocaine en dehors de l'espace public : commerces de proximité, résidences communes. L'ASEM est une association fédératrice des Maliens. Elle existe sur l'ensemble du territoire et dispose d'une antenne dans quasiment toutes les villes universitaires. Les autres communautés nationales sont organisées suivant le même mode associatif et se regroupent régulièrement autour d'activités ayant pour but la promotion de la culture de leurs pays d'origine. Bien souvent, la majorité des participants à ces activités sont d'autres étudiants subsahariens et quelques camarades de classe marocains. Dans le cadre de la CESAM (Confédération des élèves, étudiants et stagiaires africains du Maroc) se retrouvent, toutes nationalités confondues, les étudiants subsahariens pour des activités de nature similaire à celles des associations nationales: football, sorties récréatives, journées culturelles annuelles dans les différentes villes, rencontres conviviales autour des fêtes nationales, etc. 
15 À Fès, dans le quartier de l'Atlas, se trouve également un fast- food, l'Immigré, fréquenté quasi-exclusivement par des étudiants d'Afrique subsaharienne. Le propriétaire de l'Immigré serait lui-même un Marocain revenu d'un séjour en Europe. Certains étudiants s'y reconnaissent et échangent les cordialités en moyenne une fois par jour. Baba, étudiant à HECF, témoigne : «Je me sens comme chez moi ici. Je viens deux ou trois fois par jour. Et l'enseigne est bien trouvée, 'l'Immigré', j'ai l'impression que c'est fait à notre intention ». Cette déclaration contraste avec d'autres discours des étudiants qui se définissent parfois par opposition aux « immigrés ", démontrant là leur rapport ambivalent aux migrants en situation irrégulière provenant d'Afrique subsaharienne.

\section{Représentations de soi et d'autrui, les rapports ambivalents des étudiants avec les « immigrés »}

En dépit de l'existence des critères objectifs de définition de la migration, comme l'installation dans un territoire nouveau pour une longue durée, nous avons formulé, lors de notre terrain exploratoire au Maroc en 2012, l'hypothèse selon laquelle la mobilité étudiante n'est pas une migration à proprement parler. La question des représentations sociales de soi et d'autrui, chez les étudiants, a été avant tout le résultat d'un travail inductif: c'est la multiplication des occurrences des termes « immigrés » et « clandestins » employés alternativement pour désigner les migrants subsahariens en séjour irrégulier qui nous a conduit à approfondir la réflexion sur ce sujet.

17 Cette question permet de comprendre que la différence entre "étudiant» et « migrant » est liée à un ensemble de représentations sociales et de fonctions assignées dans le discours populaire via les médias de masse, aux catégories de migrant travailleur manuel et d'étudiant qui exerce une activité intellectuelle. Ainsi, il ressort de nos entretiens et de nos discussions régulières que la question des représentations des «immigrés » et de la charge symbolique du mot «immigré » a une connotation négative. Dans leurs discours, les étudiants adoptent une position ambivalente. Tantôt, ils se déterminent comme des "immigrés", comme Baba s'associant au nom de l'enseigne du restaurant où il mange, tantôt, ils se départissent d'eux, soulignant que ces derniers sont illettrés et en situation irrégulière : « Nous ne sommes peut-être pas chez nous, mais pas de la même façon que les clandestins. Eux, ils sont sans papiers » résume Aminata, étudiante à Sup' Management. Ces étudiants maliens admettent leur altérité, mais ils se conçoivent comme étrangers autrement, en comparaison avec les migrants irréguliers.

\section{Conclusion}

Le Maroc est manifestement un pays d'émigration et d'immigration, et les étudiants étrangers, majoritairement originaires d'Afrique subsaharienne, participent beaucoup à cette nouvelle donne. L'essor du secteur privé de l'enseignement supérieur et l'ouverture internationale vers le sud qui s'en est suivie, combinée à la demande croissante d'éducation en Afrique de l'Ouest, font de cette nouvelle configuration une tendance qui se consolidera dans les prochaines années. 
19 La posture d'étrangers dans laquelle se découvrent les étudiants maliens, contraint ces derniers à se questionner sur leur place dans la société d'accueil. Dans cette situation, ils optent pour des positions ambivalentes qui sont en réalité le reflet d'un positionnement tantôt en phase avec les catégories dans lesquelles ils se sentent cantonnés dans le discours public, tantôt en opposition aux représentations des Subsahariens, qu'ils estiment misérabilistes. Ainsi, ils sont étrangers, comme leurs compatriotes en situation irrégulière, mais de façon différente, positive. Cette analyse des représentations sociales de l'étudiant étranger au Maroc, figure renouvelée de la présence étrangère dans le Royaume, pourrait être complétée par une entrée par les représentations sociales de l'étranger par les populations autochtones, en s'intéressant aux évolutions de ces représentations qui, sans doute, se nourrissent des mouvements migratoires actuels et à venir.

\section{BIBLIOGRAPHIE}

A. Belkadi, M. Charef, «Les étudiants étrangers dans l'enseignement supérieur public et privé marocain ", dans S. Mazzella (dir.), La mondialisation étudiante. Le Maghreb entre Nord et Sud, Paris, Karthala/IRMC, 2009, p. 243-255.

J. Berriane, «La formation des élites subsahariennes au Maroc », dans M. Mokhefi, A. Antil (dir.), Le Maghreb et son Sud. Vers des liens renouvelés, Paris, CNRS, 2012, p. 155-171.

C. Wihtol de Wenden, « Migrations en Méditerranée, une nouvelle donne », Confluences Méditerranée, $\mathrm{n}^{\circ}$ 87, 2013/4, Méditerranée : mare nostrum pour les migrants ?, p. 19-30

Human Rights Watch, Abused and expelled: Ill-Treatment of Sub-Saharan African Migrants in Morocco, HRW reports, 2014 http://www.hrw.org/sites/default/files/reports/morocco0214_ ForUpload_0.pdf

S. M. Laouali, J.-B. Meyer, « Le Maroc : pays d'accueil d'étudiants étrangers », Hommes \&

Migrations, $\mathrm{n}^{\circ} 1300,2012$, p. 114-123 


\title{
Quelle intégration pour les étrangers au Maroc? Les écueils d'un terme à éviter
}

\author{
Sylvain Beck
}

1 Cet article se propose d'interroger l'usage du terme «intégration » concernant la présence des étrangers au Maroc. De plus en plus utilisé comme allant de soi dans les discours publics, il devrait pourtant être systématiquement critiqué et redéfini dans le contexte politique et historique marocain. Le dictionnaire Le Trésor de la langue française en propose une définition précise. C'est une « phase où les éléments d'origine étrangère sont complètement assimilés au sein de la nation tant au point de vue juridique que linguistique et culturel ». Cette définition sociologique associant intégration et assimilation prolonge en effet la définition générale du même dictionnaire qui est «l'action d'incorporer - c'est-à-dire de mélanger intimement afin d'obtenir un tout homogène - un ou plusieurs éléments étrangers dans un ensemble constitué ». C'est l'association entre la présence d'étrangers et l'intégration qui est controversée en sociologie. D'une part, la plupart des travaux montrent que le processus d'assimilation d'un migrant n'est jamais complètement achevé. D'autre part, la nation étant une notion abstraite, elle ne constitue pas un ensemble cohérent auquel les étrangers pourraient être complètement intégrés. Au Maroc, la question de la place de nouveaux arrivants se pose à juste titre. Se pose alors la question de l'utilisation au Maroc de ce terme qui, pour des raisons historiques et culturelles, s'est propagé en France au point de devenir polémique.

2 L'analyse de différentes situations de Français à Rabat et Casablanca montre différents degrés d'immersion qui ne se traduisent jamais en termes d'intégration. Nous nous sommes focalisés sur la vie quotidienne d'enseignants, dans leur vie personnelle et professionnelle. Socialisés en France selon l'idéologie républicaine, nous avons estimé que leurs représentations sur l'intégration pourraient nous renseigner sur la manière de définir leur place au Maroc. Dix-huit mois d'observations à Rabat et Casablanca entre 2009 et 2013 ont permis de recueillir quarante-cinq entretiens semi-directifs auprès d'enseignants français. Il faut considérer la particularité de ces villes en tant 
que capitales administrative pour l'une, et économique pour l'autre, fondées durant la période coloniale. Mais derrière les ressemblances de certaines infrastructures et quartiers avec la France, l'observation des pratiques quotidiennes montre une appropriation de l'espace urbain et de l'usage de codes sociaux et de normes spécifiquement marocains. Boire un café, faire des achats, prendre un bus ou un taxi, traverser la rue ou chercher une adresse sont des actes quotidiens parmi d'autres qui rappellent chaque jour que la société marocaine a une histoire et un mode d'organisation sociale qui lui sont propres. La plupart des personnes interrogées ont souligné le décalage de leur perception au fur et à mesure de leur séjour. Les entretiens se sont focalisés sur les raisons du départ, les conditions d'arrivée, de séjour, ainsi que les pratiques quotidiennes. Deux dimensions principales permettent de distinguer leur statut juridique et leur degré d'immersion dans la langue et la culture marocaine. D'une part, leur statut professionnel détermine leur position sociale et la durée de leur séjour: fonctionnaires titulaires ou non dans l'éducation nationale française, ils exercent dans les établissements français ou privés marocains, francophones ou bilingues, avec un contrat d'expatriation, de détachement ou de droit local. D'autre part, leur vie familiale entrâne des relations avec la société d'accueil : célibataires, en couple français ou franco-marocain, avec ou sans enfants scolarisés. Cet article présente trois profils en fonction de leur trajectoire, leur situation professionnelle et leurs pratiques quotidiennes, en questionnant l'usage du terme intégration.

\section{Les « affinitaires », une double appartenance contrastée}

3 Christine vit à Rabat depuis 35 ans. Titulaire dans l'éducation nationale française détachée au lycée français de Rabat depuis 22 ans avec un contrat de détachement. Elle est mariée avec un homme marocain avec qui elle a eu deux enfants, âgés de 22 et 26 ans. Au cours de l'entretien, elle délimite les différents milieux de sa vie quotidienne entre une sphère à laquelle elle se sent intégrée - sa famille, sa belle-famille, ses amis Français et Marocains -, et son milieu professionnel. Elle se sent davantage étrangère lorsqu'elle quitte ce milieu pour rencontrer d'autres personnes qui lui renvoient systématiquement sa position d'étrangère, malgré sa volonté d'intégration, notamment en parlant arabe. L'exemple de Christine est significatif d'un profil affinitaire. Une double appartenance s'est opérée au fur et à mesure de la socialisation dans l'environnement marocain. Pourtant, Christine souligne les limites de son appartenance au Maroc. Elle s'en est accommodée au fil du temps. Arrivée au Maroc avec son mari rencontré en France pendant leurs études, elle se dit " ouverte d'esprit ", et optimiste quant à ses capacités d'intégration dans une société qui lui est étrangère. Quelques années après son arrivée, elle a travaillé à Rabat pendant deux ans, alors que son mari terminait ses études au Canada. Vivant seule, elle rendait visite régulièrement à sa belle-famille qui vivait dans la médina de Marrakech et ne parlait pas français. Christine a alors appris à se débrouiller seule au quotidien et à parler en darija. Or, trente-cinq ans plus tard, elle évoque des "limites » à son intégration en insistant sur son repli au sein d'un groupe de personnes qu'elle connaît bien.

$4 \mathrm{Au}$ cours de l'entretien, elle évoque une société "très fermée", une intimité impénétrable de l'organisation sociale qui laisse l'étranger à une place extérieure. Elle explique que son expérience lui a appris à composer selon les limites que l'organisation 
sociale marocaine lui impose. Elle explique que son conjoint lui a permis un certain sentiment d'intégration, qui se joue dans la relation intime de la famille et du couple. Étrangers dans une société qui leur est familière, les "affinitaires" composent avec une double appartenance nationale ayant les avantages et les inconvénients d'un entredeux qu'ils transmettent à leurs enfants. En définitive, les « affinitaires » installés au Maroc ne se sentent pas vraiment intégrés, mais souvent très bien accueillis.

\section{Les « expérimentateurs », un séjour temporaire}

5 Aurélien, 42 ans, célibataire et sans enfants, est enseignant titulaire en France, détaché au lycée français de Casablanca depuis un an. Précédemment, il a enseigné en banlieue parisienne pendant sept ans et au lycée de Rabat pendant quatre ans. Pour lui, l'expérience d'enseignement hors de France est comme un voyage, une expérience temporaire caractéristique du profil expérimentateur.

Il met en avant l'apprentissage par expérience de sa situation d'étranger. Une analyse plus profonde de son parcours montre qu'il ne s'agit pas seulement d'un choix, mais aussi d'une détermination par des représentations du voyage, de l'altérité, des ascendances d'origine italienne, et une socialisation progressive au goût du déplacement. Comme d'autres enseignants rencontrés, le choix du Maroc se situe dans la continuité de liens en France avec des personnes d'origine maghrébine, soit des amitiés, soit des rencontres en tant qu'enseignant avec certains élèves et parents d'élèves. Si ces relations ont pu influencer le départ et le choix du pays, leurs affinités n'ont pas la force intégrative de celle des "affinitaires». Par exemple, pour les " affinitaires », l'apprentissage de l'arabe relève davantage d'une nécessité quotidienne de communication, notamment au sein de la belle-famille ou dans le cadre professionnel pour ceux qui exercent dans certains établissements marocains. Les " expérimentateurs " suivent un idéal d'intégration qui passe par l'effort d'apprendre la langue, même si ce n'est pas nécessaire dans leur environnement francophone quotidien.

7 Aurélien évoque la francophonie comme un critère déterminant pour le choix du Maroc. Arrivé avec ses représentations de l'immigration des Maghrébins en France, il dit avoir voulu se mettre "dans la peau de l'immigré » en observant que la position sociale des Maghrébins en France et des Français au Maroc «n'est pas du tout réversible ». En effet, les enseignants français subissent rarement des discriminations négatives et de rejet comme cela peut être le cas des Maghrébins en France ou des SubSahariens au Maroc. À la recherche d'expériences extraordinaires que leur offre leur nouvelle situation, les "expérimentateurs » trouvent les limites de leur intégration dans l'environnement qui les accueille et les cadres sociaux qui structurent leur séjour, comme le type d'établissement scolaire, la langue et le statut social des élèves. Leur environnement quotidien leur permet rarement de percevoir les multiples facettes de la société marocaine.

\section{Les « internationaux », une appartenance délocalisée}

8 Le profil des internationaux représente une opposition à la possibilité d'intégration. L'exemple le plus significatif est celui de Francis, 53 ans, professeur détaché dans une école primaire française de Casablanca. Résidant depuis sept ans, il a vécu dans sept 
pays différents en vingt ans, la plupart en Afrique, avec quelques séjours de plusieurs années en France. Il n'évoque aucun intérêt pour la langue et la culture marocaine. Lors de notre entretien, quelques jours avant l'Aïd El- Ahda, qui se déroule pendant les vacances, il prévoit de rentrer en France parce que «la fête du mouton n'est pas ma tasse de thé ». Représentant syndical, marié à une femme française, il se définit avant tout comme Breton et affirme ne pas se sentir plus acculturé au Maroc qu'en France, estimant que "c'est en France qu' [il a] des problèmes ». Il sous-entend ainsi ne pas se sentir intégré lorsqu'il rentre en France et revendique une appartenance régionale. Avec sa femme qui est française, ils gardent des habitudes de leur pays d'origine. Ses activités sociales sont essentiellement liées au syndicat des enseignants du primaire et sa participation à une association de Français hors de France. Il est davantage investi dans un réseau associatif transnational de la communauté française hors de France. Il a appris l'arabe au début de son séjour, mais s'est découragé devant la difficulté de la langue et le peu d'utilité qu'il y trouvait.

9 La particularité de Francis par rapport à Christine et Aurélien est que son déplacement ne s'inscrit pas dans une recherche personnelle de découverte, de rencontre, ou une réinvention de son histoire familiale. Le déplacement s'inscrit davantage dans la continuité d'une mobilité géographique familiale. Ses parents eux-mêmes ont été enseignants dans le primaire hors de France, principalement en Afrique, années durant lesquelles Francis a été scolarisé. Il a lui-même exercé plus de vingt ans dans sept pays différents entrecoupés de quelques séjours en France. Restant dans des cercles francophones, ses habitudes l'ont conduit à s'inscrire activement dans les réseaux associatifs transnationaux francophones en limitant son intérêt pour l'environnement social local dans lequel il ne se sent pas légitime de participer en tant qu'étranger, si ce n'est dans le cadre de l'exercice de sa profession.

\section{L'intégration, les difficultés d'une notion stricte}

Dans un pays qui se révèle depuis peu de temps comme un pays d'immigration, le terme « intégration » semble être importé spontanément, notamment par l'usage du français et l'enseignement francophone, par des étudiants marocains en France et certains intellectuels français ou franco-marocains. Mais la vision jacobine qu'il renferme estelle prise en compte dans ses usages au Maroc? Son usage est très discuté en France dans les sciences sociales, notamment du fait que ce soit un concept normatif et universaliste représentant le " point de vue du dominant sur le dominé » (Lapeyronnie, 1993, p. 17). Ses significations sont plus nuancées et peuvent se résumer entre une posture assimilationniste qui favorise davantage le point de vue des institutions et leur universalité et une posture multi culturaliste qui valorise le point de vue des individus et leurs particularités. Mais la plupart des auteurs français recommandent une vigilance particulière du fait de son caractère polémique. En effet, l'étendue de sa définition modifie la signification en fonction de la position sociale, le niveau et le type de formation du locuteur, le pays où le sujet est né, son histoire personnelle, ses intérêts et ses ambitions (Xavier de Brito \& Vasquez, 1996). Ainsi, le terme définit de manière très stricte un ensemble trop vaste pour décrire la réalité. Certains auteurs suggèrent de l'abandonner. D'autres proposent d'en mesurer rigoureusement les différentes dimensions selon des facteurs précis : l'emploi, le logement, la scolarité, la participation politique (Lapeyronnie, 1993). En France, le modèle d'intégration par 
assimilation s'inscrit dans une vision jacobine de la citoyenneté, ancrée dans des principes républicains aux ambitions universelles. Est-ce que ce terme de la langue française pourrait être pertinent dans la société marocaine ? Sur un plan socio-culturel, si certains enseignants français sont impliqués au sein d'associations humanitaires ou culturelles, aucune pratique assidue de l'islam n'a pu être observée ni de participation à des mouvements islamiques, tels que confréries soufies ou autres mouvements spirituels. Certains ont des affinités avec l'islam, une certaine connaissance du Coran ou une conversion pour leur mariage. Manger un couscous le vendredi, participer à l'Aïdel-Kébir ou comprendre et utiliser des expressions comme inch'Allah ou bism'illah sont monnaie courante. En revanche, rares sont ceux qui jeûnent pendant le ramadan, organisent l'Aïd chez eux ou se privent d'alcool. Les mariages franco-marocains sont généralement avec des personnes non pratiquantes. Si la plupart des enseignants français rencontrés ont appris des rudiments d'arabe, rares sont ceux qui en ont une maitrise courante car la communication en leur présence se fait généralement en français. Sur un plan économique, s'ils jouissent d'un confort indéniable par rapport à la majorité des Marocains, ils ne font pas non plus partie de l'élite économique au Maroc. Selon les cas, la place des Français au Maroc repose généralement sur un bon accueil, une hospitalité qui peut parfois sembler intéressée par la fonction privilégiée qu'ils occupent dans l'organisation sociale marocaine. Le Royaume chérifien étant régi par le droit du sang (jussanguinis), l'acquisition de la nationalité restant exceptionnelle et la cohésion nationale reposant sur l'appartenance religieuse avec le Roi comme commandeur des croyants, la place des étrangers ne se pose pas en termes d'intégration. Il ne s'agit pas d'un contrat social républicain centralisé. L'usage du terme intégration est un écueil de la francophonie qu'il conviendrait de redéfinir dans l'appréhension récente de l'immigration au Maroc. Pourtant, il est apparu de manière redondante récemment dans le langage courant, véhiculé par certains médias et discours politiques.

Il pourrait également être pertinent de se pencher sur les traductions du terme arabe ou d'usage au Maroc désignant la place de l'étranger au Maroc. La société marocaine développe un rapport spécifique aux étrangers en termes de discriminations et de différenciations fondées sur l'apparence physique et l'hexis corporelle. L'accès aux droits, les relations de pouvoir et les possibilités de mobilité sociale ne concernent pas seulement les étrangers, mais aussi les Marocains.

\section{BIBLIOGRAPHIE}

D. Lapeyronnie, L'individu et les minorités. La France et La Grande-Bretagne face à leurs immigrés, Paris, PUF, 1993.

D. Loch, « Integration as a sociological concept and national model for immigrants : scope and limits », Identities : Global Studies in Culture and Power, n² 21, Issue 6, 2014, p. 623-632.

D. Schnapper, Qu'est-ce que l'intégration ?, Paris, Gallimard, 2007. 
M. Wieviorka, «L'intégration : un concept en difficulté », Cahiers internationaux de sociologie, $n^{\circ} 125,2008$, p. 221-240.

A.-X. de Brito, A. Vasquez, «L'intégration, mais qu'est-ce donc? Analyse fondée sur une recherche ethnographique au niveau du collège », Revue française de pédagogie, $n^{\circ} 117,1996$, p. 29-37. 


\title{
Nomadic Paths to Modes of Being and Ways of Cosmopolitan Becoming in La littérature-Monde :Youssouf Amine Elalamy's Amour Nomade (2013)
}

\author{
Valérie K. Orlando
}

1 As in most developing countries, literature offers a barometer for socio cultural change and a way to document social issues and the sometimes socio-political « schizophrenia » of nations on the fast- track of globalization. Since 1999, Morocco has witnessed huge socio- political transitions which have influenced democratic reform.

Encouraged by increased transparency, promoted by a more democratic monarchy led by King Mohamed VI, men and women authors writing in French and Arabic as well as Spanish, English, and even Moroccan Arabic (Darija), are not only exploring the sociocultural and political debates of their country, a nation like others in the Arab world in transition, they are also engaging with some of the most poignant human rights and environmental issues of our era. Their work represents a cosmopolitan world view that privileges transnational and transcultural exchanges.

\section{Introduction : Yae and Moroccan cosmopolitanism}

3 Youssouf Amine Elalamy, popularly known in Moroccan francophone literary circles as "YAE ", is one of the most dynamic and transnationally known authors of French expression writing in Morocco today. YAE's work is at the forefront of an engaged cosmopolitan discourse, defined by Anthony Appiah as englobing two ideas :

One is the idea that we have obligations to others, obligations that stretch beyond those to whom we are related by the ties of kith and kind, or even the more formal ties of a shared citizenship. The other is that we take seriously the value not just of human life 
but of particular human lives, which means taking an interest in the practices and beliefs that lend them significance. People are different, the cosmopolitan knows, and there is much to learn from our differences.

Today, in cosmopolitan Morocco, YAE's work also engages with what philosopher Abdelkébir Khatibi designates as "une pensée-autre ", an-Other way of thinking about otherness and marginality (Khatibi, 1983). In the last decade, this " pensée-autre " has inspired increased literary production in French on topics that extend beyond the country to include other parts of the Maghreb, Africa, and the globe: «Oui, trouver autre chose, se situer selon une pensée-autre, une pensée peut-être inouïe de la différence. Oui, oui, une telle libération est rigoureusement nécessaire pour toute pensée qui se réclame ainsi de sa volonté, en un risque qui ne peut qu'être grand, de toutes les manières » (Khatibi, 1983, p. 11).

5 YAE's works, both as a novelist and a visual artist, capture the shifting boundaries and the winds of change taking place in Morocco and, indeed, across the globe. His novels, Un Marocain à NY (1998), Les Clandestins (2000), Oussama, mon amour (2011) and Amour nomade (2013), translated into multiple languages, are at the forefront of novels that thematically explore the challenges of the 21st century, while also experimenting with the very foundation of narrative form and language use. Themes tackling poverty, inequality, immigration, women's rights and human rights, terrorism and the political tensions between the West and the Arab world in our post-9/11 era are just some of the subjects depicted on the pages of Elalamy's works. For the purposes of this article, I will concentrate on Amour Nomade (2013), and cite his essay, A Novel in the City (2014).

\section{Littérature-monde, afropolitanism and « making the story go » in our era of globalization}

6 YAE's novels, certainly the most recent, Amour nomade (2013) and Oussama, mon amour (2011), both of which place a young man inthe midst of intense sociocultural as well as personal questioning, also represent a new kind of cosmopolitan African writing. This 21st century form promotes an Afropolitan world view construed through French expression that is inspired by the transnational exchange that takes place in what Michel Le Bris defines as

«La littérature-monde»:

[ «ittérature-monde, très simplement, pour revenir à une idée plus large, plus forte de la littérature, retrouvant son ambition de dire le monde, de donner un sens à l'existence, d'interroger l'humaine condition, de reconduire chacun au plus secret de lui-même. Littérature-monde, enfin, à l'heure où sur un tronc désormais commun se multiplient les hybridations, dessinant la carte d'un monde polyphonique, sans plus de centre, devenu rond... (Le Bris, 2007, p. 41-42).]

7 Works produced by authors writing from/in «La littérature-monde » who hail from African, historically francophone, countries view French as a lingua-franca encouraging a pan-African spirit that reaches not only other Maghrebis who speak French, but beyond, to the larger diaspora. Writing today from a francophone, African transnational perspective, renders authors such as Elalamy and Fouad Laroui from Morocco, Malika Mokeddem and Boualem Sansal from Algeria, Calixthe Beyala from Cameroon, Alain Mabanckou from the Congo, Marie Ndiaye from Senegal and 
Abdourahman Waberi from Djibouti, among many others, as true Afropolitans, who are dedicated to a world view construed within the parameters of Cameroonian Achille Mbembe's definition of Afropolitanism, as a «stylistic, an aesthetic and a certain poetics of the world. It is a manner of being in the world which refuses, on principle, any form of victim identity", but at the same time, "does not mean that it is not conscious of the injustices and the violence which the law of the world inflicted on this continent and its people » (2006).

8 According to Mbembe, the Afropolitan model offers a theoretical framework that disassociates itself from past literary moments which, today, have little relevance for globalized transnationally driven societies. Mbembe clarifies that the three previous literary movements that significantly shaped the themes of the novel after decolonization-anti-colonial nationalism, African socialism, and pan- Africanism-no longer qualify as helpful frameworks through which to study the position of authors who are often mobile, living and travelling constantly between continents, cultures, and modes of creativity. The Afropolitan novel of the 21st century defines a way of being African in the world that disassociates the author from the quotidian postcolonial tropes of previous decades.

9 For Elalamy and the authors writing in an Afropolitan framework, the French language is transnational, "absorbed», as Le Bris notes, "par un processus continu d'hybridations multiples » (2007, p. 40). Transformed and hybridized, novels in French cross linguistic and cultural boundaries to become, "une littérature nouvelle, bruyante, colorée, métissée, qui [dit] le monde en train de naître » (Le Bris, 2007, p. 32). Crossing borders, honing in on the human issues of our times, makes YAE's novels relatable to readers all over the world.

Un Marocain à New York (1999) focuses on turning the stereotyping, Western gaze on the Arab-Other back on itself, creating a critique of American culture that is humorous and thought-provoking. Les Clandestins (2001) is a novel about illegal immigration and the dangers it presents to those who decide to leave their homelands for Europe in hope of a better life, only to discover that such a life is impossible. Oussama, mon amour is a work that engages with the topic of disenfranchised youth who often feel, no matter their country of origin, disconnected from their society and culture due to limited socioeconomic prospects. In the end, out of desperation, they are pushed to commit acts of violence. Amour nomade is a novel featuring a protagonist who seeks to nomadically trace lines between ways of telling a story that captures the elements of our common, human condition. These narratives all denote the author's ability to cast his literary net wide. Elalamy's net is one made from a fabric of mixtures and penséeautres. Not totally rooted in any one identity (Moroccan, Arab, Berber, French), his novels, rather, exude a range of multiple human emotions recognizable by all who read them. YAE, as an Afropolitan author, working within the Littérature-monde ideal, knows that his creativity is generated through perpetual movement-- déplacement. The author's protagonist, Tachfine's, very survival and sense of being-in-the-world are grounded in the knowledge that « en tant que nomade et fils de nomade, il sait que l'espoir de survie réside dans le mouvement et le déplacement d'un point vers un autre » (Elalamy, 2013, p. 155).

11 In general, what is evident about African authors writing in the 21st century, is not uniquely that the Afropolitan author's world is " en train de naitre ", but also that his/ her text is being born in a new form, as the very boundaries of the Western novel and 
the French language are challenged, fragmented, and reconstructed to reflect new systems and ways of looking at the world. Particularly YAE's most recent novel, Amour nomade, exemplifies a fusion of Western and African conceptions of narration, entreating readers to meld with narrators in order to traverse the unknown and the unexplored.

Elalamy's most recent novel is not only a "novel » on paper, bound between two covers, it is also a parallel, visual, three-dimensionally conceptualized art form : Amour nomade was first a virtual novel that was "performed » and internationally "shown » across Morocco and Europe. As a three dimensional, live work, it encourages the active participation of readers, while also entreating participants to think about the reconceptualization of what The Novel is and will be in the future. YAE's international project has physically taken a nomadic journey to Rotterdam, the Netherlands (April 2009), Rabat, Morocco (June 2009), Copenhagen, Denmark (December, 2009) and Cologne, Germany (October 2011). The author's A Novel in the City on which Amour nomade is based, is his pictorial, interdisciplinary and cross- national artistic installation that challenges notions of reading a text while it promotes the visual representation of the written word.

For the first time ever, a novel is published in a "city format » rather than a «book format " Entirely handwritten, the novel occupies the walls, buildings and other spots of a city. The story unfolds as a gigantic ink worm that gradually « infects the city » As the storyline progresses, so does the literary virus that ends up contaminating the urban space. This latter becomes a narrative in itself, a place of encounters, emotions, discovery and exploration. Just as the walls of the city help read the story, the narrative, in its turn, takes the readers on a walk through the city; thereby helping them read the city as well. Entitled Amour nomade, YAE's urban installation novel will enable the reader, who will have to keep on walking and progressing in space, to literally experiment nomadism. (Elalamy, 2014).

As a visual story written " on a city ", YAE's principal protagonist, Tachfine's, journey becomes universally everyone's to see-no matter their language or their nation. As conceptualized in the nomadic model framed in Mille Plateaux: Capitalisme et schizophrénie (1980) by French philosophers, Gilles Deleuze and Félix Guattari, Elalamy's story picks up speed "to deterritorialize », challenging borders as it carries us off to other places, times and ways of knowing. Readers, caught up in the visual experience of reading in/on a city, like nomads, are compelled to "faire avancer l'histoire ». Elalamy notes that with the novel on the city, Amour nomade obligates the reader ..... to move ahead through the city to keep the story alive and hopefully find the much expected food for thought. In both cases, the reader is taken on a journey, with a beginning and an end, with places to simply pass through, hurry, traverse, and places to linger in, dream away by, return to. By using the city as the story's support structure, the project emphasizes that every city is an open book ready to be discovered (the different spaces, the architecture, the urban design, etc.). (Elalamy, 2014). 


\section{Nomadic thought and Becoming in Amour Nomade: Tachfine's Becoming-Nomad and Being-in-the-World}

"Moving ahead» to "keep the story going" are the defining characteristics of Elalamy's Amour nomade which reflect also the larger commitment to the national and global transcultural contributions that Morocco today is making. YAE's novel inspired by movement and deterritorialization that take the protagonist, Tachfine, to new ways of being and becoming. Amour nomade is "une histoire entièrement écrite avec de l'eau » about a young man whose nomadic tribe, the Beni Maarouf, face great hardship in the vast desert of an unnamed country. In order to survive, the protagonist leaves the safety of the tribe to embark on a nomadic quest that takes him to other stories, adventures, and modes of being-in-the-world. Tachfine «n'est pas vraiment le héros mais c'est quand même lui qui fait avancer l'histoire" (Elalamy, 2013, p. 12). Although a modern tale, the novel is inspired by centuries of Maghrebi storytelling, reflecting the great narratives of yore such as Kitäb alf laylah wa-laylah (One Thousand and One Nights [Arabian Nights]).

The author's novels are not just about one region, one continent or one tribe, but rather the nomadic lines of flight that are possible in the Littérature-monde that men and women, as narrators and protagonists, follow in order to enrich their own being as they enrich others'. In YAE's words, « tout le monde est nomade » (Elalamy, 2013, p. 15). The nomad's world is where the individual establishes what Martin Heidegger named long ago as a Being-in-the-world, wherein there is « an understanding of existence-an understanding of the being of all beings...other than its own » (Heidegger, 1962, p. 33). This being is understood as connected to and formulated by a Being-already-alongside with others. As the philosopher explains in Being and Time, «Being-in-the-world is not just a fixed staring at something that is purely present-at-hand.... [it is] fascinated by the world with which it is connected» (Heidegger, 1962, p. 88).

This article, thus, seeks to explore the intersection of Elalamy's visual work and his prose by delving into what "makes his stories go ». I maintain that while he is a Moroccan author, and particular characteristics of his novels are inspired by his Moroccan identity, he is more an international, Afropolitan writer who seeks to connect with others across the world in order to establish new paths to and from narrative traditions, languages, modes of being and ways of thinking. These transnational connections are possible, in part, because they revolve around issues that appeal and are pertinent to our common humanity.

\section{BIBLIOGRAPHIE}

K. A. Appiah, Cosmopolitanism : Ethics in a World of Strangers, New York, Norton, 2006.

G. Deleuze and F. Guattari, Mille plateaux : capitalisme et schizophrénie, Paris, Les éditions de Minuit, 1980. 
M. Heidegger, Being and Time, New York, Harper Collins, 1962.

M. Le Bris, Pour une littérature-monde, Paris, Gallimard, 2007.

A. Mbembe, « Afropolitanisme », Africultures, $n^{\circ}$ 66, 2006.

A. Khatibi, Amour bilingue, Montpellier, Fata Morgana, 1983.

Y.-A. Elalamy, Amour nomade, Casablanca, La croisée des chemins, 2013. 


\section{From Slavery to the Screen : Sub- Saharan Migrants in Moroccan History and Cinema}

Jamal Bahmad

1 In recent years, there has been a remarkable growth in both global interest and academic research on migration in the Mediterranean region. The debates have been dominated by security questions and the increasing fortification of passageways into the global North.

2 In the meantime, southern Mediterranean countries like Morocco have seen a rapid transformation from transit migration zones to destination countries on the edge of Fortress Europe. However, so far little academic research has been carried out on the social and cultural representations of migration candidates in the destination countries of the Global South. Migration in its various concrete and imaginary manifestations has become a dominant theme in Moroccan cinema in the new century. Drawing on my extended research on Maghrebi cinema in the era of globalisation, this article aims to articulate the condition and unheard voice of sub-Saharan migrants in Moroccan cinema. A focus on film as a popular art allows for an in-depth investigation not only of the social and cultural representations of continental migration in Africa, but also crucially for a close examination of the lesser-known role of the sub-Saharan migrant in the cultural production of the self and the Other in Morocco today. As I will demonstrate through a critical reading of the growing body of films featuring subSaharan characters, Moroccan filmmakers have mobilised the increasing presence of sub-Saharan migrants in Moroccan society to question national identity and the ambivalent Othering of the country's Africanness in its discourses and practices. In the second part of this article, I will argue that sub-Saharan migrants on screen are not passive victims of power relations, but instead active agents of social change and the articulation of new cosmopolitan visions in the face of the colonial present. The prevalent dreams about migration on screen are not simple dreams but rather fragments of a sophisticated critique of neoliberal globalisation. 


\section{Routes and roots : the sub-saharan presence in Morocco}

3 In an interview with the Moroccan history magazine Zamane, Choukri El Hammel, author of Black Morocco: A History of Slavery, Race and Islam (2012), asserts that racism is deeply rooted in Moroccan society and is even constitutive of national identity. This goes against the grain of the long-held belief that racism is the preserve of Western capitalist societies. In fact, as El Hammel and other historians of race like Mohamed Ennaji (2007) have shown, racism and racial segregation have existed in Morocco and Muslim-majority countries long before the hegemonic rise of the modern West and its colonial domination of Islamic lands. Whilst the Quran is said to be clearly against racism and slavery, the latter has been an essential component of Muslim societies from the beginning. Religious scholars have often justified this practice in response to the labour and ideological needs of their societies. El Hammel focuses his study on Morocco where throughout history the institution of slavery was justified in the name of religion. He cites the example of the Moroccan sultan Moulay Abderrahmane. When approached about the subject of abolition by a British delegation headed by Sir Drummond Hay, the British consul in Tangier, in 1842, the Moroccan sultan's response was clear: «Know then that the slave trade is a subject on which all sects (religions) and all nations have agreed from the age of the sons of Adam until today, and that we know of no sect whose laws prohibit it, and no one has had to ask these questions before, because the issue is evident at all levels and therefore needs no more proof for it is as clear as daylight " (qtd. in Tourabi 2013, p. 41).

Even enlightened historians like Ibn Khald un justified slavery and racism on the basis of the black race's alleged inferiority. In his Muqaddima, he asserts : "The only people who accept slavery are the Negroes, owing to a lower degree of humanity and their status being closer to the animal stage » (qtd. in Tourabi $2013: 41$ ). Like most societies that practiced slavery, Morocco was also the scene of abolitionist discourses and treatises. The influential Moroccan historian Abu al-Abbas Ahmadibn Khalid al-Nasiri al-Slawi, for example, wrote in his magnum opus Kitab al-Istiqsa li-Akhbar duwwal alMaghrib al-Aqsa in the late 19th century : «I am talking about this social plague which is the enslavement of blacks from the Sudan, whatever the confession of the race to which they belong, Muslim or pagan, that we are used to taking from their countries in large numbers every year, like sheep for sale in auction as beasts of burden, or even more indecently, in the urban and country markets of the Maghreb. [...] People shamelessly turn a blind eye to this crime which has been committed in broad daylight from generation to generation, so much so that the mass of people believe that the justification of slavery lies in dark complexion and origins from the Sudan. By God, this is one of the most abhorrent and serious practices in matters of religion " (qtd. in Tourabi 2013, p. 42)

5 In the modern period, slave trade intensified and Morocco witnessed the arrival of dozens of thousands of sub-Saharan slave labourers and soldiers. Despite important regional variations and the widespread societal prohibition of interracial marriage, the influx of sub-Saharan populations gradually changed Moroccan society and culture. The region of Tafilalet in south-eastern Morocco, for example, sits at the juncture of the main traditional caravan routes between Europe and the Maghreb to the north and Timbuktu and the rest of Africa to the south. This geostrategic location has put the 
desert region at the crossroads of historical exchanges between Africa north and south of the Sahara. Trans-Saharan trade, slavery, scholarly and religious exchanges, military expeditions and other forms of contact such as the rise of powerful dynasties, whose influence extended to both sides of the Sahara, have all combined to shape the culture of the region. Less known, however, is how Tafilalet today remains a unique and dynamic contact zone of cultural exchange between two allegedly sealed-off parts of the African continent. The predominant image of a rigidly divided Africa is premised on the trope of the Sahara as a cultural vacuum and an impenetrable border dividing the continent into the northern 'white' and sub-Saharan 'black' Africa.

6 However, besides the ethnic mosaic of the Tafilalet desert made up of Imazighen (Berbers), Isemkhan (descendants of sub-Saharan slaves) and Arab settlers, local music is testimony to a strong movement of cultural circulation and human mobility across the Sahara. Popular culture in the region is living proof of how African cultures circulate and influence one another across the porous and nomadically inhabited Sahara. The local population today continues to perform its Africanness through musical forms inherited from centuries of cross-Saharan exchange.

7 In the twenty-first century, Tafilalet's popular culture is not only dynamic but also going global. Traditional performance music and arts in particular are thriving owing to their incorporation into the cultural economy of international tourism, which has become a major source of income for local communities. The actors in the tourism sector have savily mobilised cultural heritage and folklore for the entertainment of international holidaymakers in the towns and villages of Tafilalet. Khamlia is a small village located on the edge of the sand dune attractions of Merzouga and only a few miles from Sijilmassa, the historic city whose rulers (including the current Moroccan monarchy), religious brotherhoods and scholars exerted considerable influence from Muslim Spain to the Sahel region.

8 The Khamlia villagers are descendants of slaves brought to the region from West Africa between the 16th and 19th centuries. They worked the land for the nomadic Ait Khabbash, a white Amazigh (Berber) border community and part of the Ait Atta tribal confederation. Slavery waned from the nineteenth century onwards and was formally abolished after the French colonial conquest in the 1930s. The Khamlia villagers were granted land rights by the Ait Khabbash and lived on subsistence farming and jobs at a nearby lead mine. The mine closed down in the 1970s, but the rapid growth of international tourism in the region over the last three decades has created employment opportunities in the village. Most permanent or seasonal jobs are centred on the performance of Gnawa music, particularly slave blues, which the villagers have kept alive over time thanks to performances at weddings or on the occasion of religious ceremonies such as Eid Mawlid (Prophet Muhammad' Birthday) and Eid al-Adha (Feast of the Sacrifice).

However, Khamlia and Tafilalet are relative exceptions in a country still largely racially segregated. Morocco's rich contact with sub-Saharan Africa has largely been kept out of school textbooks. This culture of denial fuels racism against sub-Saharan migrants and refugees in Morocco today. The rate of racist and criminal behaviour has increased in tandem with the growing numbers of migrants and displaced persons arriving in Morocco. Whilst they often come here with the dream to cross to an ever increasingly fortified Europe, the reality today is that they are unlikely to go beyond Morocco or return to their countries of origin. What I call the reluctant diaspora is growing in size 
and is trying to craft a place for itself in a hostile environment. In recent years, Morocco has come under pressure to act against mounting racism toward this vulnerable community. International organisations have demanded that Morocco introduce new legislation to combat racial discrimination and acts of violence against sub-Saharan immigrants. In January 2014, the country reluctantly introduced a residence permit application system to regularise the situation of refugees and undocumented migrants and refugees from sub-Saharan Africa, Syria and further afield.

10 However, the system has been criticised by human rights activists in Morocco and abroad for being discriminatory against the majority of sub-Saharan migrants, who arrived illegally and undocumented in Morocco years. Whilst the legal dispute over the new migration laws goes on between the Moroccan state and civil society activists, the saga and suffering of sub-Saharan migrants in Morocco goes largely unheard and often in total indifference from the rest of society.

\section{Screening the Other Within}

11 Sub-Saharan characters began to make a remarkable appearance on Moroccan film screens in the early 2000s. This obviously goes hand in hand with the growing presence of sub-Saharan (im)migrants in the kingdom. What is also remarkable is that these human populations are kept in the background of the action in what is obviously a reflection of their marginal status in society. With the rare exception of films like Leila Kilani's documentary Tanger, le rêve des brûleurs (Tangier: The Burners' Dream, 2003), Moroccan films have tended to feature sub-Saharans individuals and communities as secondary visual indicators of a changing society. This is the case, for instance, in Faouzi Bensaïdi's neo-Noir thriller What a Wonderful World (2006).

A number of sub-Saharan characters feature in this film, but they hardly have a voice of their own. They are the quiet embodiment of displacement and deadly dreams of an impossible departure to Europe. Hicham in What a Wonderful World is the prototype of the underclass youth in Casablanca torn between the illusory attractions of the Western El Dorado disseminated by global techno scapes, on the one hand, and his physical confinement on an impoverished continent by the same globalisation's neocolonial mechanisms, on the other. This paradoxical unevenness of global capitalism creates a lethal dreamscape, whereby youth are disembedded from their local reality whilst being condemned to tragic attempts at an impossible migration to the North. At the end of the film, the boat on which Hicham and sub-Saharan migrants leave Morocco is crushed by a titanic cruise ship in the Mediterranean.

13 In another Casablanca-set film from the early 2000s - Mustapha Derkaoui's Gharamiyat al-Haj Mokhtar Soldi (The Love Affairs of Haji Mokhtar Soldi, 2000) - the eponymous lead character is seen at one point urinating down a bridge on barely visible sub-Saharans sitting around a camp fire underneath. The peeing Haji ironically declares that this country has been soiled by these undesired persons from West Africa. The speechless (im)migrants feature only for a few seconds on the screen. They do not even protest against this inhumane treatment in a society that has condemned them to live or rather survive on the margins. They are not entitled to even basic human rights like respect and peaceful existence. Put within this film's critical discourse about the state of neoliberal Morocco at the turn of the new century, we are led to conclude that even 
if sub-Saharan characters do not feature prominently in Moroccan films of that period, they are in fact a measure of a changing society's loss of human values and solidarity. Derkaoui thus mounts a critique of neoliberal globalisation from below, that is, from the perspective of its victims. This cinematic discourse is even more evident in another popular film made by Derkaoui three years later. Casablanca by Night (2003) is the story of Kelthoum, a young girl from the Old Medina forced into underage prostitution by the dire economic needs of her family in search of a colossal sum of money to pay for a heart operation for their youngest child. The film revolves around the difficult life of the characters and their brutal exploitation at the hands of the neoliberal lords of 21stcentury Casablanca. What is more is there is even worse than life under these circumstances.

In Casablanca, there are multiple others without a name or any rights to the city or even to their humanity. This is illustrated by a fleeting moment in the film when a nameless sub-Saharan migrant is hit by a red cab in the streets of downtown Casablanca. The poor man simply dusts himself and swiftly disappears into the mean streets of Casablanca by night. He is probably afraid to be arrested by the police and be deported to a no man's land on the Algerian or Mauritanian borders.

This kind of 'life' recalls Giorgio Agamben's theory of homo sacer or non-sovereign subjects living in "a state of exception" a permanent state whereby the Law is suspended $(2005$, p. 40$)$. Their life or deaths are equal because they are conceived as «bare life » (Agamben 1998, p. 4). Derkaoui's film thus associates the bare life of subSaharan migrants to that of poor Moroccans in what turns out to be a critique of market globalisation's transformation of Casablanca and Morocco. In other words, socioeconomic injustice has reduced poor Moroccans like Kelthoum and her family to this bare life embodied by sub-Saharan migrants. This puts the invisible sub-Saharan characters on screens into a central piece of Moroccan cinema's representation of a changing society in the era of globalisation. Social and economic injustice has created multiple Others in this society so much so some sections of society are as vulnerable and disposable as are the lives of sub-Saharan migrants in this country. Moroccan cinemas puts up the mirror to society by foregrounding the bare lives of the Others within, be they sub-Saharan migrants or poor Moroccans living under precarious conditions.

The increasing visibility of sub-Saharan individuals and communities on Moroccan films screens reflects the growth in size and kind of this community in Morocco today. Sub-Saharan migrants on screen are not passive victims of power relations. Through their association with struggling Moroccan characters, they become instead active agents of social change and the articulation of new cosmopolitan visions in the face of the colonial present. Moroccan filmmakers have zoomed in on both vulnerable social groups in the new century to articulate a postcolonial critique of a society rapidly transforming in conditions of neoliberal capitalism since the introduction of market reforms in the 1980s. The prevalent dreams about migration among poor Moroccans and sub-Saharans on screen are not mere dreams, but rather elements of a sophisticated critique of neoliberal globalisation. 


\section{BIBLIOGRAPHIE}

G. Agamben, Homo Sacer : Sovereign Power and Bare Life, Stanford, Stanford University Press, 1998.

G. Agamben, State of Exception, Chicago, Chicago University Press, 2005.

C. El Hammel, « Les noirs ont été marginalisés », interview, Zamane, 36, novembre 2013, p. 62-63.

A. Tourabi, « Au pays des esclaves », Zamane, 36, novembre 2013, p. 42-44.

A. Tourabi, « Racisme ancien, racisme moderne », Zamane, 36, novembre 2013, p. 40-41. 


\title{
Communautarisme, cosmopolitisme, internationalisme. Étude de cas de la région Atlantique
}

\author{
Suleiman G. Nasser
}

Nous appréhenderons notre questionnement sur la migration en termes d'anthropologie politique, dans l'interaction entre les processus de migrations internes, la transformation du régime économique local et les effets culturels et sociétaux de la mondialisation. La notion de civilité est à notre sens essentielle pour qui veut comprendre les formes politiques et collectives d'interprétation et d'adaptation d'une communauté rurale. Notre étude porte sur la localité d'Azemmour, ville située au sudouest de Casablanca $(72 \mathrm{~km})$ et à côté d'El Jadida $(16 \mathrm{~km})$ à l'embouchure du fleuve Oum Errabiaa. Cette localité rassemble à la fois les populations rurales, lors des occasions festivalières, en particulier en été, et les marchés du mardi où se retrouvent les paysans de la région. Cette petite ville dans la zone Atlantique du Maroc se situe dans l'interaction entre les processus de migrations internes, de transformation du régime économique local et des effets culturels et sociétaux de la mondialisation. à partir des années 80 puis, dès la moitié des années 90 , le gouvernement marocain a proposé des programmes successifs de développement pour les populations rurales. Cette politique a eu des effets plus ou moins limités concernant Azemmour et son aire d'influence (la zone Ouled Rahmoun): le mal-développement reste massif dans une zone profondément déchirée par les tensions entre migration interne (vers Casablanca) et développement touristique (vers El Jadida).

2 Nous sommes en effet dans un état de spéculation qui se traduit par une économie litoralisée, avec l'effet particulier d'un «tourisme de casino » (à Mazagan/El Jadida), accompagné d'un relatif développement touristique à El Jadida. Les populations rurales interagissent de manière plus ou moins passive aux différentes échelles de l'espace public, c'est à dire la communauté rurale, l'arrondissement (douar) et le chef-lieu "Azemmour ", qui reste officieux puisque c'est la ville d'El Jadida qui est la capitale officielle de la région Atlantique. Cette division administrative ne correspond pourtant pas à la réalité de la fabrication et de la répartition de la parole publique, qui reste 
largement communautaire et lignagère. La zone Ouled Rahmoun n'a pas véritablement remis en question la légitimité de la tradition orale comme moyen de transmission d'un mode de légitimité entre les générations.

3 Dans les communautés locales, les mutations économiques et culturelles ont bouleversé les modes de vie en créant un fossé entre les générations. Les aînés sont en possession de nombreux savoirs qu'ils ont eux-mêmes reçus par voie orale, suivant la tradition. Les instruits qui ont bénéficié à différents degrés de la scolarisation n'appartiennent de fait qu'à l'espace dit moderne de la vie sociale et professionnelle, ayant souvent très tôt quitté le milieu familial pour la ville. Cela suscite une réflexion générale : plus le degré d'instruction est prononcé, induisant un accès facilité à la liberté personnelle et à l'autonomie, plus les individus renforcent leurs compétences et leurs capacités d'adaptation. Ils abandonnent alors plus ou moins progressivement des savoir-faire traditionnels hérités de leur milieu d'origine. Ce processus de déculturation se construit en rupture avec la narration de la tradition. Ce présupposé se retrouve encore dans la politologie marocaine actuelle où la question du pouvoir est toujours inférée à une asymétrie nationale ou idéologique de type laïc ou religieux. Peut-on mettre de côté cette optique trop présente et poser le sujet de manière différente ? Ne faut-il pas déterminer les objets d'abord comme des modes sociaux de représentations? Le philosophe Balthazar Gracian pose dans ce sens la question des affects dans la construction collective et du rôle de la civilité dans les formes de légitimation et de délégitimation des acteurs. Le sociologue Norbert Elias peut également être mobilisé par son idée de «société de cour ", ou curialisation de la société, où le paraître détermine un pouvoir et un type de discours politique dans l'ordre social dominant. Il existe une civilité rurale et elle a des règles politiques et sociales précises. La civilité rurale permet de donner un sens aux processus de transformations politiques, sociales et culturelles liés d'abord à la mobilisation des représentations et des lignages. La communauté rurale, le clan, l'unité familiale produisent des principes supérieurs en vue d'homogénéiser la réalité sociale et ses contraintes. «La Raison du lignage » constitue, dans notre sphère d'analyse, la grille de lecture permettant de définir les choix et compatibilités au nom d'une référence supérieure susceptible de transcender les clivages inhérents aux collectivités humaines. Cela se traduit par une politique d'alliances et de stratégies matrimoniales qui, à travers les différentes périodes de l'histoire personnelle et collective, définit l'identité légitime, le rôle des protagonistes ou la figure de l'ennemi. Chaque unité familiale a sa narration du pouvoir, sa propre lecture de la grandeur et du déclin, de la réussite et de l'échec. Toute unité collective représente idéalement une nation avec ses propres règles de conduite, ses normes, ses déficiences et ses forces. Dans le cadre de notre étude, le départ des «jeunes», la réduction des modes de subsistance dans le douar, ainsi que la difficulté de maintenir une socialisation légitime par le mariage et le travail agricole, interrogent la capacité de la collectivité humaine à conduire son existence, à assurer sa légitimité face à d'autres acteurs, à présenter une vision de son passé, de son présent et de son avenir collectif.

Chez les Charkawa - famille dont le nom étymologique chark induit des origines du Moyen-Orient et qui revendique une ascendance généalogique avec le calife Omar -, le principe déterminant reste la stratégie matrimoniale et la politique d'alliance. L'efficacité de celles-ci comporte généralement de la part du clan une dénomination positive vis- à-vis des mariés et de leurs descendants, à qui le terme "fils de Sidi » notifie la reconnaissance lignagère et clanique. Cette représentation est souvent 
rattachée à l'ordre ancien, l' "ordre des hommes", où les mariages sont d'abord le résultat de liens consanguins et d'un modèle endogame de type familial. Le caractère biologique des relations est prédominant, comme le souligne Zohra lorsque je l'interroge sur le rôle des femmes: "Avant nos familles se mariaient entre eux, entre Charkawa, on gardait le sang entre nous. Les hommes avaient une valeur, il y avait la nya [la bonne intention]. Maintenant ce n'est plus pareil. On ne veut plus choisir [son conjoint] dans la famille. On prend la première femme venue qui ne cherche pas à respecter la famille. Les hommes d'aujourd'hui veulent être aidés. On ne veut pas laisser sa femme s'occuper de la maison. On veut qu'elle travaille (...) Que reste-t-il des hommes?».

5 Pour Zohra la présence des femmes dans l'espace public et dans les lieux de travail est présentée comme un signe de la " décadence des hommes » c'est-à-dire de la réduction de leur place politique dans l'ordre communautaire. À partir de cette lecture se configure une dynamique de pouvoir et de perte du pouvoir, ce dernier entendu comme capacité de commandement et de décision dans le clan par l'homme.

6 Toute stratégie matrimoniale extérieure, qui se voudrait émancipée des logiques consanguines et patriarcales est vue comme porteuse de dissensus et de rupture dans l'ordre social. A contrario, toute politique suscitant les unions familiales jugées bénéfiques pour le groupe est vécue comme consolidant le principe même de la communauté clanique. Le pouvoir est représenté soit comme extérieur, c'est-à-dire utilisé par des acteurs non légitimes, soit comme interne, avec un principe d'ordre social et familiale.

7 La politique communautaire se définit d'abord par son clan et son sang: Amiyine et Charkawa, se construisent chacun par une politique solide d'alliances matrimoniales et de réseaux d'intérêts. Le principe structurant de tout discours du gouvernement familial étant la solidarité et son efficience, chaque difficulté interne est renvoyée à l'entrée dans le clan de facteurs étrangers, généralement des femmes épousées en dehors de la famille proche. Cette configuration symbolique et psychologique subit cependant une lente modification.

8 Le territoire du clan se dilate dans un nouvel espace moins défini par des allégeances claniques que par des nécessités sociales et économiques. L'altérité réside moins dans l'autre clan que dans l'émergence d'une culture importée du monde urbain. Dans les représentations, le danger ne réside plus uniquement dans l'effacement du modèle endogamique mais dans la mise en question des catégories traditionnelles d'identités et de normes définissant les critères d'inclusion et d'exclusion au groupe social, représenté par le clan et son sous-groupe qu'est la famille. La rétraction du territoire géographique et symbolique du clan, ainsi que l'effet de rapprochement avec les centres périurbains et urbains (Azemmour, El Jadida) brouillent l'identification au modèle traditionnel. Le "légendaire clanique ", produit successif de l'accumulation de mythes, de générations, de souvenirs, a de plus en plus de peine à alimenter l'univers symbolique des hommes et des femmes de Douar Hawzia. La conséquence visible est la migration, mais de manière plus profonde elle se trouve dans le sentiment de fragilité identitaire et territoriale, lié notamment à l'échec dans le devoir de protection caractéristique d'un groupe social endogamique. Une sorte de sentiment de vide devant le gouffre se fait jour dans les discussions et les représentations des habitants du douar. Les récriminations sur le délitement des liens familiaux et sur le rôle prédominant de l'argent dans les relations sociales, sont des exemples de ce nouveau discours critique 
qui fait le constat d'une lente érosion de la mémoire collective et du «légendaire clanique ».

9 Le sentiment de désaffiliation conduit à une «identité désarticulée » : l'individu ne se perçoit plus comme maître de son territoire symbolique et géographique. Il ressent un déclassement psychologique lié au processus de déracinement culturel. Le projet familial ne consiste plus à assurer à long terme la pérennité du lignage mais se réduit à concentrer, au jour le jour, tous les efforts à la survie du groupe social qu'est la famille. La terre, c'est-à-dire le territoire, ne constitue plus un ancrage suffisant de légitimité, comme espace de ressource et d'affiliation. La solidarité, donnée par le lien organique entre les membres de la famille, tend à devenir un principe irréductible aux éventuels changements de résidences, de localisation et de migration. Elle se transforme et se manifeste dans un nouveau vocabulaire de la dépendance économique entre les " anciens ", restés dans la communauté, et les "enfants ", obligés de quitter l'espace d'origine. La nature du lien maintenu dépend notamment du type d'alliance matrimoniale réalisé, avec la cousine ou le cousin du «bled», ou avec une personne extérieure au groupe. Pour les anciennes générations nées dans les années 1930-1950, le devoir paradoxale de favoriser le déracinement pragmatique des nouvelles générations, afin de fuir les travaux de la terre pour rechercher une meilleure vie, renvoie cependant à l'oubli et à la frustration causée par les nouveaux besoins insatisfaits : le manque de reconnaissance économique et symbolique des jeunes adultes partis chercher fortune dans les grands centres urbains. Il s'agit donc de retrouver les moyens actifs de re-subordonner les individus à l'ordre social traditionnel en soulignant la fidélité obligatoire des personnes vis-à-vis de la communauté. La référence à la «loyauté familial» devient un outil d'intimidation et de disqualification de toute personne ayant dérogé aux règles d'obéissances qui conduisent ordinairement le fils ou la fille obéissante à envoyer des sommes d'argent à la "famille», donc aux parents directs. Ce système normatif conduit souvent à l'émergence d'une critique intrafamiliale entre les « parents » et certains enfants, perçus comme récalcitrants, soit pour avoir procédé à une alliance exogamique, soit pour ne plus honorer de manière régulière des versements d'argents vis-à-vis de la communauté.

10 Dans différents domaines (comme celui du modèle agricole, ou des modes d'acquisition religieuse), le monde rural se distingue d'abord par la grande diversité d'adaptation culturelle des acteurs. Dans notre étude, différents régimes de la tradition et de la modernité interagissent jusqu'à trouver une symbiose spécifique.

11 En termes de politique de la civilité, le parfum pour homme est vécu comme "le» raffinement par excellence. Pour autant une mise trop élaborée n'est jamais très bien perçue, ni pour soi ni par rapport aux autres. « Le pouvoir du mauvais œil », l'envie et la jalousie prêtées au regard des autres sont le signe inéluctable de malédiction et d'événements négatifs pour celui qui a la malchance de l'attirer. La moustache est le trait dissociatif par excellence de l'adolescence. Il est un élément important de la masculinité et aussi de la force virile comme source de légitimité et de représentation de soi. Celui qui refuse le port de l'attribut voit sa personne progressivement remise en question, ainsi que sa présence au sein du groupe. Un jeune homme de la famille des Charkawy, tailleur de profession, osa refuser le mariage avec une cousine et convoler avec une personne extérieure au groupe: le fait qu'il n'ait pas de moustache était souvent évoqué, notamment par les "cousins", afin de démontrer que l'exogamie maritale était le produit d'une féminisation du caractère. La barbe n'est que peu visible 
à part pour une seule famille du groupe des Amiyines, plus marquée par l'islam politique par l'entremise du frère aîné, professeur d'éducation islamique à Casablanca. L'ordre normatif s'exprime dans les corps mais aussi dans les discours, qui renvoient souvent à une altérité proche ou lointaine, perçue comme hostile ou dérangeante.

À l'aune de ces réflexions, l'exode de la campagne à la ville représente non seulement une étape d'une progressive transformation dans la conception du monde et de ses contraintes mais aussi la réponse première d'un long processus de réaménagement de l'appartenance. Celle-ci n'est pas réductible à un vocable identitaire, elle est aussi un régime de compréhension de l'ordre institutionnel communautaire et de son état de stabilité ou de mutation.

\section{BIBLIOGRAPHIE}

P. Bourdieu, J. B. Thompson, «Préface », dans Langage et pouvoir symbolique, Seuil, 2001.

M. Ennaji, Le sujet et le mamelouk : esclavage, pouvoir et religion dans le monde arabe, Milles et une nuit, 2007.

B. Gracian, L'homme de cour (traduit de l'espagnol par A. de la Houssaie), Champ Libre, 1972.

A. Gramsci, Cahier de prisons, Paris, Gallimard, 1969.

S. Gabryel Nasser, « Epistémè et gnoséologie du politique, les éléments de l'idéologie métaphysique », trad. M. El Othmany, El Fikr (La Pensée), VIII, 26, 2004.

S. Gabryel Nasser, «Une réfutation nécessaire : Khaldoun et le déterminisme sociopolitique. Une approche comparative : Balthazar Gracian », trad. M. El. Othmany, El Fikr (La Pensée), IX, 26, 2005. 


\title{
Migrants subsahariens à Rabat, une entrée spatiale : l'épreuve des espaces publics
}

\author{
Khadija Karibi
}

1 En été 2013, en nous rendant au centre-ville de Rabat, nous avons constaté la présence de commerçants subsahariens. Une présence récente, puisqu'en achevant une thèse sur les espaces publics centraux de Rabat en 2011, cette présence passait inaperçue et se limitait aux espaces publics de proximité. De plus, par la proximité de notre lieu d'habitat des quartiers connaissant une concentration élevée de ressortissants subsahariens, nous avons été témoin de l'évolution de leur installation dans ces quartiers. Nous avons ainsi décidé d'interroger les formes et les modes d'accès aux espaces publics pour les ressortissants subsahariens et d'étudier les effets que ces présences peuvent générer en termes de reconfiguration des espaces et d'interactions réciproques avec les Marocains.

2 La notion d'espace public est à considérer ici dans sa matérialité spatiale, en tant que support de l'interaction sociale, et dans sa prédisposition à assurer les enjeux de mobilité, de sociabilité, d'urbanité et d'interactions.

3 La réflexion que nous développons est le résultat d'un travail de terrain mené entre 2005 et 2011 dans le cadre d'une thèse de doctorat et, entre 2013 et 2014, à l'occasion d'une étude sur la densité et les formes urbaines. Le quartier Douar Hajja, connu pour être habité par une population importante de migrants subsahariens, fut l'un des cas d'étude. Pour les besoins de cet article, nous avons effectué une investigation ciblée entre septembre et octobre 2014 dans certains espaces publics de Rabat et dans les lieux habités ou fréquentés par les ressortissants subsahariens. Outre les constats et observations tirés d'une posture de membre de la société marocaine, nos investigations se sont axées sur l'observation et des entretiens qualitatifs auprès de ressortissants subsahariens de profils, statuts et nationalités différents, ainsi qu'auprès de Marocains.

4 Si la migration subsaharienne a suscité l'intérêt de plusieurs chercheurs, son impact spatial et urbain reste moins étudié. Rares sont les travaux qui en traitent directement, 
l'approchant de manière marginale, en tant qu'un des éléments de la dynamique migratoire. Les aspects sociaux, économiques, politiques et les conditions de vie demeurent fortement interpellés. Les espaces urbains sont abordés dans leur articulation avec la géographie du cheminement migratoire en tant que «lieux de transit ».

5 Federica Infantino (2011) parle de l'émergence d'enclaves, ou de niches transnationales, discrètement intégrées dans la vie culturelle de Casablanca qu'elle désigne comme «lieux de l'Afrique ». Johara Berriane (2007) parle d'« espaces de rencontres » que forment la rue, le quartier et l'université comme supports de perceptions et de rencontres des étudiants subsahariens avec les Marocains. Pour leur part, Jean-Louis Edogue Ntang et Michel Peraldi (2011) qualifient les quartiers d'installation de migrants subsahariens de "lieux invisibles » où ils sont contraints à des mobilités intra-urbaines entre les espaces périphériques de Rabat.

\section{La migration subsaharienne au Maroc, une nouvelle réalité urbaine?}

6 La migration en provenance d'Afrique subsaharienne au Maroc est perçue comme un phénomène nouveau subordonné à une représentation médiatisée et réductrice des Noirs. Cette réalité «nouvelle » ne peut être considérée en tant que telle qu'au vu de sa forme inédite (Bredeloup et Pliez, 2005). Certains anciens écrits arabes ont relaté en premier les échanges séculaires existants entre l'Afrique du nord et les pays subsahariens (Tamsir Niane, 1985).

7 Au Maroc, dès l'antiquité, des rapports sont établis avec l'empire du Soudan occidental dont les évocations sont encore perceptibles, notamment dans les chansons populaires.

8 Toutefois, ce n'est que récemment que la présence des ressortissants subsahariens commence à s'imposer comme "nouvelle réalité » dans de nombreuses villes marocaines. Cette présence est alimentée par une double forme d'immigration: irrégulière (à partir des années 1990) et régulière impulsée par l'ouverture du Maroc sur l'Afrique subsaharienne et drainant une arrivée croissante d'étudiants, de travailleurs, etc.

9 Pourtant, l'ampleur accordée à la migration subsaharienne semble excessive. Le Recensement Général de la Population et de l'Habitat (2004) révèle que les ressortissants subsahariens régulièrement présents au Maroc ne représentent que $0,01 \%$ de la population totale. Selon le ministère de l'Intérieur et celui de la Migration, ceux en situation irrégulière comptent entre 25000 à 40000 (conférence de presse, Salé, 2013).

\section{Migrants subsahariens et espaces publics, l'élargissement prudent des lieux de « visibilité »}

10 Au milieu des années 1990, certains migrants subsahariens qui arrivaient par autocar s'arrêtaient, de nuit, sur la route côtière à Akkari. Des chauffeurs de petits taxis les transportaient à Douar Hajja où des réseaux de migration s'étaient établis, comme nous l'a témoigné un chauffeur de taxi. C'était un « business » lucratif (100 dirhams la place). Douar Hajja semble avoir été le premier contact de ces migrants subsahariens avec 
Rabat, ce qui expliquerait la forte concentration de cette population dans ce quartier. Cela a ensuite été autour du quartier Bouitat. Les lieux d'accueil se sont étendus aux environs de ces deux quartiers, plus largement à Takkadoum, Youssoufia et J5, puis vers d'autres quartiers plus éloignés, notamment l'Océan, Diour Jamâa et Douar Kora. Les premières spatialisations des migrants coïncidaient avec les quartiers les plus stigmatisés de Rabat (Douar Hajja et Bouitat) en tant qu'espaces de marginalisation et d'insécurité. Progressivement, l'élargissement des lieux d'habitat s'est fait dans des quartiers relativement moins précaires, tout en restant cantonné dans des quartiers populaires. L'accès aux quartiers aisés restant limité à une minorité de ressortissants (travailleurs, étudiants, diplomates...).

11 L'individuation des trajectoires migratoires a fait que de nouveaux critères sont rentrés en jeu dans le choix du lieu de résidence. Outre le prix, s'ajoute selon les entretiens que nous avons effectués, la recherche de sécurité, la mobilité et la proximité des espaces centraux. La mise en service du tramway et de nouvelles lignes de bus a eu un impact sur l'ouverture vers d'autres quartiers plus lointains (Salé, Témara et Hay El Fath), notamment pour les étudiants et les employés.

12 Il n'en demeure pas moins que cette "démocratisation » de l'habiter reste cantonnée dans les quartiers populaires, donnant lieu à une polarisation spatiale de la présence subsaharienne. L'augmentation du nombre des étudiants inscrits dans les écoles privées et le recrutement de certains migrants dans les centres d'appel ont accru leur présence dans le centre-ville et le quartier de l'Agdal qui concentrent ces services.

13 Les espaces centraux historiques exercent une attractivité notoire sur les migrants subsahariens, particulièrement la médina, lieu privilégié d'approvisionnement pour la diversité des produits disponibles et les bas prix. L'ancien centre colonial est visité pour son urbanité et l'image qu'il véhicule.

14 La présence de plus en plus marquée de subsahariens dans l'espace public en général s'observe aussi dans les petits commerces de rue, dans les Mouqef (lieux où se regroupent les ouvriers proposant leurs services) de Kamra et de Takkdoum ou dans les rues pour ceux sollicitant la charité, particulièrement les femmes avec enfants, plus vulnérables et accédant difficilement au marché de travail.

15 Cependant, l'accès aux espaces publics n'est pas pour autant acquis. Des filtres se dressent en lien avec le statut de l'espace considéré, la disponibilité des moyens de transport, le contrôle policier et les difficultés liées à la stigmatisation dont font l'objet les Africains subsahariens. Dans leurs rapports avec les Marocains, ces derniers se trouvent souvent mis à l'épreuve et acculés à témoigner de leur "bonne conduite " dans leur lieux d'habitat et dans les espaces publics. Une étudiante témoigne : «Quand nous avons loué une chambre à Salé, nos colocataires marocaines étaient méfiantes... et quand elles ont fini par nous connaître... Elles nous disent qu'on n'est pas comme les autres »[A. Gambie]. Cette mise à l'épreuve récurrente relate l'image stéréotypée portée sur les ressortissants subsahariens. Certains observent une distanciation, soit par divergence des représentations réciproques, soit par crainte de dénonciation quand leur situation administrative est irrégulière.

16 L'hostilité a atteint son paroxysme avec l'affichage de pancartes dans des immeubles de Casablanca stipulant «Interdiction de louer aux Africains »; images relayées par les réseaux sociaux et les médias. C'est également ce que montre la réaction hostile de certains habitants et riverains envers des migrants subsahariens, refoulés par les 
autorités policières marocaines des zones frontalières nord à Kamra et installés temporairement près de la gare routière, dans l'impasse d'une unité de voisinage. Ceuxci reçoivent néanmoins régulièrement des plats de couscous le vendredi de la part d'habitants des quartiers proches, réactivant la notion de Aâbir Sabil (transitant) à charge religieuse de bienfaisance, révélant également des perceptions divergentes et instables de la part des "voisins" marocains. Au-delà, les étudiants subsahariens évitent de s'afficher avec ceux considérés comme migrants irréguliers, par réfutation de l'image qu'ils renvoient et par peur d'être assimilés à eux, voire d'être interpellés par la police en cas de rafle.

Dans le langage commun, les étrangers subsahariens sont désignés par " $\mathrm{Al}$ Afarica » (les Africains). Il s'agit ici d'une mise à distance, le Marocain se reconnaissant souvent moins dans son appartenance africaine qu'arabe et maghrébine. Les premiers cours d'histoire reçus à l'école soulignent cet aspect. Le clivage culturel semble constituer un obstacle dans les rapports entre Africains subsahariens et Marocains comme il revient dans les propos des uns et des autres. Pour plusieurs de nos interviewés subsahariens, l'urbanisme et l'architecture de la médina et de la ville nouvelle et contemporaine accentuent la référence arabe et occidentale.

La reconfiguration des espaces publics par les commerçants subsahariens à la sauvette semble fluctuante et moins marquée. L'accès à ces espaces, notamment centraux, étant régulé, leur présence (notamment à $\mathrm{Bab} \mathrm{El} \mathrm{Had}$, au centre-ville ou à Bouitat) s'affiche, mais demeure néanmoins instable, au gré des conjonctures et des interventions des forces de l'ordre. Pourtant, dans différentes réactions de Marocains sur les réseaux sociaux et les blogs, la migration subsaharienne est perçue comme une "invasion ", limitée ici aux "forêts squattées et aux espaces envahis par les commerçants » et atteinte à la horma (intégrité) du pays.

\section{Des lieux d'entre-soi... aux lieux de mixité}

19 L'entre soi est alors recherché par les ressortissants subsahariens, qui y voient une façon de vivre comme au pays, de s'épanouir, d'entretenir les solidarités. Il s'exprime dans des espaces fermés et réservés : lieux de culte, cafés, espaces de rencontre et de divertissement aménagés dans les maisons. Les quelques boutiques spécialisées de la capitale, comme par exemple l'International boutique africain au quartier Kora à Yacoub El Mansour, constituent des lieux de rencontres et d'échanges entre Africains subsahariens et permettent de régler des affaires, prendre un rendez-vous, se divertir... Cet entre-soi peut être extensible en dehors de Rabat, à la recherche de sociabilités entre compatriotes. L'installation de connaissances dans d'autres villes leur octroie une mobilité fluide, comme en témoigne un groupe d'étudiants et travailleurs éthiopiens : "Grâce à la possibilité de location de voitures et à la présence de nos concitoyens dans différentes villes, nous avons pu visiter tout le Maroc... ». Profiter d'autres aménités urbaines que n'offre pas Rabat constitue aussi un motif récurrent pour fréquenter Casablanca ou d'autres villes comme Kenitra, Fès, etc.

Pour les étudiants que nous avons interviewés, la Cité internationale constitue une étape initiatique d'accès à la ville. Le passage de la Cité au quartier marque le passage d'une vie "communautaire " à une vie "fermée». Au sein de la cité, les étudiants vivent avec sérénité le statut partagé d'« étrangers ", contrairement au quartier où ce 
statut a des conséquences en termes d'interactions et de représentations réciproques avec les Marocains.

21 Cependant, des espaces de mixité entre Africains subsahariens et Marocains apparaissent. Les cafés constituent des lieux où l'interaction est favorable, notamment lors de la diffusion des matchs de football. C'est aussi un lieu idéal pour l'apprentissage de la darija. Sur les terrains de sport, les tournois organisés créent des liens, parfois durables. La religion comme facteur de mixité n'apparaît réellement que dans les mosquées, particulièrement pendant le Ramadan et les jours de fêtes. Des ONG prennent le relais en offrant des espaces de rencontre. La fondation Orient-Occident dans le quartier Amal (proche de J5) notamment, propose aux étrangers de différentes nationalités et aux Marocains une plate-forme de rencontres autour d'activités ludiques, pédagogiques ou sportives.

Au-delà de l'appartenance religieuse, la maîtrise de la darija devient déterminante, facilitant «l'intégration ». Ceux qui ne la maîtrisent pas, se trouvent plus souvent contraints à la distanciation.

Cette étude a permis de montrer que les manifestations spatiales de la migration subsaharienne à Rabat se construisent progressivement dans des marginalités urbaines. Elle s'ancre dans les quartiers populaires et s'intègre dans une expérience empreinte d'altérité et de nouvelles sociabilités, non exemptes de frictions et de représentations mitigées, voire conflictuelles. Cette expérience est à inscrire dans l'histoire urbaine de Rabat et dans une large mesure dans le référentiel identitaire marocain, qui, malgré la reconnaissance officielle de «l'identité africaine » (cf. Constitution de 2011), n'a pas eu réellement de répondant dans l'usage quotidien.

Si la pratique des espaces publics par les migrants subsahariens semble dans un premier temps initiatique, limitée à la proximité des lieux de résidence, elle s'élargit à travers des porosités urbanistiques et sociales. Par ce qu'ils offrent comme sociabilités, les lieux d' « entre- soi » semblent transcender une fermeture, réelle ou supposée, des espaces publics. De même que les espaces de mixité annoncent une interaction en cours de construction. Reste à savoir si les annonces récentes de changement de la politique migratoire inaugureront une nouvelle forme de sociabilités et de coproduction urbaine au Maroc.

\section{BIBLIOGRAPHIE}

J. Berriane, «Les étudiants subsahariens au Maroc : des migrants parmi d'autres? », Atelier sur les migrations africaines : comprendre les dynamiques des migrations sur le continent, Accra, Centre for Migration Studies and International Migration Institut, 2007, p. 18-21.

S. Bredeloup, O. Pliez, « Migration entre les deux rives du Sahara » (introduction), Autrepart, $\mathrm{n}^{\circ} 36,2005$, p. 3-20.

D. Tamsir Niane, «Introduction », dans volume IV de l'Histoire générale de l'Afrique, l'Afrique du XIIe au XVIe, Dijon, Jeune Afrique/ UNESCO, 1985. 
J.-L. Edogue Ntang, M. Peraldi, « Un ancrage discret. L'établissement des migrations subsahariennes dans la capitale marocaine », dans M. Peraldi (éd.), D'une Afrique à l'autre, migrations subsahariennes au Maroc, Paris, Karthala, 2011, p. 35-52.

F. Infantino, «Barbès à Casa ? Lieux cosmopolites d'Afrique dans la métropole marocaine », dans M. Peraldi, D'une Afrique à l'autre, migrations subsahariennes au Maroc, Paris, Karthala, 2011, p. 73-100. 


\section{Conclusion}




\title{
Le Maroc comme carrefour migratoire et pays d'accueil : quels défis pour le futur?
}

\author{
Ellinor Zeino-Mahmalat
}

1 Les drames de réfugiés arrivant sur le territoire européen par bateau en traversant le détroit de Gibraltar, ainsi que les incidents qui se répètent depuis le début des années 2000 en lien avec les tentatives de franchissement des enclaves espagnoles de Ceuta (Sebta) et Mellila par des migrants d'Afrique noire, ont marqué l'image du Maroc comme terre d'émigration ou de transit vers l'Europe. Le Maroc semblait être, jusqu'ici, un lieu de transit peu attractif pour de longs séjours, voire comme pays d'immigration.

2 Ce n'est que récemment que scientifiques, médias et hommes politiques locaux se sont consacrés à la thématique de l'immigration vers le Maroc et aux multiples rôles du Maroc en tant que pays d'émigration, d'immigration et de transit.

3 La présente publication part de ce présupposé et va au-delà, élargissant la catégorie de «migrant » et illustrant différentes formes de séjour et de résidence des étrangers au Maroc. Elle envisage ainsi des processus de transformation sociale qui se complètent mutuellement, que ce soit dans la société et le monde politique marocains ou du côté des étrangers résidents. L'immigration légale/ régulière, moins médiatisée, joue un rôle croissant pour l'économie et la société. Elle est vouée à imprégner et à transformer davantage à l'avenir le Royaume chérifien. Après presque 60 ans d'indépendance, marqués par l'émigration des Marocains et par la formation à l'échelle mondiale d'une diaspora de quelque cinq millions de Marocains résidents à l'étranger (MRE), le monde politique et sociétal marocain doit maintenant - à son tour - se poser les questions d'une immigration économiquement viable, socialement supportable et politiquement voulue. Ces enjeux se greffent sur des réalités qui restent, cependant, en partie floues, concernant le marché du travail marocain, le rôle des différents acteurs institutionnels ou les catégories assignées ou réelles des étrangers au Maroc qui rendent leurs lectures difficilement lisibles et visibles. Parallèlement, les étrangers résidents au Maroc jouent, par leurs différentes formes d'interaction avec les Marocains ou par leurs attentes et 
leurs exigences à l'égard du pays d'accueil, un rôle déterminant quant au processus de (re)définition de son image et de son identité nationale.

4 La situation géographique particulière du Maroc a influé sur ses relations avec le monde extérieur et sur la compréhension de sa place et de son rôle. Situé en extrêmeoccident (arabe maghrib) du continent africain, le Royaume chérifien a pu, mieux que ses voisins, se protéger contre les influences extérieures et les envahisseurs, comme il en a été par exemple des Ottomans. Même aujourd'hui, tant les mutations politiques aux Proche et Moyen-Orient, que les processus de globalisation et de modernisation avec leurs diverses répercussions sur le mode de vie des gens, semblent atteindre le pays avec un certain retard, ou de façon atténuée. Il en est ainsi pour la prise en charge de certaines populations étrangères, présentes sur le territoire de manière plus ou moins durable. Pour illustration, on peut citer l'arrivée ces dernières années de réfugiés de différents pays en conflit, d'investisseurs et commerçants chinois qui ont renforcés leur présence, notamment à Casablanca, des ressortissants subsahariens de plus en plus attirés par le Maroc comme pays d'immigration ou, encore, des migrations du nord, anciennes mais rendues plus visibles aujourd'hui. Ces phénomènes marquent une tendance croissante vers la mobilité et la migration à partir de et vers le Maroc et défient sa capacité de s'adapter aux transformations sociales en cours. Cela implique d'intégrer dans l'analyse les enjeux de coopérations régionales.

Le Maroc, entre l'océan Atlantique à l'ouest et les montagnes de l'Atlas à l'est, bénéficie d'une proximité particulière avec l'Europe via le détroit de Gibraltar, tout en étant contraint au sud par le désert du Sahara. Cela a facilité l'adoption d'une orientation nord-sud dans ses relations diplomatiques, qui s'est renforcée depuis 1994 par la fermeture à l'est de la frontière terrestre avec l'Algérie. Cette structure relationnelle a également été nourrie par l'histoire récente des protectorats espagnol et français sur le Royaume. Le Maroc se définit volontiers dans les débats publics comme une plateforme entre l'Afrique sub-saharienne au sud et l'Europe au nord. Cela renvoie à la place historique des royaumes marocains qui ont jadis joué un rôle important d'interface et de liaison sur la route transsaharienne entre le nord et le sud, de même que comme espace de transit, que ce soit pour des denrées, des êtres humains (esclaves) ou des biens culturels.

6 La relation historico-culturelle particulière du Maroc avec l'Afrique de l'Ouest se reflète aussi dans les conditions d'accès au territoire dont bénéficient les citoyens de différents pays. Si ces facilités concernent également les ressortissants des pays européens, le Maroc a opéré ces dernières années une revalorisation stratégique de ses relations diplomatiques, commerciales, politiques et sécuritaires avec les États d'Afrique de l'Ouest francophone. Le déploiement de différents programmes a permis un resserrement des liens entre ces États et le Maroc dans le cadre de la coopération bilatérale et internationale, visant notamment les étudiants, entrepreneurs ou religieux. Ce "marketing diplomatique», qui avait aussi pour but de consolider la position géostratégique du Maroc vis-à-vis d'autres concurrents régionaux tels que l'Algérie, s'est concrétisé par la volonté affirmée par le Royaume et son Souverain de renforcer la politique africaine et, à la fin 2014, par la signature de nombreux accords bilatéraux entre le Maroc et des États d'Afrique de l'Ouest (Mali, Sénégal, Côte d'Ivoire, Gabon). La coopération bilatérale accrue entre le Maroc et les États d'Afrique de l'Ouest pourrait renforcer la mobilité actuelle entre les pays et le tropisme déjà marqué des Ouest-Africains à l'égard de leur voisin du Nord. 
7 Tandis que le Royaume du Maroc souligne son « africanité » à l'égard de ses voisins du Sud et endosse le rôle du "grand frère », il est notamment devenu vis-à-vis de son voisin du Nord, l'Union européenne, le "gendarme» ou le "gardien de but », qui contribue à surveiller les frontières extérieures européennes, à contrer ou à réguler les arrivées de migrants africains et de réfugiés. Dans l'attitude du Maroc à l'égard des migrants subsahariens supposés transiter par le territoire pour rejoindre l'Europe, se dessinent assez vite les limites et défis de ce rôle du Maroc en tant que trait d'union entre l'Europe et l'Afrique. Si pour certains étrangers le Maroc est effectivement perçu comme un pays de transit dans leur voyage vers l'Europe, pour d'autres il est aussi et surtout un pays d'immigration.

8 Le Maroc n'est donc pas seulement un pays de passage. Il est aussi un pays d'accueil et de destination pour différents types d'immigrations, d'origines géographiques diverses, d'Europe, d'Afrique et d'ailleurs, permanentes ou limitées dans le temps. Officiellement, environ 74000 étrangers vivant au Maroc sont enregistrés actuellement, dont presque $40 \%$ d'Européens et $14 \%$ d'Algériens. Les avantages et les attraits qu'offre le Maroc comme pays de destination sont de nature géographique, économique, linguisticoculturelle, mais aussi politique. En tant que pays politiquement stable, en voie de modernisation économique et sociétale, offrant une proximité géographique et linguistico-culturelle avec l'Europe, le Maroc attire un groupe-cible potentiellement large d'étrangers désireux de s'expatrier.

9 D'une part, le Maroc présente de nombreux avantages pour des chercheurs d'emploi autant que pour des investisseurs étrangers. Les grandes entreprises marocaines ou internationales établies dans la métropole commerciale et industrielle de Casablanca, dans les secteurs de la banque, des télécommunications, de la logistique, du consulting ou de l'industrie (entre autres: Banque marocaine pour le commerce et l'industrie BMCI, Maroc Télécom, Royal Air Maroc, Office chérifien des phosphates - OCP) attirent de plus en plus de jeunes diplômés à orientation internationale des pays voisins africains ou d'Europe francophone, qui voient dans le Maroc des perspectives pour démarrer ou pour développer leur carrière professionnelle. Sans compter que, dans un climat de crise économique et financière persistante en Europe depuis 2009, de plus en plus d'Européens, en particulier du sud de l'Europe, cherchent des opportunités d'emploi au Maroc, notamment dans la coopération au développement ou dans les secteurs comme celui de la culture, du tourisme ou de l'événementiel. Les facilitées offertes pour la création d'entreprises ouvrent également des perspectives en lien avec des approches transnationales.

10 Comme nous l'avons souligné, le Maroc a établi depuis des années sa réputation de destination attractive en matière de formation supérieure pour une migration étudiante principalement originaire d'Afrique subsaharienne francophone. En 2014, quelque 12000 étudiants issus de près de 40 pays africains étaient inscrits auprès d'établissements d'enseignement supérieur publics ou privés marocains. La demande grandissante en formation au Maroc et le développement parallèle d'établissements d'enseignement privés, indiquent que le Maroc constitue une alternative pour les élites africaines, pour lesquelles l'accès au marché de la formation européen ou occidental est souvent pénible ou tout simplement impossible.

11 Certaines formes de "mobilité religieuse » représentent une dimension importante des échanges et liens entretenus avec l'Afrique sub-saharienne. Les relations religieuses et culturelles qui rapprochent le Maroc d'un grand nombre d'États d'Afrique de l'Ouest 
depuis des centaines d'années, en premier lieu le Sénégal, se manifestent par des visites régulières de pèlerins et par un marché de "tourisme religieux" vers le Maroc en pleine croissance. Au-delà, un programme de formation instauré par le Roi Mohammed VI en 2014 pour les imams africains, dont les premiers ont été les Maliens, est appelé à former ces prochaines années des centaines d'hommes et de femmes de religion au Maroc. En tant que pays historiquement malékite et centre de diffusion de cette école au sud du Sahara, ainsi que berceau de deux confréries soufies très influentes et développées en Afrique - Tidjaniyya et Qadiriya - le Maroc attire chaque année des milliers de croyants et de pèlerins ouest-africains.

Enfin, le Maroc est devenu un pays de résidence privilégié pour des retraités et des particuliers européens et autres étrangers, qui se sont établis dans le pays tantôt pour la saison d'hiver, tantôt pour toute l'année.

Les différents profils des étrangers au Maroc esquissent diverses attentes vis-à-vis de leur pays d'accueil, des types d'interaction avec la société marocaine et renvoient à des enjeux variés pour le Maroc. Tandis que les réfugiés, les nouveaux arrivants et les migrants en situation irrégulière aspirent prioritairement à des conditions de sécurisation physique, juridique et d'assurance des droits sociaux et économiques de base, les étudiants et travailleurs qualifiés se préoccupent davantage d'intégration pérenne sur le marché du travail marocain. Cela étant dit, les frontières entre régularité et irrégularité administrative et les modalités de passage de l'une à l'autre de ces situations ne sont pas si évidentes.

Pour les migrants régulièrement installés au Maroc, étudiants ou travailleurs, européens et subsahariens en particulier, la priorité est de lever les obstacles juridiques liés au droit à une résidence stable et de garantir une meilleure égalité des chances sur un marché du travail qui favorise les employés marocains (loi de "préférence nationale »). Dans ce contexte, de jeunes étudiants et diplômés, africains et européens en particulier, ont des attentes limitées quant à leur pays de résidence. Pour eux, le Maroc n'est pas un "eldorado" mais une opportunité pour leur carrière professionnelle, que ce soit via un diplôme marocain et une expérience à l'étranger valorisés dans leur pays d'origine, ou d'une éventuelle offre d'emploi attrayante au Maroc.

Les divers profils d'étrangers et de migrants au Maroc déterminent aussi en partie leurs possibilités d'intégration dans la société marocaine. D'une part, le contexte familial, national, économique et social ou linguistico-culturel des étrangers au Maroc est susceptible de favoriser - ou pas - leur insertion dans la société marocaine ou dans certaines de ces sphères. Des attaches familiales par le conjoint, des origines binationales, un statut social valorisé, la maîtrise du dialecte marocain ou de la langue française, une culture ou une pratique religieuse musulmane, des connaissances du Maroc, etc., sont autant de facteurs qui peuvent soutenir l'accès et l'acceptation auprès des membres de la société marocaine. Il faut cependant souligner que différentes formes de motivation et de perception liées à l'intégration dans la société marocaine coexistent. Tandis que de nombreux migrants européens et africains ne recherchent qu'une expérience passagère de séjour à l'étranger, une amélioration de leurs conditions de vie économiques ou de leur parcours professionnel, se cantonnant dans le cercle élargi de leur "communauté d'expatriés ", d'autres, en revanche, recherchent un lien plus étroit avec la société locale. 

réseaux indigènes, créant ainsi des structures «parallèles » de communauté de vie. Les associations d'étudiants africains, les communautés religieuses (en particulier chrétiennes) ethniquement marquées ou internationales, les communautés d'expatriés européens, mais aussi la constitution de quartiers ethniquement marqués comme à Casablanca et Rabat sont autant de formes d'expression de la diversité étrangère sur le sol marocain. Parallèlement, des lieux de rencontres entre Marocains et étrangers se développent, des mariages bi nationaux sont conclus, des influences diverses s'opèrent, de nouvelles mobilités sont constatées entre «ici» et «là-bas», remodelant le cosmopolitisme marocain et l'interrogeant, sans pour autant se déployer, dans les mêmes temps, au niveau des dispositifs publiques, légaux ou les débats politiques en la matière.

17 Les polémiques qui ont suivi la publication, en 2012, de la Une d'un journal marocain intitulée le péril noir montrent le malaise qui entoure la question du racisme et de la discrimination quotidienne à l'égard des migrants subsahariens. Ces débats ont dévoilé en outre des craintes et des stéréotypes sur les migrations et sur les différentes catégories de migrants, de même que l'urgente nécessité de clarifier les multiples dimensions de ces réalités et d'élargir les questionnements les concernant pour un débat plus ouvert et déstigmatisant. L'immigration illégale et l'arrivée de nouveaux réfugiés sont de plus en plus ressenties comme une menace pour le Maroc, venant conforter des amalgames récurrents, que viennent renforcer des procédures souvent opaques. Le nombre croissant d'Européens à la recherche d'un travail, souvent en séjour irrégulier, pourrait aussi être vu de façon critique à l'avenir. La nette et visible augmentation de la mobilité, des séjours temporaires ou de l'établissement sur le long terme d'étrangers sur le territoire marocain au cours des dix dernières années ont contraint l'État marocain à faire davantage face aux questions concernant la migration et de l'immigration.

18 L'idée qu'ont les Marocains de leur identité nationale, de même que la politique d'immigration du Maroc, sont actuellement régulièrement questionnées. L'accès à la citoyenneté par la naturalisation repose essentiellement sur le principe du droit du sang (lat. jus sanguinis) et fait perdre de son sens à la question de l'intégration des étrangers installés sur le territoire. Pourtant, les interactions entre étrangers et Marocains, les cohabitations au Maroc et à l'étranger, impactent inévitablement les relations à l'identité nationale, au pays ou à la culture d'appartenance ou d'origine, ainsi que les perceptions de cette identité nationale, comme l'illustrent les positionnements de la nouvelle Constitution de 2011 sur ces questions.

L'image officielle que le Royaume du Maroc essaye de promouvoir est celle d'une monarchie à la fois éclairée et traditionnelle. Les Marocains sont, par leur naissance et leurs origines, des citoyens avec des droits et des devoirs civiques et, en même temps, des membres indéfectibles de la monarchie, ce qu'ils demeurent même s'ils émigrent ou acquièrent une autre nationalité. Une intégration juridique et sociale des migrants n'est pas l'objectif de la politique d'immigration marocaine. Au contraire, la politique d'immigration actuelle a pour objectif la régularisation et, de plus en plus, le contrôle et la sauvegarde de la sécurité intérieure. C'est ainsi que doit être comprise la nouvelle mesure de "régularisation» introduite en septembre 2013, visant à promouvoir la reconnaissance juridique et l'enregistrement de migrants irréguliers. Le nombre d'étrangers séjournant irrégulièrement au Maroc est évalué par le ministère de 
l'Intérieur marocain entre 35000 et 40000 . Si la nouvelle politique a pour objectifs un contrôle plus efficace et une idée plus précise sur le séjour des étrangers sur son territoire, la focalisation sur certaines catégories de populations étrangères et l'absence d'attention à d'autres semblent limiter ou interroger cette ambition globale. Il est cependant légitime de se demander dans quelle mesure l'immigration et la mobilité vont changer, par un jeu de miroir, l'image que non seulement les Marocains, mais aussi les nouveaux arrivants, se font du Maroc. Cet effet de miroir, découlant aussi de la forte émigration et présence de Marocains à l'étranger, pourrait d'ailleurs aussi interroger le regard porté sur l'immigration au Maroc. La société marocaine, largement conservatrice, n'est pas pour autant isolée hermétiquement du monde extérieur, ni à l'abri de processus de transformation interne. Les nouvelles possibilités offertes par la mobilité accrue vont poursuivre l'internationalisation du marché du travail et de la formation, celle de la production et de la consommation, continuant à exposer la société marocaine à de nouvelles idées et influences socio-culturelles.

La question demeure ouverte : comment l'État et la société réagiront, dans un pays en développement en cours de modernisation tel que le Maroc, à ces mutations et tendances sur le long terme? Les mobilités et les processus de modernisation économique ne débouchent pas nécessairement sur une société cosmopolite et ouverte. Souvent, ils débouchent aussi sur des tendances contradictoires de retrait ou de repli qui peuvent mener à la xénophobie et au populisme. Ce qui est certain, c'est qu'une confrontation sur des bases sûres avec l'immigration et ses processus de transformation profonds de l'État et de la société (y compris pour les étrangers qui y résident) n'est pas à l'ordre du jour au Maroc. Le présent recueil offre un premier aperçu thématique, large et solide sur la migration, la mobilité et la présence étrangère au Maroc. 


\section{Liste des auteurs}

1 ALIOUA Mehdi, professeur assistant en sociologie à l'Institut d'études politiques de l'Université internationale de Rabat (UIR).

2 BAHMAD Jamal, Postdoctoral Research Associate, Center for Near and Middle Eastern Studies, Philipps University of Marburg, Germany.

3 BAMBA Mamadou, enseignant-chercheur à l'Université Alassane Ouattara de Bouaké (Côte-d'Ivoire), chercheur associé à l'Institut des mondes africains (IMAF), Paris.

4 BARRIÈRE Dorothée, enseignante et historienne, diplômée de l'IEP de Grenoble.

5 BECK Sylvain, doctorant GEMASS, Université Paris 4, Sorbonne.

6 BOUDARSSA Chadia, doctorante en sociologie à l'Université Paris 7 Diderot, rattachée au Laboratoire de changement social et politique (LCSP).

7 COYAULT Bernard, doctorant en anthropologie, EHESS.

8 DESSERTINE Anna, doctorante Laboratoire d'ethnologie et de sociologie comparative UMR 7186 (ED. 395).

9 EBA NGUEMA Nisrine, docteur en droit public, faculté des Sciences juridiques, économiques et sociales de Souissi, Rabat.

10 KARIBI Khadija, enseignante, École nationale d'architecture, Rabat.

11 KHROUZ Nadia, politologue, chercheure associée au CJB.

12 LANZA Nazarena, doctorante IDEMEC/AMU (Aix-en-Provence), chercheure associée au CJB.

13 LE BIGOT Brenda, doctorante en géographie UMR 8504 Géographie-Cités Université Paris 1 Panthéon-Sorbonne.

14 NASSER Souleiman G., philosophe et anthropologue politiste, chargé d'enseignement à l'EHESS Paris, chercheur associé CHERPA Science-Po Aix-Marseille, professeur de philosophie à l'Institut d'enseignement supérieur de Montpensier.

15 NIANDOU Touré, doctorant en sociologie à l'Université Paris Descartes, rattaché au CEPED.

16 NZAMBA Lionel, doctorant en droit public, faculté des Sciences juridiques, économiques et sociales (FSJES), Rabat 
17 ORLANDO Valérie, Professor, French and Francophone Literatures and Cultures, University of Maryland.

18 SIDI HIDA Bouchra, chercheure associée à la CRIEC, UQAM, Canada.

19 TAING Jean-Pierre, doctorant en géographie, Aix-Marseille Université et LPED (UMR 151).

20 TERRAZZONI Lisa, post-doctorante CADIS / EHESS.

21 WEYEL Silja, doctorante, Graduate School of Gouvernance, Maastricht University, PaysBas.

22 ZEINO-MAHMALAT Ellinor, docteur en science politique et relations internationales, chargé de projet, Coopération européenne et internationale, Fondation KonradAdenauer, bureau de Rabat, de 2012 à 2015. 